\title{
Measurement Uncertainties and Minimum Detectable Concentrations for the In Situ Nal Gamma Spectroscopy Systems Used at Fernald
}

Environmental Assessment Division Argonne National Laboratory

Operated by The University of Chicago, under Contract W-31-109-Eng-38, for the

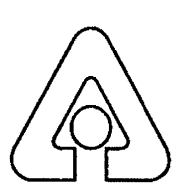

United States Department of Energy 
Argonne National Laboratory, with facilities in the states of Illinois and Idaho, is owned by the United States Government and operated by The University of Chicago under the provisions of a contract with the U.S. Department of Energy.

\section{DISCLAIMER}

This report was prepared as an account of work sponsored by an agency of the United States Government. Neither the United States Government nor any agency thereof, nor The University of Chicago, nor any of their employees or officers, makes any warranty, express or implied, or assumes any legal liability or responsibility for the accuracy, completeness, or usefulness of any information, apparatus, product, or process disclosed, or represents that its use would not infringe privately owned rights. Reference herein to any specific commercial product, process, or service by trade name, trademark, manufacturer, or otherwise does not necessarily constitute or imply its endorsement, recommendation, or favoring by the United States Government or any agency thereof. The views and opinions of document authors expressed herein do not necessarily state or reflect those of the United States Government or any agency thereof, Argonne National Laboratory, or The University of Chicago.

Available electronically at http://www.osti.gov/bridge/

Available for a processing fee to U.S. Department of Energy and its contractors, in paper, from:

U.S. Department of Energy

Office of Scientific and Technical Information

P.O. Box 62

Oak Ridge, TN 37831-0062

phone: (865) 576-8401

fax: (865) 576-5728

email: reports@adonis.osti.gov 


\section{Measurement Uncertainties and Minimum Detectable Concentrations for the In Situ Nal Gamma Spectroscopy Systems Used at Fernald}

by M.J. Davis

Environmental Assessment Division

Argonne National Laboratory, 9700 South Cass Avenue, Argonne, Illinois 60439

June 2004

Work sponsored by U.S. Department of Energy,

Assistant Secretary for Environmental Management 


\section{NOTICE}

This technical memorandum is an information product of Argonne's Environmental Assessment Division (EAD). It presents results of ongoing work or work that is more limited in scope and depth than that described in formal reports issued by EAD. This memorandum has undergone internal technical review and has been edited according to EAD's quality assurance requirements. In contrast to a formal technical report, this memorandum has not been externally peer reviewed.

For more information on the division's scientific and engineering activities, contact:

Director, Environmental Assessment Division

Argonne National Laboratory

Argonne, Illinois 60439

Telephone (630) 252-3107

email: ead@anl.gov

Publishing support services were provided by Argonne's Information and Publishing Division. 


\section{CONTENTS}

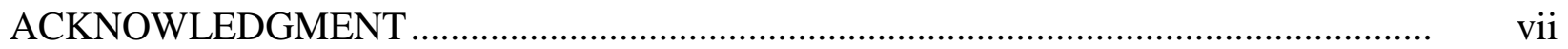

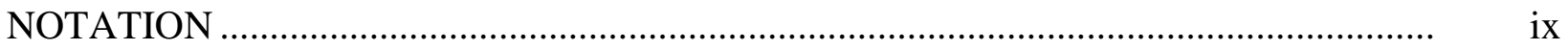

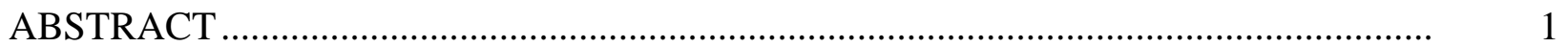

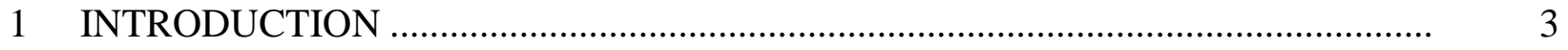

2 MEASUREMENT PROCESS AND SOURCES OF UNCERTAINTY ........................ 6

$3 \quad$ APPROACH TO QUANTIFICATION OF UNCERTAINTY ………………............. 10

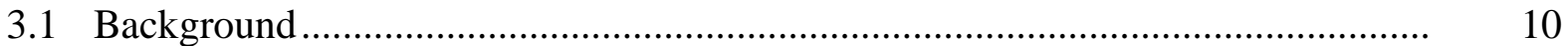

3.2 Determination of Soil Concentrations of Radionuclides ...................................... 10

3.3 Determination of Uncertainty in Concentrations .................................................. 12

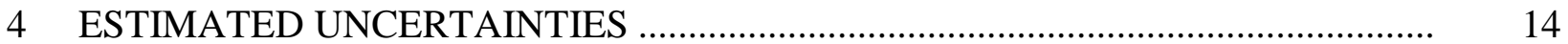

5 MINIMUM DETECTABLE CONCENTRATIONS...................................................... 18

6 TRIGGER LEVELS FOR URANIUM WASTE ACCEPTANCE CRITERION .......... 21

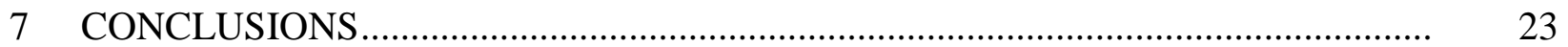

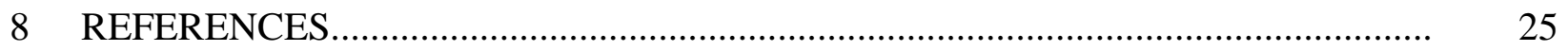

APPENDIX A: Uncertainty Analysis .......................................................................... 27

APPENDIX B: Uncertainties in Calibration Sources and Pad........................................... 35

APPENDIX C: Uncertainty in the Soil Profile of Radionuclides ....................................... 37

APPENDIX D: Uncertainties Associated with Calibration ............................................... 39

APPENDIX E: Uncertainties in Net Count Rates ............................................................... 41

APPENDIX F: Uncertainties Due to Radon Corrections ..................................................... 49

APPENDIX G: Uncertainty in Moisture Corrections ..................................................... 57

APPENDIX H: Determination of Background Counts by Using Sanding ........................ 65

APPENDIX I: $\quad$ Determination of Detection Limits ............................................................. 


\section{CONTENTS (Cont.)}

APPENDIX J: Determination of Standard Deviations in Measured

Uranium Concentrations at WAC Level............................................... $\quad 79$

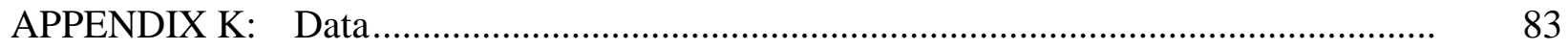

APPENDIX L: $\quad$ Example Calculations .................................................................

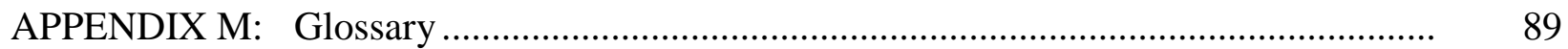

\section{FIGURES}

1.1 Platforms Used at Fernald for Deploying NaI Systems ....................................

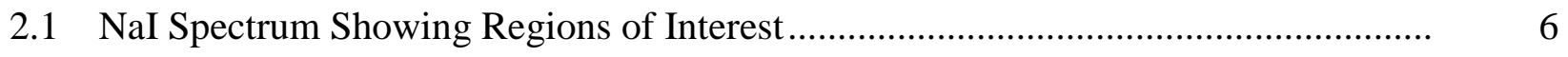

4.1 Combined Relative Uncertainty in Dry-Weight Concentration as a Function of Concentration ...........................................................................

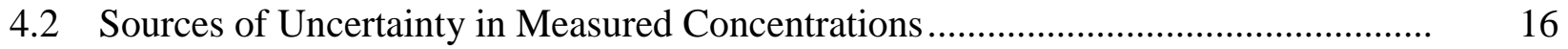

A.1 Variation of the Factor Multiplying the Relative Variance in the Uncorrected Wet-Weight Concentration of ${ }^{226} \mathrm{Ra}$ as a Function of the Uncorrected Wet-Weight Concentration of ${ }^{226}$ Ra.

E.1 Relationships between Background Counts and Net Counts for

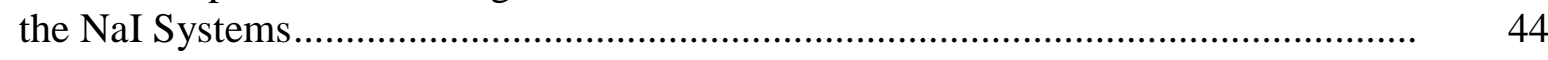

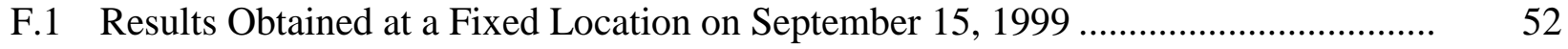

G.1 Calibration Curve for Zeltex Instrument (No. 971667)

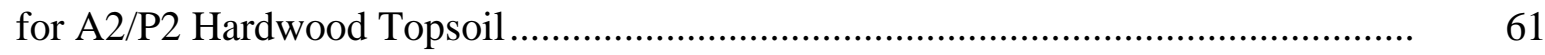

G.2 Relative Uncertainty in $M$ as a Function of Absorbance .................................... 63

H.1 Comparison of Variability in Gross and Background Counts............................... 66

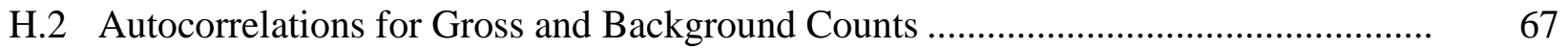

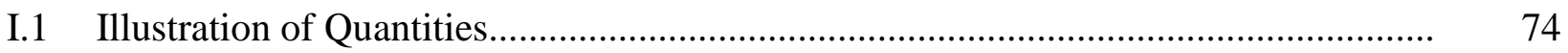




\section{TABLES}

2.1 Summary of Sources of Uncertainty Considered for Measurements Made with the NaI Systems

4.1 Summary of Combined Relative Uncertainties in the Measurements of Dry-Weight Concentrations for the NaI Systems ...............................................

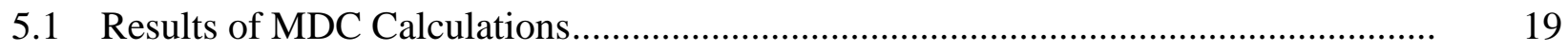

6.1 Trigger Levels for Uranium WAC ...................................................................... 22

A.1 Relative Variances for EMS Measurements .....................................................

A.2 Relative Standard Deviations for EMS Measurements......................................... 32

A.3 Relative Uncertainties in Dry-Weight Concentrations......................................... 33

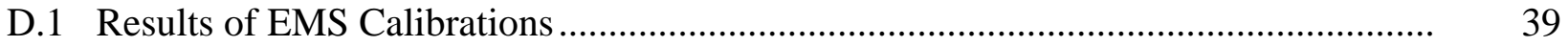

D.2 Covariances for Calibration Coefficients ......................................................... 40

E.1 Contributions to the Variance in the Net Count Rate..............................................

E.2 Data for Background Counts and Net Counts for Three NaI Systems....................... 45

E.3 Components of Variances Associated with Counting ........................................ 47

F.1 Concentrations of ${ }^{226} \mathrm{Ra}$ and ${ }^{222} \mathrm{Rn}$ at Fernald .................................................

F.2 Sensitivity of Uncertainties in 226 Ra Concentrations Measured

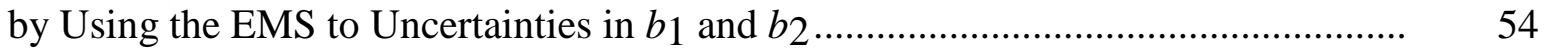

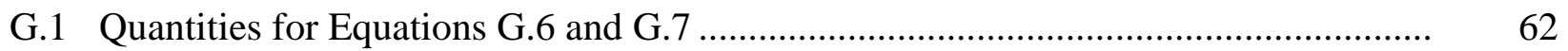

G.2 Absorbance Measurements ..............................................................................

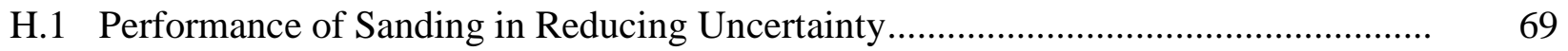

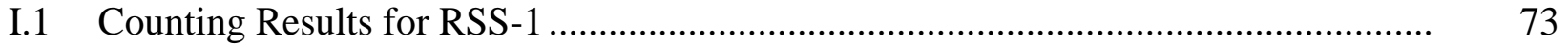

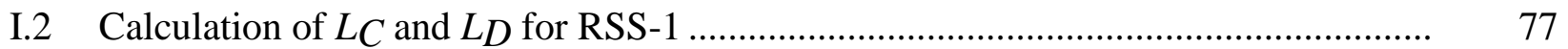

J.1 Weighted Variances for Isotopic Net Count Rates and Determination of WAC Triggers for a 4-Second Count ..................................................................... 


\section{TABLES (Cont.)}

K.1 Calibration Coefficients for the NaI Systems ........................................................... 83

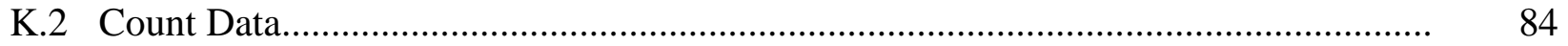




\section{ACKNOWLEDGMENT}

The measurements used in this report were provided by the Real Time Instrumentation Measurement Program of Fluor Fernald, Inc., as were the photographs shown in Figure 1.1 and the spectrum shown in Figure 2.1. 


\section{NOTATION}

The following is a list of the acronyms, initialisms, and abbreviations (including units of measure) used in this document.

\section{ACRONYMS, INITIALISMS, AND ABBREVIATIONS}

$\begin{array}{ll}\text { ANSI } & \text { American National Standards Institute } \\ \text { DOE } & \text { U.S. Department of Energy } \\ \text { EMS } & \text { excavation monitoring system } \\ \text { FCP } & \begin{array}{l}\text { Fernald Closure Project } \\ \text { final remediation level }\end{array} \\ \text { HPGe } & \text { high-purity germanium (detector) } \\ \text { ISO } & \text { International Organization for Standardization } \\ L_{C} & \begin{array}{l}\text { critical level } \\ \text { detection limit }\end{array} \\ L_{D} & \text { minimum detectable concentration } \\ \text { MDC } & \text { sodium iodide } \\ \text { NaI } & \begin{array}{l}\text { photomultiplier tube } \\ \text { polyvinyl chloride }\end{array} \\ \text { PMT } & \begin{array}{l}\text { region of interest } \\ \text { relative standard deviation } \\ \text { radiation scanning system } \\ \text { radiation racking system } \\ \text { ROI }\end{array}\end{array}$




\section{UNITS OF MEASURE}

$\begin{array}{llll}\mathrm{Bq} & \text { becquerel(s) } & \mathrm{L} & \text { liter(s) } \\ \mathrm{cm} & \text { centimeter(s) } & \mathrm{m} & \text { meter(s) } \\ \mathrm{eV} & \text { electron-volt(s) } & \mathrm{m}^{3} & \text { cubic meter(s) } \\ \mathrm{ft} & \text { foot (feet) } & \mathrm{mph} & \text { mile(s) per hour } \\ \mathrm{g} & \text { gram(s) } & \mathrm{pCi} & \text { picocuries(s) } \\ \mathrm{in} . & \text { inch(es) } & \mathrm{ppm} & \text { part(s) per million } \\ \mathrm{kBq} & \text { kilobecquerel(s) } & \mathrm{s} & \text { second(s) } \\ \mathrm{keV} & \text { kiloelectron-volt(s) } & \mu \mathrm{m} & \text { micrometer(s) } \\ \mathrm{kg} & \text { kilogram(s) } & & \end{array}$




\title{
MEASUREMENT UNCERTAINTIES AND MINIMUM DETECTABLE CONCENTRATIONS FOR THE IN SITU NaI GAMMA SPECTROSCOPY SYSTEMS USED AT FERNALD
}

\author{
by
}

\author{
M.J. Davis
}

\begin{abstract}
This report determines the uncertainties associated with measurements made by using the mobile gamma-ray spectrometers deployed at the U.S. Department of Energy's Fernald Closure Project to characterize soil contaminated with ${ }^{238} \mathrm{U},{ }^{226} \mathrm{Ra}$, and ${ }^{232} \mathrm{Th}$. It also examines minimum detectable concentrations (MDCs) for these instruments. The spectrometers use sodium iodide $(\mathrm{NaI})$ detectors and are mounted on a variety of platforms that allow access to all areas of the site, including deep excavations. They are utilized for surveying large areas to obtain distribution patterns for radionuclides in soil, determining whether activity concentrations exceed action levels for hot spots, and determining if the concentration of total uranium exceeds the allowable level for Fernald's on-site disposal facility. Soil cleanup levels at Fernald are 82 parts per million (ppm) for total uranium $\left(27.3 \mathrm{pCi} / \mathrm{g}\right.$ for $\left.{ }^{238} \mathrm{U}\right), 1.7 \mathrm{pCi} / \mathrm{g}$ for ${ }^{226} \mathrm{Ra}$, and $1.5 \mathrm{pCi} / \mathrm{g}$ for ${ }^{232} \mathrm{Th}$. The waste acceptance criterion (WAC) for total uranium for the disposal facility is $1030 \mathrm{ppm}$. Uncertainties associated with counting, efficiency calibration, the calibration pad and sources used, the vertical distribution of contaminants in soil, the use of moisture corrections, and the use of corrections to account for the loss of radon from soil are examined. (Loss of radon is an important process because measurement of ${ }^{226} \mathrm{Ra}$ relies on emissions from progeny of ${ }^{226} \mathrm{Ra}$ and because ${ }^{222} \mathrm{Rn}$ is an intermediate, highly mobile decay product.) The importance of each source of uncertainty depends on the radionuclide of interest and level of contamination. The combined relative uncertainty (relative standard deviation) in measurements of dry-weight concentrations near three times the cleanup levels (the action levels for hot spots) is about $30 \%$ for 4 -second measurements of $238 \mathrm{U}, 40 \%$ for $226 \mathrm{Ra}$, and $20 \%$ for ${ }^{232} \mathrm{Th}$. (Measurement uncertainties for ${ }^{226} \mathrm{Ra}$ are elevated because of the magnifying effect of the correction process used to account for the loss of ${ }^{222} \mathrm{Rn}$ from soil.) For measurements of total uranium near the WAC level, the total relative uncertainty is about $20 \%$ for 4 -second measurements. When only uncertainties due to counting errors are considered, a trigger level of $900 \mathrm{ppm}$ can be used with 4-second measurements to determine, with a 95\% level of confidence, if concentrations of total uranium in soil exceed the WAC level. The MDCs for 4-second measurements are well below three times the relevant cleanup levels for all three radionuclides considered.
\end{abstract}




\section{INTRODUCTION}

Mobile gamma-ray spectrometers with sodium iodide (NaI) detectors are utilized at the U.S. Department of Energy's (DOE's) Fernald Closure Project (FCP) to characterize soil contaminated with ${ }^{238} \mathrm{U},{ }^{226} \mathrm{Ra}$, and ${ }^{232} \mathrm{Th}$. A NaI detector is a scintillation detector (consisting of a NaI crystal, a photomultiplier tube, and associated electronics) used to detect and measure gamma photons emitted during radioactive decay. An approach for quantifying the uncertainties in measurements made with these systems is presented in this report, as is an approach for determining minimum detectable concentrations (MDCs) for the systems. Uncertainties in measurements and MDCs are estimated by using these methods, and the results for the various systems used at the FCP are provided here.

The NaI systems are deployed on a variety of platforms that allow access to the range of field conditions encountered on the Fernald site during remediation. The systems are not available commercially and were constructed specifically for use at Fernald. Detector platforms (see Figure 1.1) include the radiation tracking system (RTRAK, a full-size farm tractor, top left photo); radiation scanning system (RSS, a three-wheeled cart that is pushed manually, top right photo); Gator ${ }^{\mathrm{TM}}$ (a modified John Deere utility vehicle, bottom left photo); and excavation monitoring system (EMS) (an excavator-mounted platform, bottom right photo). The EMS is capable of deploying either NaI or high-purity germanium (HPGe) detectors and is attached to a standard excavator, as shown in the figure. The main component of the EMS, which is mounted to the excavator arm, is about 2-m (6.6 ft) tall. It can be lengthened by using extensions to allow access to deeper excavations.

The NaI systems use uncollimated $10 \times 10 \times 40$-cm $(4 \times 4 \times 16$-in. $)$ NaI crystals. The crystals were hermetically sealed in aluminum housings and coupled to photomultiplier tubes (PMTs) that are 9-cm (3.5-in.) in diameter by the manufacturer. The crystal/PMT assembly is surrounded with nonstatic polypropylene material for both thermal insulation and physical shock protection and encased in a polyvinyl chloride (PVC) tube or aluminum enclosure. The crystals are mounted at a height of $31 \mathrm{~cm}(1 \mathrm{ft})$ above the ground, except in the case of the EMS, for which the deployment height can be varied. Crystal orientation is either perpendicular or parallel to the path of travel.

The NaI systems detect and quantify ${ }^{238} \mathrm{U},{ }^{226} \mathrm{Ra}$, and ${ }^{232} \mathrm{Th}$ activity by assuming secular equilibrium with their progeny $234 \mathrm{mPa},{ }^{214} \mathrm{Bi}$, and ${ }^{208} \mathrm{Tl}$, respectively, which emit distinct gamma rays. Because of their poor energy resolution (about $50 \mathrm{keV}$ ), NaI detectors cannot separate peaks that are within approximately $50 \mathrm{keV}$ of each other and are subject to interference from gamma photons with energies near those of the analytes of interest. The energy regions of interest (ROIs) used for the detectors were selected to minimize interference. The gamma energies used are 1001, 1764.5, and $2614.6 \mathrm{keV}$ for ${ }^{238} \mathrm{U},{ }^{226} \mathrm{Ra}$, and ${ }^{232} \mathrm{Th}$, respectively (for ${ }^{234 \mathrm{mPa},}{ }^{214} \mathrm{Bi}$, and $\left.{ }^{208} \mathrm{Tl}\right)$. The corresponding energy ranges are 940.87-1040.35, 1648.98-1918.19, and $2403.92-2825.28 \mathrm{keV}$. The $1460.8-\mathrm{keV}^{40} \mathrm{~K}$ peak is also used in analysis; the energy range used for the peak is $1338.82-1572.90 \mathrm{keV}$. The detectors use multichannel 

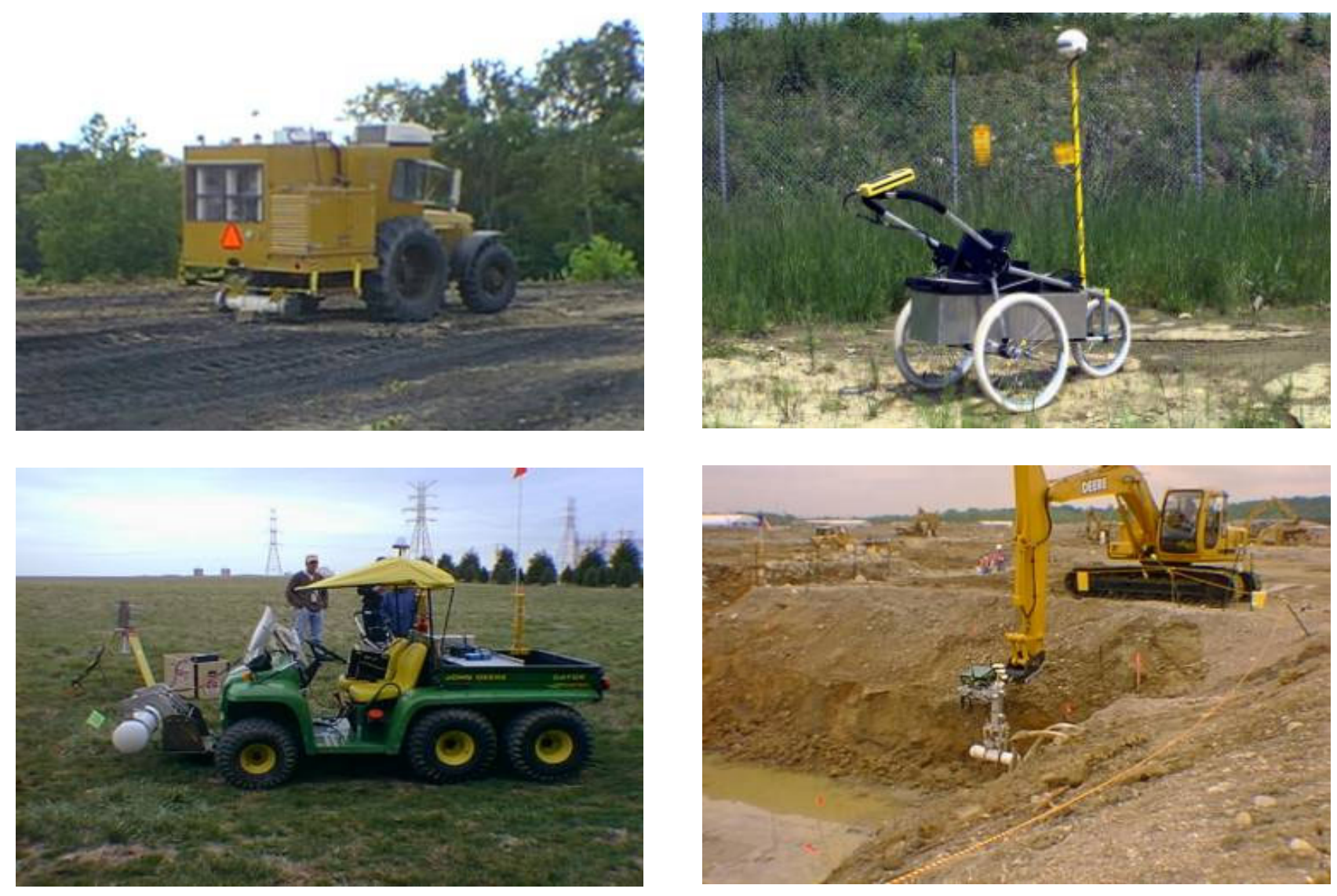

\section{FIGURE 1.1 Platforms Used at Fernald for Deploying NaI Systems}

analyzers with 512 channels and a nominal energy gain of $5.85 \mathrm{keV}$ per channel and a $-1.34-\mathrm{keV}$, zero offset to collect a gamma-ray spectrum. The nominal widths of the ROIs are 18 , 47 , and 73 channels for ${ }^{238 \mathrm{U},}{ }^{226} \mathrm{Ra}$, and ${ }^{232} \mathrm{Th}$, respectively, and 41 channels for ${ }^{40} \mathrm{~K}$. The platforms typically move at a speed of $0.45 \mathrm{~m} / \mathrm{s}$ ( 1 mile per hour, or $\mathrm{mph}$ ), and a spectral acquisition time of 4 seconds is used. Spectra may be aggregated to increase counting time, with an accompanying loss of spatial resolution.

An energy calibration is performed on the NaI systems before and after field measurements. The energy calibrations use a ${ }^{232} \mathrm{Th}$ source and gamma photons associated with ${ }^{212} \mathrm{~Pb}(238.6 \mathrm{keV})$ and ${ }^{208} \mathrm{Tl}(2614.6 \mathrm{keV})$. If a peak falls outside the permitted channel range, amplifier gain is adjusted to move the peak to the proper channel. During field operations, energy gain tracking is used to ensure that ROIs are shifted to the proper channels if the system gain changes. Therefore, ROI positions may shift slightly, and the base widths may be adjusted, although the ROI widths remain constant in terms of energy. The tracking is done by using the $1460.8-\mathrm{keV}$ gamma ray from ${ }^{40} \mathrm{~K}$ and the $2614.6-\mathrm{keV}$ gamma ray from ${ }^{208} \mathrm{Tl}$; adjustments are made approximately once per minute.

Efficiency calibrations of the $\mathrm{NaI}$ systems are carried out annually on a pad into which ${ }^{238} \mathrm{U},{ }^{226} \mathrm{Ra}$, and ${ }^{232} \mathrm{Th}$ standards are placed. The standards used were prepared at Fernald and 
consist of $3.2 \times 15-\mathrm{cm}(1.25 \times 6$-in. $)$ plastic tubes containing radioactive material. They are placed in concentric rings in the pad to simulate a large homogeneous soil source. The radius of the outer ring of sources is $2.07 \mathrm{~m}$. The pad can accommodate 45 standards. When all 45 standards of a given isotope are used, the pad has an effective soil concentration (as seen from a detector placed in the center of the pattern) of $327 \mathrm{pCi} / \mathrm{g}$ for ${ }^{238} \mathrm{U}, 20.4 \mathrm{pCi} / \mathrm{g}$ for ${ }^{226} \mathrm{Ra}$, and $9.05 \mathrm{pCi} / \mathrm{g}$ for ${ }^{232} \mathrm{Th}$. When a NaI system is calibrated, it is placed in the center of the pad with the detector at a height of $31 \mathrm{~cm}$ (12 in.). A calibration requires four 300 -second measurements, one measurement each for the three primary isotopes (using all 45 standards in each case) plus a background measurement. The calibration process is described in detail in DOE (2001).

The numerical results presented in this report are based on measurements obtained by using the NaI systems under controlled conditions on the calibration pad. For measurements made with source standards, the gamma rays used for energy gain tracking differ from those used in field operations, but the basic gain-tracking methodology is the same. In particular, the gamma

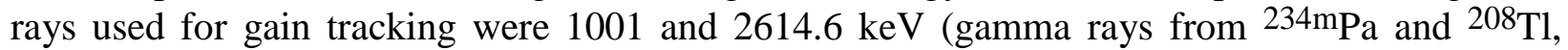
respectively) for uranium measurements, 609.3 and $1764.5 \mathrm{keV}$ (both gamma rays from ${ }^{214} \mathrm{Bi}$ ) for radium measurements, and 583.2 and $2614.6 \mathrm{keV}$ (both gamma rays from ${ }^{208} \mathrm{Tl}$ ) for thorium measurements. These gamma emissions produce count rates high enough to generate prominent, relatively interference-free spectral peaks with small counting uncertainties when reasonably short count times are used. Use of the most prominent spectral peaks available will result in the most accurate calibration parameters. Any differences between the results presented here and those obtained when the gain tracking is based on the gamma rays used in field operations are small and of no practical significance.

The mobile NaI systems are deployed at Fernald for various purposes. The systems provide complete coverage of an area at a cost much less than that associated with physical sampling followed by laboratory analysis. They are used to survey large areas to obtain distribution patterns for radionuclides, determine whether activity levels exceed criteria for hot spots, and determine if the concentration of total uranium in the soil exceeds the allowable level for Fernald's on-site disposal facility. Cleanup levels for radionuclides in soils (final remediation levels, FRLs) at Fernald are 82 parts per million (ppm) for total uranium ( $27.3 \mathrm{pCi} / \mathrm{g}$ for $238 \mathrm{U})$, $1.7 \mathrm{pCi} / \mathrm{g}$ for ${ }^{226} \mathrm{Ra}$, and $1.5 \mathrm{pCi} / \mathrm{g}$ for ${ }^{232} \mathrm{Th}$. Hot spot levels are defined as three times these levels. The waste acceptance criterion (WAC) for total uranium for the disposal facility is 1030 parts per million (ppm). The FRLs and the uranium WAC define the important action levels for soil remediation at Fernald. Therefore, performance of the $\mathrm{NaI}$ systems is discussed in terms of these action levels. Additional discussion of the use of the NaI systems is provided in DOE (2004).

Chapter 2 presents a discussion of the measurement process used and the associated sources of uncertainty. Chapter 3 develops an approach for quantifying uncertainty, and the uncertainties are discussed in Chapter 4. The method for determining MDCs is discussed in Chapter 5. Trigger levels for use with the NaI systems for determining whether soil concentrations of uranium potentially exceed WAC levels are discussed in Chapter 6. Major conclusions are given in Chapter 7. The appendices are an integral part of the report since they provide most of the technical details. The technical material was placed in these appendices to simplify the presentation. A glossary of technical terms is provided in Appendix M. 


\section{MEASUREMENT PROCESS AND SOURCES OF UNCERTAINTY}

Measurements are made with the $\mathrm{NaI}$ systems to estimate the dry-weight concentrations of ${ }^{238} \mathrm{U}$ (or total uranium), ${ }^{226} \mathrm{Ra}$, and ${ }^{232} \mathrm{Th}$ in soil. The overall measurement process involves a $\mathrm{NaI}$ system, the pad used to calibrate it, and an instrument for measuring soil moisture. Various sources of uncertainty influence the measured values of the variables of interest. The actual measured quantities (e.g., counts) are used in a data reduction equation to determine dry-weight concentrations of the radionuclides. Uncertainties in the measurement process result in uncertainties in the estimated dry-weight concentrations. The uncertainties associated with estimated dry-weight concentrations are discussed in this chapter.

The general process used to determine soil concentrations of ${ }^{238} \mathrm{U},{ }^{226} \mathrm{Ra}$, and ${ }^{232} \mathrm{Th}$ with the NaI systems involves the following steps:

1. Total counts in the region of interest for each radionuclide are measured during a counting period (Figure 2.1).

2. The continuum of the spectrum in the ROI is estimated by using a sanding process applied to the total counts in the ROI, as described in Appendix $\mathrm{H}$.

3. The net count rate is determined for each ROI by taking the difference between the total counts and the counts in the continuum (the background) and dividing the result by the actual system live time for the counting period.

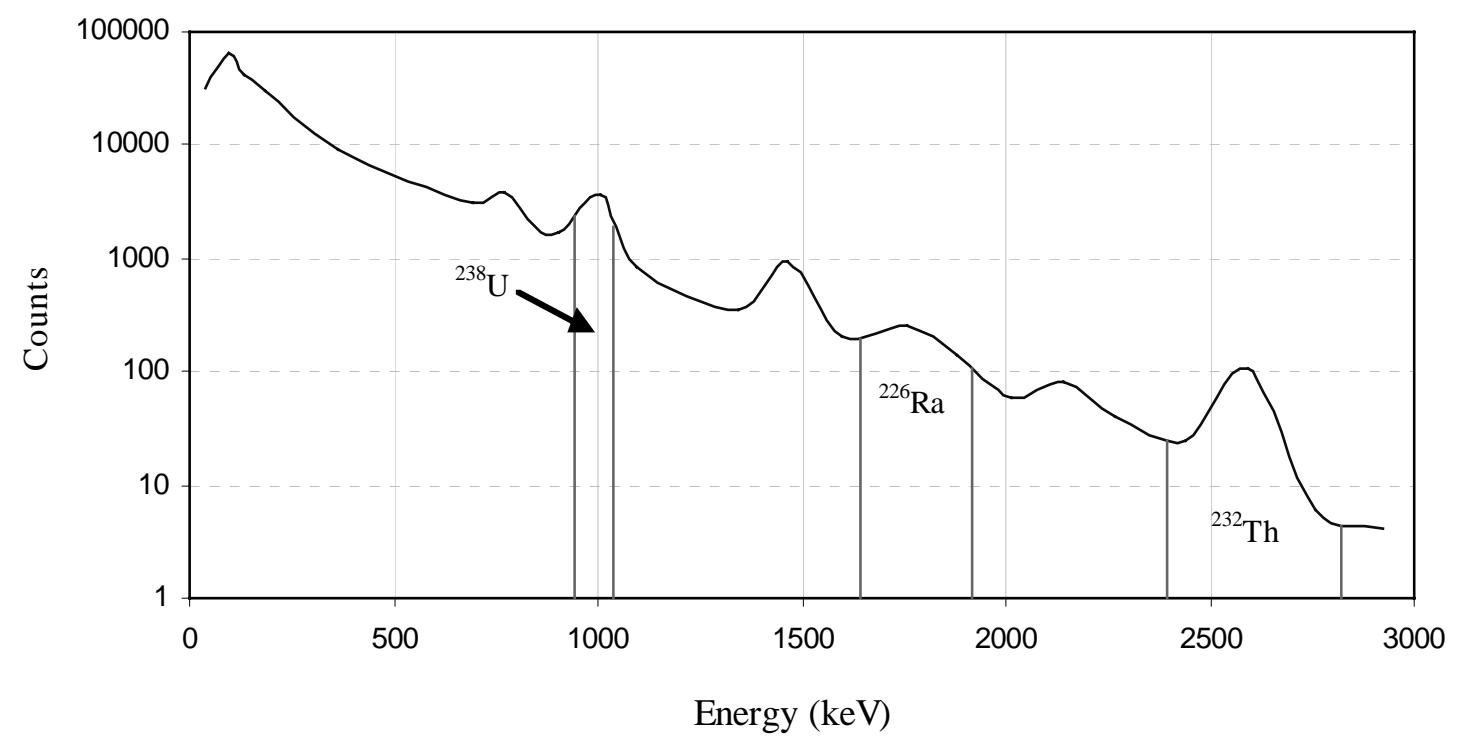

FIGURE 2.1 NaI Spectrum Showing Regions of Interest 
4. Net count rates as determined in the previous step are used in calibration equations to estimate wet-weight soil concentrations of radionuclides.

5. For ${ }^{226} \mathrm{Ra}$, an empirical adjustment is made to the wet-weight concentration to account for radon loss from soil, as discussed in Appendix F. (Loss of radon from soil also reduces the concentration of ${ }^{214} \mathrm{Bi}$ in the soil. Therefore, a correction is necessary because the concentrations of ${ }^{226} \mathrm{Ra}$ and ${ }^{214} \mathrm{Bi}$ will not be equal.)

6. Measurements of soil moisture are made in the field by using a Zeltex KJE-100 near-infrared reflectance moisture meter. The results are used to convert wet-weight soil concentrations to dry-weight concentrations.

As noted above, various sources of error affect the overall measurement process. These sources are discussed below. The general approach used to quantify the uncertainties associated with the measurement process is presented in Chapter 3. Results of applying the approach to the $\mathrm{NaI}$ systems used at Fernald are presented in Chapter 4. Much of the analysis related to evaluation of uncertainty is presented in Appendices A through G. The evaluations presented in the appendices are an integral part of the overall analysis and should not be viewed as merely supporting material. Appendices are used to allow a simpler and more streamlined presentation of results in the main part of the report.

The following sources of uncertainty associated with the estimated concentrations of radionuclides determined by using the $\mathrm{NaI}$ systems are considered in the analysis presented here:

1. Uncertainty associated with net count rates for the uranium, thorium, and radium regions of interest. As is shown in Appendix E, these uncertainties result primarily from uncertainties in the gross counts for a measurement.

2. Uncertainty associated with the calibration sources and calibration pad. This source of uncertainty is examined in Appendix B.

3. Uncertainty associated with the (efficiency) calibration coefficients of the instruments. Calibration uncertainties result from counting uncertainties associated with a calibration, errors associated with the positioning of the detector to be calibrated, possible environmental influences during calibration, and variability in instrument behavior. This source of uncertainty is evaluated in Appendix D.

4. Uncertainty associated with the vertical distribution of radionuclides in the soil. It is implicitly assumed when using the calibration equations developed for the NaI systems that radionuclides are distributed uniformly with depth. The uncertainty associated with using this assumption is considered in Appendix C. 
5. Uncertainty resulting from the use of an empirical correction of radium concentrations to account for radon loss from soil. The radon correction process multiplies the relative uncertainty in the uncorrected wet-weight concentration by a factor of about 2.8 for a dry-weight ${ }^{226} \mathrm{Ra}$ concentration equal to three times the final remediation level (FRL). (This multiplication occurs even if no uncertainty is present in the correction process itself.) This source of uncertainty is evaluated in Section A.2 of Appendix A and in Appendix F.

6. Uncertainty associated with making moisture corrections to obtain dry-weight concentrations. This source of uncertainty is examined in Appendix G.

The following potentially significant sources of uncertainty related to estimating soil concentrations of radionuclides are not considered quantitatively in the analysis presented here:

1. Uncertainty resulting from the application of the (efficiency) calibration equations outside the range of conditions for which the equations were developed. The equations were developed by using sources that are equivalent to elevated concentrations of radionuclides. However, the possible influence of severe interference is not quantified.

2. Uncertainty resulting from any improper definition of the ROIs with respect to the photopeaks of interest or from any other nonrandom sources of error in the gross and background counts. If the ROI is not properly located, uncertainty can increase substantially.

3. Uncertainty associated with the model used to correct for radon loss from soil. Only increases in uncertainties resulting from the application of the model are considered. The correctness of the model itself is not evaluated. However, sensitivity of results to uncertainty in the model is examined in Appendix F.

4. Uncertainty associated with the effects of weather conditions or the time of day when measurements of $226 \mathrm{Ra}$ concentrations are made. Such effects can be significant; the subject is discussed in Appendix F.

5. Uncertainty resulting from the horizontal variability in the distribution of radionuclides. The results provided by a NaI system are a weighted average concentration over the field of view of the system. Horizontal variability results in an overestimate of the concentrations in some portions of the field of view and an underestimate of the concentration in others. In addition, for moving detectors, small areas with elevated concentrations may not be properly characterized because they do not remain in the detector's field of view for a full counting period. Also, the processing used to determine counts in the continuum results in spatial averaging as the detector is moved. 
6. Uncertainty resulting from effects involving surface cover or topography. Measurements are assumed to be made on flat soil surfaces having no cover. Site conditions are expected to be optimized prior to performing measurements. Issues related to surface conditions and topographic effects are discussed in DOE (2004). The effects associated with measurements made on nonflat surfaces primarily apply to the EMS. Conservative corrections for measurements made in nonflat terrain were developed, but associated uncertainties are not evaluated.

7. Uncertainty associated with any differences between the responses of HPGe detectors and $\mathrm{NaI}$ detectors to different vertical distributions of radionuclides or other parameters (e.g., moisture). Results obtained by using HPGe detectors are used as the basis for estimating uncertainties associated with such vertical distributions.

Information on the sources of uncertainty considered is summarized in Table 2.1. The table indicates the nature of the uncertainty (random or systematic), gives the appendix in which the uncertainty is discussed, and provides some brief comments.

\section{TABLE 2.1 Summary of Sources of Uncertainty Considered for Measurements Made with the NaI Systems}

\begin{tabular}{|c|c|c|c|}
\hline Source of Uncertainty & $\begin{array}{c}\text { Appendix } \\
\text { Where Discussed }\end{array}$ & $\begin{array}{c}\text { Nature of } \\
\text { Uncertainty }\end{array}$ & Comments \\
\hline Counting errors & $\mathrm{E}$ & Random & Uncertainty is evaluated in detail. \\
\hline Efficiency calibration & $\mathrm{D}$ & Systematic & Uncertainty is evaluated in detail. \\
\hline $\begin{array}{l}\text { Calibration pad and } \\
\text { sources }\end{array}$ & $\mathrm{B}$ & Systematic & A conservative evaluation is used. \\
\hline $\begin{array}{l}\text { Vertical distribution } \\
\text { of contaminants }\end{array}$ & $\mathrm{C}$ & Random & A conservative evaluation is used. \\
\hline Radon correction & $\mathrm{F}$ & Systematic & $\begin{array}{l}\text { Actual uncertainty is not quantified; a perfect } \\
\text { correction is assumed. }^{\mathrm{a}}\end{array}$ \\
\hline Moisture correction & $\mathrm{G}$ & $\begin{array}{c}\text { Random } \\
\text { Systematic }\end{array}$ & A conservative evaluation is used. \\
\hline
\end{tabular}

a The correction process results in a multiplication of the uncertainties associated with wet-weight concentrations. The uncertainty in the correction process itself is not considered. A sensitivity analysis is done to evaluate the significance of possible uncertainties in the coefficients used in the correction. 


\section{APPROACH TO QUANTIFICATION OF UNCERTAINTY}

\subsection{BACKGROUND}

The approach used here to estimate uncertainties associated with measurements made with the NaI systems is consistent with that provided in the American National Standard for Expressing Uncertainty (American National Standards Institute [ANSI] 1997). That standard is the U.S. version of the International Organization for Standardization's (ISO's) Guide to Uncertainty in Measurement, which is the de facto international standard for assessing measurement uncertainties. The approach outlined below follows that given by ANSI (1997).

The objective of making measurements is to estimate the value of some quantity. In general, the quantity $(Y)$ is determined from other quantities $\left(X_{1}, X_{2}, \ldots, X_{N}\right)$ by a functional relationship (a data reduction equation):

$$
Y=f\left(X_{1}, X_{2}, \ldots, X_{N}\right)
$$

The standard uncertainty of $y$, which is the estimate of $Y$, is obtained by properly combining the standard uncertainties (the estimated standard deviations) of the input estimates $x_{1}, x_{2}, \ldots, x_{N}$. This combined standard uncertainty of $y, u_{\mathrm{c}}(y)$, is the positive square root of the combined variance:

$$
u_{c}^{2}(y)=\sum_{i=1}^{N}\left[\partial f / \partial x_{i}\right]^{2} u^{2}\left(x_{i}\right)+2 \sum_{i=1}^{N-1} \sum_{j=i+1}^{N}\left(\partial f / \partial x_{i}\right)\left(\partial f / \partial x_{j}\right) u\left(x_{i}, x_{j}\right)
$$

where

$$
\begin{aligned}
& u^{2}\left(x_{i}\right)=\text { estimated variance of } x_{i}, \\
& u\left(x_{i}, x_{j}\right)=\text { estimated covariance of } x_{i} \text { and } x_{j}, \text { which equals } u\left(x_{i}\right) u\left(x_{j}\right) r\left(x_{i}, x_{j}\right), \text { and } \\
& r\left(x_{i}, x_{j}\right)=\text { estimated correlation coefficient associated with } x_{i} \text { and } x_{j} .
\end{aligned}
$$

When $x_{i}$ and $x_{j}$ are independent, the correlation (and covariance) is zero. Equation 3.1 is based on a first-order Taylor series approximation of $Y=f\left(X_{1}, X_{2} \ldots, X_{N}\right)$. Derivations can be found in standard texts (e.g., Bevington and Robinson 1992).

\subsection{DETERMINATION OF SOIL CONCENTRATIONS OF RADIONUCLIDES}

Wet-weight concentrations for ${ }^{238} \mathrm{U},{ }^{226} \mathrm{Ra}$, and ${ }^{232} \mathrm{Th}$ in soil are determined by using the following equations: 


$$
\begin{gathered}
C_{W U}=P V\left(F_{1} r_{N U}+F_{2} r_{N R a}+F_{3} r_{N T h}\right), \\
C_{W R a}=P V\left(F_{4} r_{N U}+F_{5} r_{N R a}+F_{6} r_{N T h}\right), \text { and } \\
C_{W T h}=P V\left(F_{7} r_{N U}+F_{8} r_{N R a}+F_{9} r_{N T h}\right),
\end{gathered}
$$

where

$P=$ factor (having no units) that accounts for any biases associated with the use of the calibration pad that have not been corrected. In practice, no such errors are known, and this factor equals 1 in all cases; however, it has an associated uncertainty. It is assumed to be the same for all radionuclides.

$V=$ factor (having no units) that adjusts for the effect of any nonuniform vertical distribution of radionuclides in the soil. This factor equals 1 in all calculations but has an associated uncertainty. It is assumed to be the same for all radionuclides.

$F_{i}=$ calibration coefficients (these coefficients are provided in Appendix K).

$r_{N U}, r_{N R a}$, and $r_{N T h}=$ net count rates for the uranium, radium, and thorium ROIs.

Equations 3.2a-c are the calibration equations for a NaI system (DOE 2001) modified to explicitly include the quantities $P$ and $V$. These equations can be written as follows:

$$
C_{W}=P V C_{W 0},
$$

where $C_{W 0}$ is the wet-weight concentration unadjusted by $P$ and $V$, as given by the calibration equation for the $\mathrm{NaI}$ system.

For ${ }^{238} \mathrm{U}$ and ${ }^{232} \mathrm{Th}$, the dry-weight concentration is given by

$$
C_{D}=M C_{W},
$$

where $M$ is a factor that adjusts for the moisture content of the soil. Moisture corrections are discussed in Appendix G.

For ${ }^{226} \mathrm{Ra}$, the wet-weight concentration must be adjusted for radon loss from soil before $M$ is used to correct to a dry-weight basis. This correction is discussed in Appendix F. NaI measurements of ${ }^{226} \mathrm{Ra}$ made at Fernald are not currently corrected for diurnal variations in atmospheric radon content. The uncertainty associated with such a correction is not considered quantitatively here. However, the issue is discussed qualitatively in Appendix F. 


\subsection{DETERMINATION OF UNCERTAINTY IN CONCENTRATIONS}

When Equations 3.1 and 3.2a are used, Appendix A (Section A.1) shows that the relative variance for the wet-weight concentration for ${ }^{238} \mathrm{U}, C_{W U}$, is

$$
u^{2}\left(C_{W U}\right) / C_{W U}^{2}=u^{2}(P)+u^{2}(V)+\left[u_{\text {calib }}{ }^{2}+u_{\text {count }}^{2}\right] / C_{W U^{2}},
$$

where

$$
\begin{aligned}
u_{\text {calib }}^{2}= & r_{N U^{2}} u^{2}\left(F_{1}\right)+r_{N R a^{2}} u^{2}\left(F_{2}\right)+r_{N T h}^{2} u^{2}\left(F_{3}\right) \\
& +2\left[r_{N U} r_{N R a} u\left(F_{1}, F_{2}\right)+r_{N U} r_{N T h} u\left(F_{1}, F_{3}\right)+r_{N R a} r_{N T h} u\left(F_{2}, F_{3}\right)\right]
\end{aligned}
$$

and

$$
u_{\text {count }}^{2}=F_{1}^{2} u^{2}\left(r_{N U}\right)+F_{2}^{2} u^{2}\left(r_{N R a}\right)+F_{3}^{2} u^{2}\left(r_{N T h}\right) .
$$

The combined relative variance in the dry-weight concentration for ${ }^{238} \mathrm{U}$ is then given by

$$
u_{c}{ }^{2}\left(C_{D U}\right) / C_{D U}{ }^{2}=u^{2}(M) / M^{2}+u^{2}\left(C_{W U}\right) / C_{W U}{ }^{2} .
$$

The equations that give the relative variances for measurements of ${ }^{232} \mathrm{Th}$ are identical, except that the calibration coefficients $F_{1}, F_{2}$, and $F_{3}$ become $F_{7}, F_{8}$, and $F_{9}$, respectively.

For $226 \mathrm{Ra}$, the process used to adjust the wet-weight concentration for radon loss from the soil affects the measurement uncertainty. Appendix A (Section A.2) shows that the combined relative variance in the dry-weight concentration for ${ }^{226} \mathrm{Ra}$ is given by

$$
\frac{u_{c}^{2}\left(C_{D R a}\right)}{C_{D R a}{ }^{2}}=\frac{u^{2}(M)}{M^{2}}+\frac{\left(b_{1}+2 b_{2} C_{W R a}\right)^{2}}{\left(b_{1}+b_{2} C_{W R a}\right)^{2}} \frac{u^{2}\left(C_{W R a}\right)}{C_{W R a}{ }^{2}},
$$

where $b_{1}$ and $b_{2}$ are empirically determined coefficients used in the equation that corrects the wet-weight concentration (see Equation F.3). $C_{W R a}$ refers to a wet-weight concentration uncorrected for radon loss. The expression for $u^{2}\left(C_{W R a}\right) / C_{W R a}{ }^{2}$ in Equation 3.6 has the same form as the expression for $u^{2}\left(C_{W U}\right) / C_{W U}{ }^{2}$ given in Equation 3.4, except that the calibration coefficients are $F_{4}, F_{5}$, and $F_{6}$.

The combined relative variance given in Equation 3.6 was determined by using a firstorder approximation (Equation 3.1). Use of such an approximation might appear to be inadequate given the nonlinear nature of the correction used for radon losses from soil. However, Appendix A shows that use of a second-order approximation changes results only minimally.

Evaluations of the various components of uncertainty included in the above equations are provided in the appendices. In particular, uncertainties in $P$ and $V$ are discussed in Appendices B and $\mathrm{C}$, respectively, and the uncertainty associated with calibration is evaluated in Appendix D. 
Uncertainties associated with counting are discussed in Appendix E. Radon corrections are considered in Appendix F. Uncertainties involving moisture corrections are examined in Appendix G. 


\section{ESTIMATED UNCERTAINTIES}

By using the approach presented in Chapter 3 (specifically Equations 3.4, 3.5, and 3.6), measurement uncertainties can be determined for various cases for the NaI systems. Expected uncertainties have been calculated for measurements of ${ }^{238} \mathrm{U},{ }^{226} \mathrm{Ra}$, and ${ }^{232} \mathrm{Th}$ made at the FRL, twice the FRL, and three times the FRL. For ${ }^{238} \mathrm{U}$, measurement uncertainties also were calculated for a soil concentration at the WAC level. In the case of an actual measurement made in the field, the uncertainty would be determined by using the actual measured count rates, which would depend on the soil concentration of the radionuclide of interest as well as the concentrations of other radionuclides in the soil. No specific relationship is expected between the soil concentration of one radionuclide, say ${ }^{238} \mathrm{U}$, and the soil concentrations of the others. However, in order to obtain expected uncertainties for specific concentrations of the radionuclide of interest, some concentrations must be assumed for the other two radionuclides. It is assumed here that the concentrations of the secondary radionuclides are approximately equal to the concentrations present in the calibration pad soil. In particular, it is assumed that when ${ }^{238} \mathrm{U}$, ${ }^{226} \mathrm{Ra}$, and ${ }^{232} \mathrm{Th}$ are not the radionuclides of interest, their concentrations are 2.0, 0.5, and $0.5 \mathrm{pCi} / \mathrm{g}$, respectively. (These values are based on HPGe measurements of concentrations in pad soil, as discussed in Chapter 5.) Interferences due to elevated concentrations of secondary radionuclides are not considered when uncertainties are evaluated.

Overall, the combined relative uncertainties (relative standard deviations) in the dryweight concentrations differ little from system to system. Table 4.1 summarizes the results for all four systems for 4-second measurements. At three times the FRL, the combined relative uncertainty in the dry-weight concentration is near $30 \%$ for ${ }^{238} \mathrm{U}, 40 \%$ for ${ }^{226} \mathrm{Ra}$, and $20 \%$ for ${ }^{232} \mathrm{Th}$. At WAC levels, the combined relative uncertainty is about $20 \%$. The uncertainties for all systems are essentially identical. The uncertainty for ${ }^{226} \mathrm{Ra}$ is elevated because of the effect of the correction process used to adjust for loss of radon from soil.

The relationship between combined relative uncertainty and contaminant concentration is shown graphically in Figure 4.1. As the concentration increases, the relative uncertainty decreases. As the figure illustrates, when concentrations are at or below the FRL, relative uncertainties are large, especially for ${ }^{238} \mathrm{U}$ and ${ }^{226} \mathrm{Ra}$. For concentrations greater than about three or four times the FRL, relative uncertainties decrease slowly as the concentration increases because the influence of counting errors on total relative uncertainty becomes small.

Figure 4.2 shows the relative importance of the various sources of uncertainty in the determination of combined uncertainty for dry-weight concentrations. The chart provides results for 4-second EMS measurements for soil concentrations of three times the FRL. The relative values shown were determined from the relative variances given in Table A.1. For example, the relative variance of 0.0392 for the dry-weight concentration given in the table for a ${ }^{232} \mathrm{Th}$ concentration of $4.5 \mathrm{pCi} / \mathrm{g}$ corresponds to a value of 1.0 (i.e., $100 \%$ ) for ${ }^{232} \mathrm{Th}$ in Figure 4.2. Similarly, for the same case, the relative variance of 0.0055 given for the uncertainty associated with counting corresponds to a relative contribution of 0.14 (i.e., 0.0055/0.0392) in Figure 4.2. 
TABLE 4.1 Summary of Combined Relative Uncertainties in the Measurements of Dry-Weight Concentrations for the NaI Systems ${ }^{a}$

Relative Uncertainty (Relative Standard Deviation)

\begin{tabular}{lcccc} 
System & ${ }^{238} \mathrm{U}(3 \times \mathrm{FRL})^{\mathrm{b}}$ & ${ }^{238} \mathrm{U}(\mathrm{WAC})^{\mathrm{b}}$ & ${ }^{226} \mathrm{Ra}(3 \times \mathrm{FRL})$ & ${ }^{232} \mathrm{Th}(3 \times \mathrm{FRL})$ \\
\hline EMS & 0.27 & 0.20 & 0.36 & 0.20 \\
Gator & 0.28 & 0.20 & 0.37 & 0.20 \\
RSS-1 & 0.27 & 0.20 & 0.36 & 0.20 \\
RSS-2 & 0.28 & 0.20 & 0.36 & 0.20 \\
RSS-3 & 0.28 & 0.20 & 0.36 & 0.20 \\
RTRAK & 0.28 & 0.20 & 0.37 & 0.20 \\
\hline
\end{tabular}

a Results are summarized from Table A.3 and are for 4-second measurements.

b The label " $3 \times$ FRL" indicates that results apply to dry-weight soil concentrations of three times the relevant FRL. "WAC" indicates that the results apply to dryweight soil concentrations of $1030 \mathrm{ppm}$.

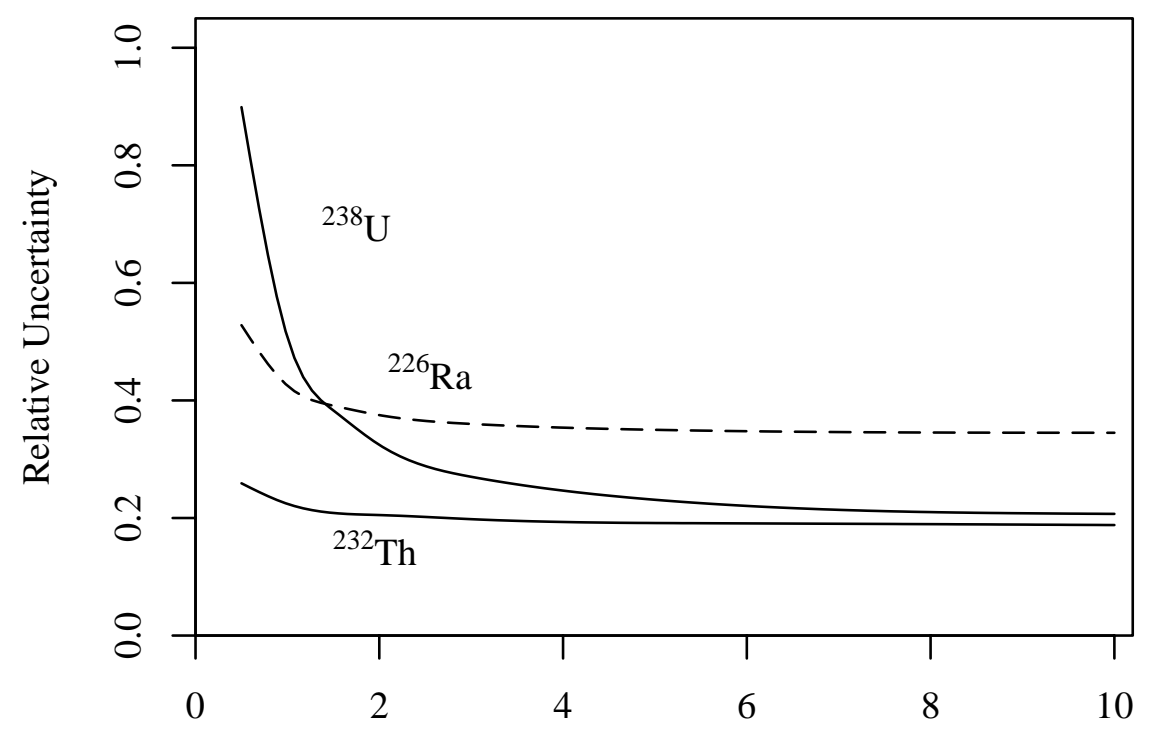

Concentration (multiple of FRL)

FIGURE 4.1 Combined Relative Uncertainty in Dry-Weight Concentration as a Function of Concentration (Relative standard deviations are provided for the EMS for 4-second measurements. They were determined in the same manner as the results shown in Table A.1. The FRLs are 27.3, 1.7, and $1.5 \mathrm{pCi} / \mathrm{g}$ for ${ }^{238} \mathrm{U},{ }^{226} \mathrm{Ra}$, and ${ }^{232} \mathrm{Th}$, respectively. $M=1.26$ ) 


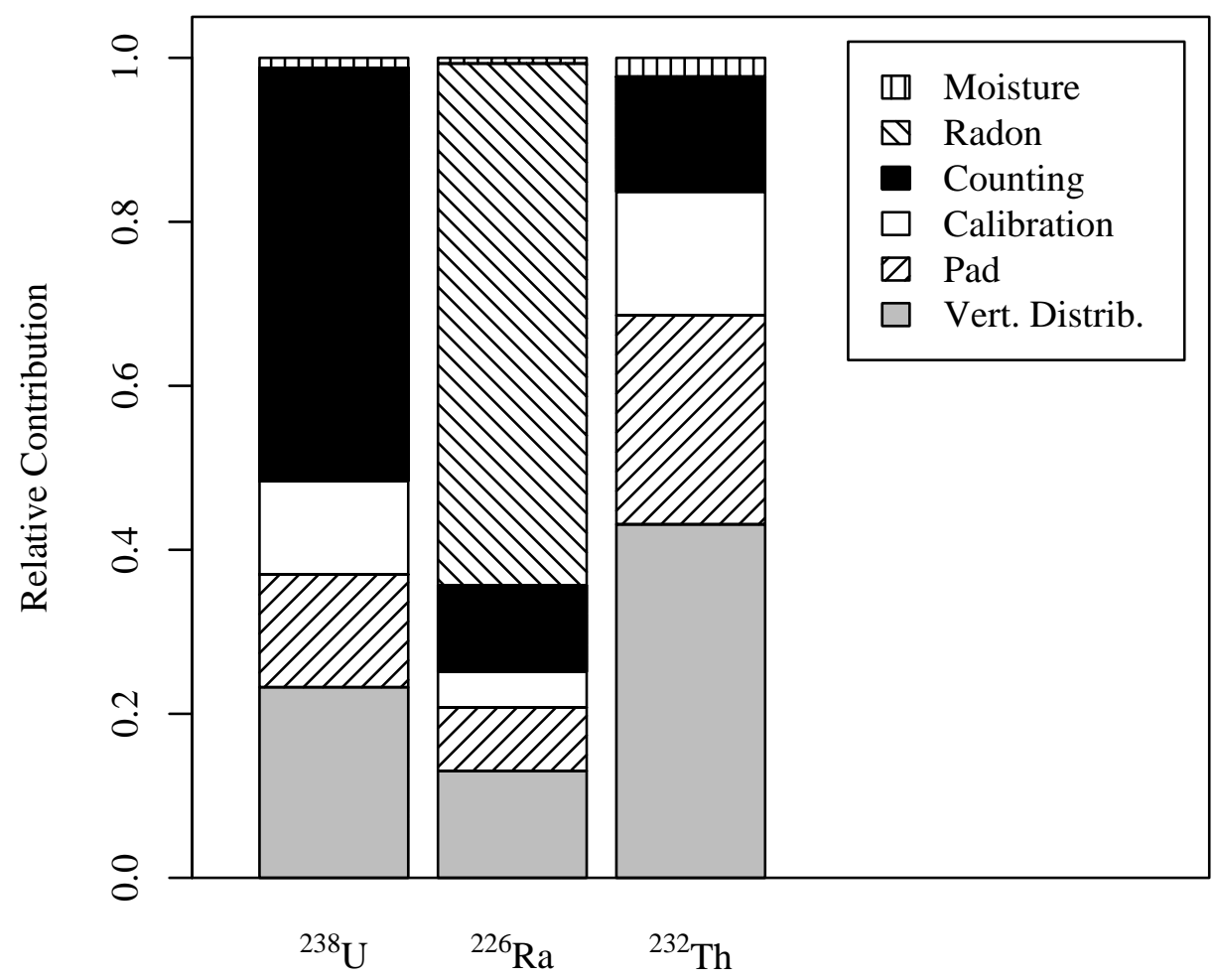

FIGURE 4.2 Sources of Uncertainty in Measured Concentrations (The chart shows the relative importance of the various factors that affect the combined variance at dry-weight concentrations of three times the FRL. Results are for the EMS for 4-second measurements and are based on the relative variances given in Table A.1.)

The uncertainty associated with the radon correction was not determined; no relative variances are given in Table A.1, for the effects of radon corrections. In Table A.1, the sum of the relative variances associated with the vertical distribution of the radionuclide, the calibration pad, the calibration process, and counting errors is multiplied by a factor (see Figure A.1) to determine the total relative variance for wet-weight concentrations for ${ }^{226} \mathrm{Ra}$. Therefore, for ${ }^{226} \mathrm{Ra}$, the sum of the relative variances for those factors does not equal the relative variance shown for the wet-weight concentration. In constructing Figure 4.2, the relative value of the difference between the sum of those factors and the value for the wet-weight concentration was assigned to the category labeled "Radon" in the figure to illustrate the importance of the correction process.

The major source of uncertainty in the $\mathrm{NaI}$ measurements depends on the radionuclide of interest. Figure 4.2 shows that for $238 \mathrm{U}$, the major source of uncertainty for measurements at three times the FRL is the counting error (contributing about 50\% of the total variance). Uncertainties associated with the vertical distribution of ${ }^{238} \mathrm{U}$, the calibration pad, and the calibration process make contributions of about $20 \%, 15 \%$, and $10 \%$, respectively. For ${ }^{226} \mathrm{Ra}$, the major sources of uncertainty at three times the FRL are ultimately the vertical distribution of the radionuclide, the counting error, and the pad. However, these uncertainties are multiplied by the factor shown in Figure A.1. The importance of the radon correction process is indicated in 
Figure 4.2 by the fact that it contributes nearly $65 \%$ of the total variance. As noted above, the uncertainty in the radon correction itself was not determined. For ${ }^{232} \mathrm{Th}$, the largest single source of uncertainty at three times the FRL is associated with the vertical distribution of ${ }^{232} \mathrm{Th}$ (nearly $45 \%$ of the total variance, largely as a result of the conservative assumptions made concerning that source of uncertainty). Uncertainties associated with the calibration pad, calibration, and counting errors contribute about $25 \%, 15 \%$, and $15 \%$ of the total, respectively. Uncertainties associated with moisture corrections contribute a negligible amount to the total uncertainty for all three radionuclides.

The uncertainty used for the vertical distribution of a radionuclide in soil is considered to be a conservative value, as is the uncertainty used for the pad. The results for ${ }^{238} \mathrm{U}$ indicate that refining those factors would not likely have much influence on the calculated combined uncertainty for measurements made at three times the FRL. (For measurements at the WAC level, however, those factors are of more significance because of the reduced importance of counting error at the more elevated concentration.) For ${ }^{226} \mathrm{Ra}$, the total measurement uncertainty is dominated by the radon correction process used, which essentially results in a multiplication of the uncertainties associated with counting and the vertical distribution. Any effort at refining the uncertainty analysis associated with measurements of $226 \mathrm{Ra}$ should first focus on the correction process. For ${ }^{232} \mathrm{Th}$, because of the reduced importance of uncertainties associated with counting and calibration, the uncertainties associated with the vertical distribution in the soil and the pad contribute about $60 \%$ of the total uncertainty. Therefore, a refinement of those factors may have some significant effect on the estimated uncertainties associated with measurements of ${ }^{232} \mathrm{Th}$.

The combined relative uncertainty is insensitive to the soil moisture level over the range of possible soil moisture levels. Only the relative counting uncertainty is influenced by the moisture level, and the influence is not significant. For ${ }^{226} \mathrm{Ra}$ and ${ }^{232} \mathrm{Th}$, the relative counting uncertainty calculated for the average soil moisture $(M=1.26)$ is within about $7 \%$ of the values obtained for $M=1.1$ or 1.4 (relative uncertainty increases as $M$ increases) at both the FRL and three times the FRL. For ${ }^{238} \mathrm{U}$, the corresponding difference is less than about $9 \%$. The influence on the combined relative uncertainty is considerably smaller, except for ${ }^{238} \mathrm{U}$ at the FRL, for which uncertainty due to the counting error dominates total uncertainty. For ${ }^{226} \mathrm{Ra}$, combined relative uncertainty estimates for $M=1.26$ are within about $3 \%$ of those obtained by using $M=$ 1.1 or 1.4 when concentrations are at or above the FRL. For ${ }^{232} \mathrm{Th}$, the difference is no more than about $2 \%$. For ${ }^{238} \mathrm{U}$, the difference is about $4 \%$ at three time the FRL and about $8 \%$ at the FRL. Therefore, uncertainties obtained by using $M=1.26$ can be applied for any expected moisture levels with little error.

Increasing measurement time reduces uncertainties associated with counting. If 4-second measurements are aggregated into 8-second measurements, the uncertainty associated with counting decreases by a factor of about the square root of two. However, such simple scaling cannot be applied in general because of the nature of the approximations used to obtain uncertainties associated with counting and the aggregation of spectra used in sanding. The issue is discussed further in Appendix E. 


\section{MINIMUM DETECTABLE CONCENTRATIONS}

A minimum detectable concentration (MDC) is an a priori estimate of the minimum net activity level that can be measured reliably by a particular system or technique under a given set of conditions. MARSSIM (2000) defines it as the net activity level that can be expected to be detected $95 \%$ of the time. The MDC is determined from a detection limit $\left(L_{D}\right)$ - which is the net response level (counts relative to a blank or background) that is an a priori estimate of the detection capability of a measurement system (MARSSIM 2000) — by using factors to convert it to units of activity. MDCs and $L_{D}$ 's are accepted quantities for specifying detection sensitivities.

The approach used for determining $L_{D}$ 's for the NaI systems is given in Appendix I. Using the $L_{D}$ 's with the calibration equations for the systems provides MDCs. The calibration

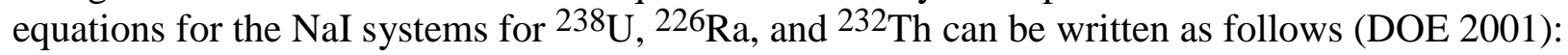

$$
\begin{gathered}
C_{W U}=F_{1} r_{N U}+F_{2} r_{N R a}+F_{3} r_{N T h}, \\
C_{\mathrm{WRa}}=F_{4} r_{N U}+F_{5} r_{N R a}+F_{6} r_{N T h}, \text { and } \\
C_{W T h}=F_{7} r_{N U}+F_{8} r_{N R a}+F_{9} r_{N T h},
\end{gathered}
$$

where $C_{W U}, C_{W R a}$, and $C_{W T h}$ are wet-weight concentrations in pCi/g; $r_{N U}, r_{N R a}$, and $r_{N T h}$ are raw (i.e., not corrected for interference from the other radionuclides) net count rates for the particular radionuclides; and $F_{1}-F_{9}$ are the calibration coefficients. The calibration coefficients for the systems are given in Table K.1 in Appendix K. The net count rates are relative to background counts for the radionuclide's ROI.

MDCs were determined with the above equations by using the net count rate for the radionuclide of interest that corresponds to the $L_{D}$ for that radionuclide. The net count rates for the other radionuclides were assumed to be equal to the values obtained on the calibration pad when no sources are present. Counting results for each of the systems with no sources in place are given in Table K.2 in Appendix K for a 300-second acquisition period. When MDCs were determined, counts were adjusted to correspond to the acquisition period being considered (i.e., 4 seconds).

Results of MDC calculations are summarized in Table 5.1 for total uranium (total uranium concentration in ppm is 2.99 times the ${ }^{238} \mathrm{U}$ concentration in $\mathrm{pCi} / \mathrm{g}$ ), ${ }^{226} \mathrm{Ra}$, and ${ }^{232} \mathrm{Th}$. The table provides MDCs, along with values of the critical level $\left(L_{C}\right)$ and $L_{D}$ for the systems. (The latter two values were determined for a 4-second acquisition period.) $L_{C}$ is defined as a net response level (relative to a blank or background) at which a detector output can be considered "above background" (MARSSIM 2000); see Appendix I for a more quantitative definition. MDCs were calculated by using the average moisture level for the calibration pad (11\%). To put the results for the MDCs in context, the table includes multiples of the FRLs for the radionuclides $(3 \times$ FRL). To allow reliable detection of hot spots, the MDCs should be less than the corresponding value of $3 \times$ FRL. All four of the platforms have MDCs for uranium, ${ }^{232} \mathrm{Th}$, and ${ }^{226}$ Ra well below $3 \times$ FRL for 4 -second measurements. 
TABLE 5.1 Results of MDC Calculations ${ }^{a}$

\begin{tabular}{lcccccc}
\hline & \multicolumn{5}{c}{ System } \\
\cline { 2 - 5 } & & & & \\
Quantity & EMS & Gator & RSS-1 & RSS-2 & RSS-3 & RTRAK \\
\hline & & & & & & \\
Uranium & & & & & & \\
$L_{C}$ & 27 & 25 & 25 & 25 & 25 & 24 \\
$L_{D}$ & 57.6 & 54.8 & 53.4 & 54.4 & 54.8 & 51.7 \\
MDC & 74 & 102 & 75 & 91 & 97 & 95 \\
$3 \times$ FRL & 246 & 246 & 246 & 246 & 246 & 246 \\
& & & & & & \\
$\mathbf{2 2 6}$ Ra & & & & & & \\
$L_{C}$ & 19 & 17 & 17 & 18 & 18 & 17 \\
$L_{D}$ & 42.4 & 39.7 & 39.4 & 40.6 & 40.9 & 38.4 \\
MDC & 1.4 & 1.7 & 1.4 & 1.5 & 1.5 & 1.7 \\
$3 \times$ FRL & 5.1 & 5.1 & 5.1 & 5.1 & 5.1 & 5.1 \\
& & & & & & \\
$\mathbf{2 3 2}$ Th & & & & & & \\
$L_{C}$ & 17 & 16 & 16 & 16 & 16 & 15 \\
$L_{D}$ & 37.0 & 34.6 & 34.5 & 34.4 & 34.8 & 33.7 \\
MDC & 0.7 & 0.7 & 0.7 & 0.7 & 0.7 & 0.7 \\
$3 \times$ FRL & 4.5 & 4.5 & 4.5 & 4.5 & 4.5 & 4.5 \\
\hline
\end{tabular}

a Basis: $L_{C}$ and $L_{D}$ were determined as described in Appendix I (background counts not constant, blank not well known). The calibration coefficients used to determine the MDCs are given in Appendix K. Measurement times are 4 seconds. A moisture correction factor of 1.11 was used (the average value for the pad). The ${ }^{226} \mathrm{Ra}$ MDC has a ${ }^{226} \mathrm{Ra}$ correction (DOE 2004) applied.

b Units: $L_{C}$ and $L_{D}$ are in counts per 4 seconds. MDCs and FRLs are in $\mathrm{pCi} / \mathrm{g}$, except those for uranium, which are in ppm. Detection limits and MDCs are relative to background concentrations in the soil of the calibration pad. MDCs are dry-weight concentrations.

The approach used in Appendix I to determine MDCs considers the variation in the background counts for the ROI as the concentration of the radionuclide of interest varies. The relationship between such background counts and net counts is approximately linear (see Figure E.1). Detection limits determined with Currie's (1968) widely used Equation 13 (equivalent to Equation 6-6 in MARSSIM) are somewhat lower than those obtained considering variations in counts in the background region (see Table I.2). As a result, the MDCs presented in this report are somewhat larger than those that are obtained with a simple application of Currie's approach.

The calculated detection limits are relative to the "blank," which corresponds to the background concentration in the pad soil. These concentrations are $0.45 \mathrm{pCi} / \mathrm{g}$ for ${ }^{232} \mathrm{Th}$ and $0.51 \mathrm{pCi} / \mathrm{g}$ for ${ }^{226} \mathrm{Ra}$, on the basis of HPGe measurements made on the pad (see, for example, Table 4-2 in DOE 2001). The uranium concentration in the pad soil cannot be determined with 
the HPGe systems, which have an MDC for uranium of about $4.6 \mathrm{ppm}$ for a 900 -second count (DOE 2004, Table 5-1). It is assumed in this report that the concentration of uranium in the pad soil is $2 \mathrm{pCi} / \mathrm{g}$, or about one-half of the MDC of the HPGe systems. The concentrations used for ${ }^{226} \mathrm{Ra}$ and ${ }^{232} \mathrm{Th}$ are based on the HPGe measurements; $0.5 \mathrm{pCi} / \mathrm{g}$ is used for both concentrations. The concentration of uranium in the pad soil (less than about $5 \mathrm{ppm}$ ) is a negligible fraction of the MDCs estimated for the NaI systems (less than about $6 \%$ for a 4 -second MDC). However, the concentration of ${ }^{226} \mathrm{Ra}$ in the pad soil is a significant fraction of the MDCs for ${ }^{226} \mathrm{Ra}$. Also, the ${ }^{232} \mathrm{Th}$ concentration in the pad soil is a sizeable fraction of the MDCs for ${ }^{232} \mathrm{Th}$ (over $60 \%$ of the 4 -second MDC). Therefore, the MDCs for ${ }^{232} \mathrm{Th}$ given in Table 5.1 likely underestimate the actual 4-second MDCs for $232 \mathrm{Th}$ by over $35 \%$ (i.e., if the actual MDC is $60 \%$ larger than the estimate, then the estimate is more than $35 \%$ below the actual value). However, given that the MDCs for ${ }^{232} \mathrm{Th}$ are well below $3 \times \mathrm{FRL}$, the underestimate is of little practical significance. The same conclusion applies to ${ }^{226} \mathrm{Ra}$ also. Example calculations for $L_{\mathrm{C}}, L_{\mathrm{D}}$, and an MDC are given in Section L.2 of Appendix L. 


\section{TRIGGER LEVELS FOR URANIUM WASTE ACCEPTANCE CRITERION}

As defined in DOE (2004), a trigger level is a specified radionuclide concentration that, if exceeded by a measurement, provides the basis for some subsequent action to be taken. Trigger levels are used because of the uncertainty associated with measurements. They are set below the relevant regulatory limit to reduce the chance of erroneously classifying soil as meeting the limit when it actually does not. As discussed in DOE (2004), minimum acceptable trigger levels are $70 \%$ of the regulatory limit. This chapter provides trigger levels for the NaI systems for use in determining whether soil exceeds the WAC for uranium for FCP's on-site disposal facility, which is $1030 \mathrm{ppm}$ of total uranium.

A WAC trigger level can be defined as follows:

$$
\text { WAC trigger }(\mathrm{ppm})=1030-k \sigma_{W A C},
$$

where $k$ is a quantile of the normal distribution, selected to provide an acceptable level of confidence that a measurement below the trigger actually corresponds to soil with a uranium concentration below $1030 \mathrm{ppm}$, and $\sigma_{W A C}$ is the standard deviation in the measured dry-weight uranium concentration at $1030 \mathrm{ppm}$.

To provide a $95 \%$ level of confidence, $k$ is 1.645 . With the uranium sources in the calibration pad, the effective uranium concentration of the pad is $993 \mathrm{ppm}$ when measured with an HPGe detector and about $980 \mathrm{ppm}$ on the basis of theoretical calculations (DOE 2001). These two results are consistent and very near the WAC of $1030 \mathrm{ppm}$. Therefore, when results obtained from measurements on the pad with uranium sources in place are used, the standard deviation in the measured uranium concentration should be near the standard deviation at the WAC level.

The estimation of $\sigma_{W A C}$ for the NaI systems is discussed in Appendix J. The determination of $\sigma_{W A C}$ considered only the variability due to counting errors. Other factors (e.g., soil moisture) also contribute random errors to measurements, but their effects were not considered in the determination of the value of $\sigma_{W A C}$ used to obtain WAC trigger levels. Systematic errors associated with calibration also were not considered when determining $\sigma_{W A C}$. Such an approach is consistent with that used for Fernald's HPGe detectors. The results for $\sigma_{W A C}$ for a single 4-second measurement are summarized in Table 6.1.

As shown in Table 6.1, all of the systems have WAC trigger levels (dry-weight basis) that are well above $70 \%$ of $1030 \mathrm{ppm}(721 \mathrm{ppm})$. The trigger levels for the systems are all similar, with a range in values of only 890 to $910 \mathrm{ppm}$. For average soil moisture levels $(M=1.26)$, the trigger would be 710 to $720 \mathrm{ppm}$ on a wet-weight basis. An example calculation of a WAC trigger level is provided in Section L.1 of Appendix L. 
TABLE 6.1 Trigger Levels for Uranium WAC

\begin{tabular}{|c|c|c|c|c|c|c|}
\hline \multirow[b]{2}{*}{ Quantity (ppm) } & \multicolumn{6}{|c|}{ System } \\
\hline & EMS & Gator & RSS-1 & RSS-2 & RSS-3 & RTRAK \\
\hline$\sigma_{W A C}$ & 76.0 & 83.8 & 73.8 & 81.3 & 81.3 & 81.4 \\
\hline WAC trigger level ${ }^{\mathrm{b}}$ & 910 & 890 & 910 & 900 & 900 & 900 \\
\hline
\end{tabular}

a Determined by using the method given in Appendix $\mathrm{J}$ and the data in Appendix K. Results are for a single 4-second measurement and are dry-weight concentrations.

b Results are rounded to two significant figures. 


\section{CONCLUSIONS}

Various sources contribute to the total uncertainty in measurements made with the NaI systems (see Table 2.1). The importance of the sources depends on the nature of the measurement (see Figure 4.2).

For measurements of ${ }^{238} \mathrm{U}$ and ${ }^{226} \mathrm{Ra}$ made near or below their FRLs, the major source of uncertainty is counting error. For measurements at three times the FRL, the counting error is still the major source of uncertainty for $238 \mathrm{U}$ and, ultimately (along with uncertainties in the calibration pad and in the vertical distribution of the radionuclide in the soil), for ${ }^{226} \mathrm{Ra}$. However, for ${ }^{226} \mathrm{Ra}$, the radon correction process used magnifies uncertainties substantially for concentrations at or above the FRL. For ${ }^{232} \mathrm{Th}$, the uncertainty in the vertical distribution of the radionuclide in soil, counting error, and uncertainty associated with the pad are major contributors to uncertainty near the FRL. At three times the FRL, the major sources of uncertainty are associated with the vertical distribution of the radionuclide in soil and with the pad (see Figure 4.2 and Appendix A).

The combined relative uncertainty in measurements of dry-weight concentrations of ${ }^{238} \mathrm{U},{ }^{226} \mathrm{Ra}$, and ${ }^{232} \mathrm{Th}$ at concentrations near three times their FRLs is about $30 \%, 40 \%$, and $20 \%$, respectively, for a 4-second measurement. Measurements of dry-weight concentrations of uranium at the WAC level have a combined relative uncertainty of about $20 \%$ for a 4 -second acquisition period (see Table 4.1). Combined relative uncertainties for moisture levels over the range for which measurements are made differ little from uncertainties for average soil moisture conditions. Increasing the counting times decreases the uncertainty, particularly for low concentrations of uranium. For practical purposes, the measurement uncertainties for all systems can be considered to be identical.

Some sources of uncertainty are better established than others. Uncertainties associated with the counting error, calibration, and moisture corrections have been established most carefully. The uncertainty associated with the vertical distribution of the radionuclides in soil is conservative and likely overstates the actual uncertainty for the Fernald site. The value used for the uncertainty associated with the pad and sources also is believed to be conservative. Refinement in the last two categories of uncertainty could have a substantial effect on the uncertainty for ${ }^{232} \mathrm{Th}$ measurements (such refinement would likely reduce the estimated uncertainty) but would be of less importance for ${ }^{238} \mathrm{U}$ and ${ }^{226} \mathrm{Ra}$ (but, again, it would likely reduce the estimated uncertainty).

The radon correction process used for ${ }^{226} \mathrm{Ra}$ measurements magnifies all sources of uncertainty associated with wet-weight concentrations, even if the correction process itself introduces no additional errors. The actual uncertainty associated with the correction process itself has not been quantified. However, such uncertainty exists and increases the total uncertainty above that given for ${ }^{226} \mathrm{Ra}$. It can be substantial in magnitude, particularly for elevated soil concentrations of ${ }^{226} \mathrm{Ra}$. The combined relative uncertainty for ${ }^{226} \mathrm{Ra}$ at three times the FRL could substantially exceed $40 \%$, particularly if measurement conditions are not optimized. 
There is little inter-platform variability (less than about 10\%) among the NaI systems for $L_{C}$ (critical level) and $L_{D}$ (detection limit). The inter-platform variability for MDCs for uranium and ${ }^{226} \mathrm{Ra}$ is larger than that for detection limits because of differences in calibration coefficients. Overall, the results indicate that the detectors in the systems behave similarly (see Table 5.1).

The MDCs for all platforms are well below three times the relevant FRL for a 4-second measurement for uranium, ${ }^{232} \mathrm{Th}$, and ${ }^{226} \mathrm{Ra}$ (see Table 5.1). For intended applications at Fernald, the presence of ${ }^{238} \mathrm{U},{ }^{226} \mathrm{Ra}$, and ${ }^{232} \mathrm{Th}$ in the soil of the calibration pad has no practical significance for determining the MDCs. Increasing the measurement time will reduce the MDCs.

For all the NaI systems currently used at Fernald, a trigger level of 900 ppm (dry-weight) provides a reasonable basis for identifying areas with uranium concentrations above the WAC level when 4-second measurements are used (see Table 6.1). For average moisture conditions $(M=1.26)$, the corresponding trigger level is $710 \mathrm{ppm}$ (wet-weight).

The uncertainties, MDCs, and trigger levels presented in this report apply only if the measurement process is carried out properly under acceptable conditions. In particular, it has been assumed that (1) soil moisture is less than about $40 \%$ with no standing water, (2) no interfering sources of gamma rays are present, (3) the systems are operating properly, (4) all areas of soil contamination are considerably larger than the field of view of the instruments used, (5) measurements are made in flat areas, and (6) ${ }^{226} \mathrm{Ra}$ measurements are made in the afternoon under stable atmospheric conditions.

The uncertainties presented in this report strictly apply to static measurements or to measurements made by using a moving system in an area with uniform soil concentrations of the radionuclide of interest. When soil concentrations vary with location, identifying locations with elevated levels of contamination (and quantifying the concentrations) becomes a more difficult problem. Some issues related to addressing nonuniform soil concentrations at Fernald are discussed in DOE (2004). In addition to the measurement uncertainties discussed in this report, one also needs to consider the probability that the area of contamination will fill the field of view of the detector during the acquisition period. Issues associated with locating hot spots by using a moving detector are discussed in Davis (2002). 


\section{REFERENCES}

ANSI (American National Standards Institute), 1997, U.S. Guide to the Expression of Uncertainty in Measurement, American National Standard ANSI/NCSL Z540-2-1997, published by the National Conference of Standards Laboratories, Boulder, Colo.

Bevington, P.R., and D.K. Robinson, 1992, Data Reduction and Error Analysis for the Physical Sciences, 2nd ed., WCB/McGraw-Hill, Boston, Mass.

Currie, L. A., 1968, "Limits for Qualitative Detection and Quantitative Determination," Analytical Chemistry 40(3):586-593, March.

Davis, M. J., 2002, "The Probability of Finding a Localized Area with Elevated Contamination by Using a Mobile Detector," Health Physics 83(4):497-503, Oct.

DOE (U.S. Department of Energy), 1999, Comparability of In-Situ Gamma Spectrometry and Laboratory Data, Fernald Area Office, Jan.

DOE, 2001, Calibration of NaI In Situ Gamma Spectroscopy Systems, Fernald Area Office, Final, March.

DOE, 2004, User Guidelines, Measurement Strategies, and Operational Factors for Deployment of In Situ Gamma Spectrometry at the Fernald Site, Fernald Area Office. Jan.

MARSSIM, 2000, Multi-Agency Radiation Survey and Site Investigation Manual, NUREG-1575, Rev. 1, EPA 402-R-97-016, Rev. 1, DOE/EH-0624, Rev. 1, Dec. 


\section{APPENDIX A:}

\section{UNCERTAINTY ANALYSIS}

\section{A.1 DETERMINATION OF UNCERTAINTY IN 238U AND ${ }^{232}$ Th CONCENTRATIONS}

From Equations 3.2a and 3.3, the dry-weight concentration for ${ }^{238} \mathrm{U}$ is given by

$$
C_{D U}=M P V\left(F_{1} r_{N U}+F_{2} r_{N R a}+F_{3} r_{N T h}\right)
$$

where $P=V=1$. Equation A.1 can be expressed as

$$
C_{D U}=f\left(M, P, V, F_{i}, r_{N j}\right)=M C_{W U}
$$

By using Equation 3.1, the combined variance for $C_{\mathrm{DU}}$ is given by

$$
\begin{aligned}
u_{c}^{2}\left(C_{D U}\right)= & C_{W U^{2}} u^{2}(M)+\left(M C_{W U}\right)^{2} u^{2}(P)+\left(M C_{W U}\right)^{2} u^{2}(V) \\
& +\left(M r_{N U}\right)^{2} u^{2}\left(F_{1}\right)+\left(M r_{N R a}\right)^{2} u^{2}\left(F_{2}\right)+\left(M r_{N T h}\right)^{2} u^{2}\left(F_{3}\right) \\
& +\left(M F_{1}\right)^{2} u^{2}\left(r_{N U}\right)+\left(M F_{2}\right)^{2} u^{2}\left(r_{N R a}\right)+\left(M F_{3}\right)^{2} u^{2}\left(r_{N T h}\right) \\
& +2 r_{N U} r_{N R a} M^{2} u\left(F_{1}, F_{2}\right)+2 r_{N U} r_{N T h} M^{2} u\left(F_{1}, F_{3}\right) \\
& +2 r_{N R a} r_{N T h} M^{2} u\left(F_{2}, F_{3}\right) .
\end{aligned}
$$

With the exception of the covariance terms involving the calibration coefficients [namely, $u\left(F_{1}, F_{2}\right)$, etc.], no covariance terms are included in Equation A.3. $M, P$, and $V$ are independent of each other and of the net count rates and calibration coefficients, so the covariance of each of those quantities with the others is zero. The covariance of the calibration coefficients with the net count rates, $u\left(F_{i}, r_{N j}\right)$, is zero because the counts used to determine the $F_{i}$ and those used to determine the $r_{N i}$ are independent. The covariance terms involving the various net count rates [terms of the form $2 F_{1} F_{2} M^{2} u\left(r_{N U}, r_{N R a}\right)$, for example] are not included because their magnitudes were checked empirically and found to be much less than the contributions from the terms involving the variances of the net count rates.

Dividing both sides of Equation A.3 by $C_{D U}{ }^{2}$ [which equals $\left(M C_{W U}\right)^{2}$ ] gives

$$
\begin{aligned}
u_{\mathrm{c}}^{2}\left(C_{D U}\right) / C_{D U^{2}}= & u^{2}(M) / M^{2}+u^{2}(P)+u^{2}(V)+\left[r_{N U^{2}} u^{2}\left(F_{1}\right)+r_{N R a}^{2} u^{2}\left(F_{2}\right)+r_{N T h}^{2} u^{2}\left(F_{3}\right)\right. \\
& \left.+F_{1}^{2} u^{2}\left(r_{N U}\right)+F_{2}^{2} u^{2}\left(r_{N R a}\right)+F_{3}^{2} u^{2}\left(r_{N T h}\right)\right] / C_{W U^{2}+2\left[r_{N U} r_{N R a} u\left(F_{1}, F_{2}\right)\right.} \\
& \left.+r_{N U} r_{N T h} u\left(F_{1}, F_{3}\right)+r_{N R a} r_{N T h} u\left(F_{2}, F_{3}\right)\right] / C_{W U}{ }^{2} .
\end{aligned}
$$


This can be written as

$$
u_{c}^{2}\left(C_{D U}\right) / C_{D U}{ }^{2}=u^{2}(M) / M^{2}+u^{2}(P)+u^{2}(V)+\left[u_{\text {calib }}^{2}+u_{\text {count }}{ }^{2}\right] / C_{W U^{2}},
$$

where

$$
\begin{aligned}
& u_{\text {calib }}^{2}=r_{N U^{2}} u^{2}\left(F_{1}\right)+r_{N R a}^{2} u^{2}\left(F_{2}\right)+r_{N T h}^{2} u^{2}\left(F_{3}\right) \\
& +2\left[r_{N U} r_{N R a} u\left(F_{1}, F_{2}\right)+r_{N U} r_{N T h} u\left(F_{1}, F_{3}\right)+r_{N R a} r_{N T h} u\left(F_{2}, F_{3}\right)\right]
\end{aligned}
$$

and

$$
u_{\text {count }}^{2}=F_{1}^{2} u^{2}\left(r_{N U}\right)+F_{2}^{2} u^{2}\left(r_{N R a}\right)+F_{3}^{2} u^{2}\left(r_{N T h}\right) .
$$

The combined relative standard uncertainty (relative standard deviation) in the measurement can be obtained by taking the square root of the right-hand side of Equation A.5a. Note (from Equation A.2) that

$$
u_{\mathrm{c}}^{2}\left(C_{D U}\right) / C_{D U}{ }^{2}=u^{2}(M) / M^{2}+u^{2}\left(C_{W U}\right) / C_{W U}{ }^{2}
$$

Therefore, from Equation A.5a, the relative variance for $C_{W U}$ is

$$
u^{2}\left(C_{W U}\right) / C_{W U}{ }^{2}=u^{2}(P)+u^{2}(V)+\left[u_{\text {calib }}{ }^{2}+u_{\text {count }}{ }^{2}\right] / C_{W U^{2}} .
$$

Equations that give the relative variances for measurements of ${ }^{232} \mathrm{Th}$ can be obtained in a similar manner. They are identical to Equations A.5-A.7 for ${ }^{238} \mathrm{U}$ except that the calibration coefficients $F_{1}, F_{2}$, and $F_{3}$ become $F_{7}, F_{8}$, and $F_{9}$, respectively.

\section{A.2 DETERMINATION OF UNCERTAINTY IN 226RA CONCENTRATIONS}

The process used to adjust the wet-weight concentration of 226Ra for radon loss from soil affects the measurement uncertainty for ${ }^{226}$ Ra. This subject is discussed in Appendix F. From Appendix F (Equation F.3), the dry-weight concentration for ${ }^{226} \mathrm{Ra}$ is given by

$$
C_{D R a}=M\left(b_{1} C_{W R a}+b_{2} C_{W R a}^{2}\right),
$$

where $b_{1}$ and $b_{2}$ are empirically determined coefficients used to adjust the wet-weight concentration to account for radon loss from soil. Note that $C_{W R a}$ refers to a wet-weight concentration, uncorrected for radon loss.

When it is assumed that there is no uncertainty in $b_{1}$ and $b_{2}$, the combined variance for $C_{D R a}$ is given by

$$
u_{\mathrm{c}}^{2}\left(C_{D R a}\right)=\left(b_{1} C_{W R a}+b_{2} C_{W R a^{2}}\right)^{2} u^{2}(M)+\left[M\left(b_{1}+2 b_{2} C_{W R a}\right)\right]^{2} u^{2}\left(C_{W R a}\right) .
$$


Dividing both sides of Equation A.9 by $C_{D R a}{ }^{2}$ and using the relationship in Equation A.8 gives

$$
\frac{u_{c}^{2}\left(C_{D R a}\right)}{C_{D R a}^{2}}=\frac{u^{2}(M)}{M^{2}}+\frac{\left(b_{1}+2 b_{2} C_{W R a}\right)^{2}}{\left(b_{1}+b_{2} C_{W R a}\right)^{2}} \frac{u^{2}\left(C_{W R a}\right)}{C_{W R a}{ }^{2}} .
$$

The expression for $u^{2}\left(C_{W R a}\right) / C_{W R a}^{2}$ in Equation A.10 has the same form as the expression for $u^{2}\left(C_{W U}\right) / C_{W U}{ }^{2}$ in Equation A.7, except that the calibration coefficients used to determine $u_{\text {calib }}$ and $u_{\text {count }}$ are $F_{4}, F_{5}$, and $F_{6}$.

The factor multiplying $u^{2}\left(C_{W R a}\right) / C_{W R a}^{2}$ in Equation A.10 results in a considerable increase in uncertainty, even when it is assumed that the process that is used adjusts the 226 Ra measurement perfectly. The multiplying factor is plotted as a function of $C_{W R a}$ in Figure A.1. It varies from a value of 1.0 for $C_{W R a}=0 \mathrm{pCi} / \mathrm{g}$ to 3.58 for $C_{W R a}=10 \mathrm{pCi} / \mathrm{g}$. For a corrected dryweight concentration of $5.1 \mathrm{pCi} / \mathrm{g}$ (three times the final remediation level [FRL], which corresponds to an uncorrrected wet-weight concentration of $2.43 \mathrm{pCi} / \mathrm{g}$ when it is assumed that $M=1.26$ ), the factor is 2.79 . Therefore, at a dry-weight concentration of three times the FRL, the radon correction process used increases the uncertainty in the wet-weight concentration, $u\left(C_{W}\right)$, by a factor of about the square root of three (about 1.7), even when any uncertainty in the correction process itself is negligible.

Given the second-order term involving $C_{W R a}$ in Equation A.8, the use of the general expression for combined standard uncertainty (Equation 3.1), which is based on a first-order Taylor series approximation, may not provide an adequate quantification of the uncertainty in $C_{D R a}$ for ${ }^{226} \mathrm{Ra}$. For the case in which no correlation exists between the $x_{\mathrm{i}}$ 's in the data reduction equation, the combined standard uncertainty based on a second-order Taylor series approximation is given by

$$
u_{c}^{2}(y)=\sum_{i=1}^{N}\left[\frac{\partial f}{\partial x_{i}}\right]^{2} u^{2}\left(x_{i}\right)+\sum_{i=1}^{N} \sum_{j=1}^{N} \frac{1}{2}\left[\frac{\partial^{2} f}{\partial x_{i} \partial x_{j}}\right]^{2} u^{2}\left(x_{i}\right) u^{2}\left(x_{j}\right)
$$

Applying this to Equation A.8, the combined variance for $C_{D R a}$ is

$$
\begin{aligned}
u_{c}^{2}\left(C_{D R a}\right)= & \left(b_{1} C_{W R a}+b_{2} C_{W R a}^{2}\right)^{2} u^{2}(M)+\left[M\left(b_{1}+2 b_{2} C_{W R a}\right)\right]^{2} u^{2}\left(C_{W R a}\right) \\
& +1 / 2\left[2 b_{2} M u^{2}\left(C_{W R a}\right)\right]^{2}+\left(b_{1}+2 b_{2} C_{W R a}\right)^{2} u^{2}(M) u^{2}\left(C_{W R a}\right),
\end{aligned}
$$

from which

$$
\frac{u_{c}{ }^{2}\left(C_{D R a}\right)}{C_{D R a}{ }^{2}}=\frac{u^{2}(M)}{M^{2}}+\frac{\left(b_{1}+2 b_{2} C_{W R a}\right)^{2}\left(1+\frac{u^{2}(M)}{M^{2}}\right)+2\left[b_{2}^{2} u^{2}\left(C_{W R a}\right)\right]}{\left(b_{1}+b_{2} C_{W R a}\right)^{2}} \frac{u^{2}\left(C_{W R a}\right)}{C_{W R a}{ }^{2}} .
$$


When second-order effects are considered, the factor multiplying $u^{2}\left(C_{W R a}\right) / C_{W R a}{ }^{2}$ increases (compare Equations A.10 and A.13). The factor from Equation A.13 is plotted in Figure A.1 along with the factor from Equation A.10. Note that while the factor obtained for the first-order correction case does not depend on the system being considered, the inclusion of a second-order correction results in the factor being related to $u^{2}\left(C_{W R a}\right)$, which does depend on the system used. Uncertainties for the various systems are discussed in Section A.3. Results for the factor for the excavation monitoring system (EMS) (uncertainties provided in Table A.1) are shown in Figure A.1. As can be seen from the figure, including second-order terms has a minimal effect on the correction factor.

The uncertainties in $b_{1}$ and $b_{2}$ are unknown. Sensitivity analysis in Appendix F (see Table F.2) shows that if uncertainties in both coefficients are as high as $60 \%$, then, for a ${ }^{226} \mathrm{Ra}$ concentration equal to three times the FRL, the uncertainty in $C_{D R a}$ increases by more than $60 \%$ relative to the case for which there is no uncertainty in $b_{1}$ and $b_{2}$. Uncertainties in concentrations are sensitive to uncertainties in $b_{2}$ at concentrations of three times the FRL and above. In addition, the correction process introduces a sizable magnifying effect in the wet-weight concentration, as discussed above. Overall, uncertainties in ${ }^{226} \mathrm{Ra}$ measurements can be expected to be significant for soils with elevated levels of ${ }^{226} \mathrm{Ra}$ (e.g., three times the FRL). (Measurements made during the morning have even larger uncertainties, although such uncertainties were not considered quantitatively; they are discussed in Appendix F.)

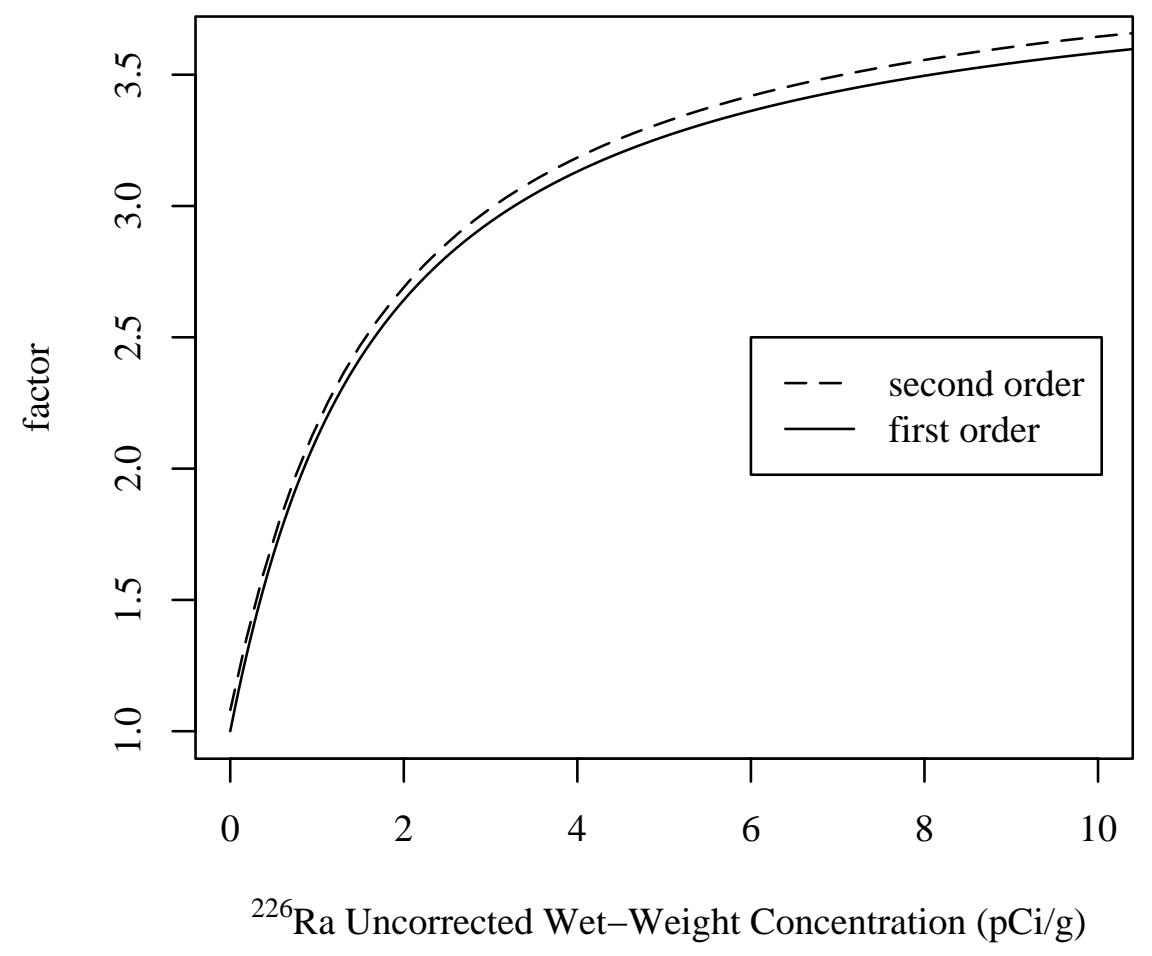

FIGURE A.1 Variation of the Factor Multiplying the Relative Variance in the Uncorrected Wet-Weight Concentration of ${ }^{226}$ Ra as a Function of the Uncorrected Wet-Weight Concentration of ${ }^{226} \mathrm{Ra}$ (The results for the second-order case are for the EMS and $M=1.26$. The factor has no units.) 
TABLE A.1 Relative Variances for EMS Measurementsa

\begin{tabular}{cccccccc}
\hline & \multicolumn{7}{c}{ Relative Variances } \\
\cline { 2 - 8 } $\begin{array}{c}\text { Dry-Weight } \\
\begin{array}{c}\text { Concentration } \\
\text { (pCi/g) }\end{array}\end{array}$ & $\begin{array}{c}\text { Vertical } \\
\text { Distribution }\end{array}$ & Pad & Calibration & Counting & $\begin{array}{c}\text { Wet-Weight } \\
\text { Conc. }\end{array}$ & $\begin{array}{c}\text { Moisture } \\
\text { Correction }\end{array}$ & $\begin{array}{c}\text { Dry-Weight } \\
\text { Conc. }\end{array}$ \\
\hline $\mathbf{2 3 8} \mathbf{U}$ & & & & & & & \\
27.3 & 0.0169 & 0.0100 & 0.0106 & 0.2190 & 0.2564 & 0.0009 & 0.2573 \\
54.7 & 0.0169 & 0.0100 & 0.0087 & 0.0685 & 0.1041 & 0.0009 & 0.1050 \\
82.0 & 0.0169 & 0.0100 & 0.0083 & 0.0366 & 0.0718 & 0.0009 & 0.0727 \\
343.3 & 0.0169 & 0.0100 & 0.0077 & 0.0055 & 0.0401 & 0.0009 & 0.0410 \\
& & & & & & & \\
$\mathbf{2 2 6} \mathbf{R a}$ & & & & & & & \\
1.7 & 0.0169 & 0.0100 & 0.0058 & 0.0468 & 0.1798 & 0.0009 & 0.1807 \\
3.4 & 0.0169 & 0.0100 & 0.0057 & 0.0211 & 0.1398 & 0.0009 & 0.1407 \\
5.1 & 0.0169 & 0.0100 & 0.0057 & 0.0136 & 0.1286 & 0.0009 & 0.1295 \\
& & & & & & & \\
$\mathbf{2 3 2} \mathbf{T h}$ & & & & & & & \\
1.5 & 0.0169 & 0.0100 & 0.0058 & 0.0167 & 0.0493 & 0.0009 & 0.0502 \\
3.0 & 0.0169 & 0.0100 & 0.0058 & 0.0083 & 0.0410 & 0.0009 & 0.0419 \\
4.5 & 0.0169 & 0.0100 & 0.0059 & 0.0055 & 0.0383 & 0.0009 & 0.0392 \\
\hline
\end{tabular}

a Results are for 4-second measurements. The influence of the correction for radon loss from soil is included in the results given for wet- and dry-weight concentrations of ${ }^{226} \mathrm{Ra}$.

b Unless otherwise stated, the dry-weight concentrations of ${ }^{238} \mathrm{U},{ }^{226} \mathrm{Ra}$, and ${ }^{232} \mathrm{Th}$ are $2,0.5$, and $0.5 \mathrm{pCi} / \mathrm{g}$, respectively. $M=1.26$. The uncorrected wet-weight concentrations for ${ }^{226} \mathrm{Ra}$ that correspond to dry-weight concentrations of $1.7,3.4$, and $5.1 \mathrm{pCi} / \mathrm{g}$ are $1.2,1.9$, and $2.4 \mathrm{pCi} / \mathrm{g}$, respectively.

\section{A.3 RESULTS}

Results for the EMS are summarized in Tables A.1 and A.2 for 4-second measurements. The general basis for the determination of relative variances is discussed in Sections A.1 and A.2. Table A.1 gives relative variances, and Table A.2 gives relative standard deviations for the various components of uncertainty and also for wet-weight and dry-weight concentrations. The columns labeled "Vertical Distribution," "Pad," "Calibration," "Counting," and "Moisture Correction" give the relative variances (standard deviations) in the wet-weight concentrations due to these sources of uncertainty. The columns labeled "Wet-Weight Conc." and "Dry-Weight Conc." give the relative variances (standard deviations) in these quantities. The entries in the tables showing relative standard deviations are the square roots of the corresponding entries in the tables showing relative variances. Note that relative variances due to the various sources of uncertainty can be added to yield the relative variances in wet- and dry-weight concentrations. However, relative standard deviations cannot be combined in this manner. 
TABLE A.2 Relative Standard Deviations for EMS Measurements ${ }^{a}$

\begin{tabular}{|c|c|c|c|c|c|c|c|}
\hline \multirow[b]{2}{*}{$\begin{array}{l}\text { Dry-Weight } \\
\text { Concentration }{ }^{b} \\
(\mathrm{pCi} / \mathrm{g})\end{array}$} & \multicolumn{7}{|c|}{ Relative Standard Deviations } \\
\hline & $\begin{array}{c}\text { Vertical } \\
\text { Distribution }\end{array}$ & Pad & Calibration & Counting & $\begin{array}{c}\text { Wet-Weight } \\
\text { Conc. }\end{array}$ & $\begin{array}{c}\text { Moisture } \\
\text { Correction }\end{array}$ & $\begin{array}{c}\text { Dry-Weight } \\
\text { Conc. }\end{array}$ \\
\hline \multicolumn{8}{|l|}{${ }^{238} \mathbf{U}$} \\
\hline 27.3 & 0.130 & 0.100 & 0.103 & 0.468 & 0.506 & 0.030 & 0.507 \\
\hline 54.7 & 0.130 & 0.100 & 0.093 & 0.262 & 0.323 & 0.030 & 0.324 \\
\hline 82.0 & 0.130 & 0.100 & 0.091 & 0.191 & 0.268 & 0.030 & 0.270 \\
\hline 343.3 & 0.130 & 0.100 & 0.088 & 0.074 & 0.200 & 0.030 & 0.202 \\
\hline \multicolumn{8}{|l|}{${ }^{226} \mathbf{R a}$} \\
\hline 1.7 & 0.130 & 0.100 & 0.076 & 0.216 & 0.424 & 0.030 & 0.425 \\
\hline 3.4 & 0.130 & 0.100 & 0.076 & 0.145 & 0.374 & 0.030 & 0.375 \\
\hline 5.1 & 0.130 & 0.100 & 0.075 & 0.117 & 0.359 & 0.030 & 0.360 \\
\hline \multicolumn{8}{|l|}{${ }^{232} \mathrm{Th}$} \\
\hline 1.5 & 0.130 & 0.100 & 0.076 & 0.129 & 0.222 & 0.030 & 0.224 \\
\hline 3.0 & 0.130 & 0.100 & 0.076 & 0.091 & 0.203 & 0.030 & 0.205 \\
\hline 4.5 & 0.130 & 0.100 & 0.077 & 0.074 & 0.196 & 0.030 & 0.198 \\
\hline
\end{tabular}

a Results are for 4-second measurements. The influence of the correction for radon loss from soil is included in the results given for wet- and dry-weight concentrations of ${ }^{226} \mathrm{Ra}$.

b Unless otherwise stated, the dry-weight concentrations of ${ }^{238} \mathrm{U},{ }^{226} \mathrm{Ra}$, and ${ }^{232} \mathrm{Th}$ are $2,0.5$, and $0.5 \mathrm{pCi} / \mathrm{g}$, respectively. $M=1.26$. The uncorrected wet-weight concentrations for ${ }^{226} \mathrm{Ra}$ that correspond to dry-weight concentrations of $1.7,3.4$, and $5.1 \mathrm{pCi} / \mathrm{g}$ are $1.2,1.9$, and $2.4 \mathrm{pCi} / \mathrm{g}$, respectively.

The results for the other systems are similar to those shown for the EMS. There is relatively little system-to-system variability. Table A.3 summarizes relative uncertainties in dryweight concentrations for all the systems.

The detailed basis for the numerical results provided in Tables A.1, A.2, and A.3 is provided in other appendices of this report. Important points are the following:

- The calibration coefficients used for the systems are given in Table K.1.

- The relative uncertainty associated with the vertical distribution of the radionuclides in soil is 0.13 , as discussed in Appendix C.

- The relative uncertainty associated with the calibration pad is 0.1 , as is discussed in Appendix B.

- When $238 \mathrm{U},{ }^{226} \mathrm{Ra}$, and ${ }^{232} \mathrm{Th}$ are the secondary contaminants, their concentrations are assumed to be $2.0,0.5$, and $0.5 \mathrm{pCi} / \mathrm{g}$, respectively. 
TABLE A.3 Relative Uncertainties in Dry-Weight Concentrationsa

\begin{tabular}{ccccccc}
\hline & \multicolumn{5}{c}{ System } \\
\cline { 2 - 7 } $\begin{array}{c}\text { Dry-Weight } \\
\begin{array}{c}\text { Concentration } \\
\text { (pCi/g) }\end{array}\end{array}$ & EMS & Gator & RSS-1 & RSS-2 & RSS-3 & RTRAK \\
\hline 238 $\mathbf{U}$ & & & & & & \\
27.3 & 0.507 & 0.565 & 0.503 & 0.553 & 0.558 & 0.572 \\
54.7 & 0.324 & 0.348 & 0.322 & 0.343 & 0.345 & 0.351 \\
82.0 & 0.270 & 0.282 & 0.269 & 0.280 & 0.281 & 0.284 \\
343.3 & 0.202 & 0.200 & 0.202 & 0.200 & 0.200 & 0.200 \\
& & & & & & \\
$\mathbf{2 2 6} \mathbf{R a}$ & & & & & & \\
1.7 & 0.425 & 0.456 & 0.435 & 0.440 & 0.434 & 0.457 \\
3.4 & 0.375 & 0.388 & 0.379 & 0.381 & 0.378 & 0.388 \\
5.1 & 0.360 & 0.366 & 0.361 & 0.362 & 0.361 & 0.366 \\
& & & & & & \\
$\mathbf{2 3 2} \mathbf{T h}$ & & & & & & \\
1.5 & 0.224 & 0.228 & 0.226 & 0.227 & 0.227 & 0.228 \\
3.0 & 0.205 & 0.204 & 0.204 & 0.204 & 0.204 & 0.204 \\
4.5 & 0.198 & 0.196 & 0.197 & 0.197 & 0.196 & 0.196 \\
\hline
\end{tabular}

a Unless otherwise stated, the dry-weight concentrations of ${ }^{238} \mathrm{U},{ }^{226} \mathrm{Ra}$, and ${ }^{232} \mathrm{Th}$ are $2,0.5$, and $0.5 \mathrm{pCi} / \mathrm{g}$, respectively. Results are for 4 -second measurements. The influence of the correction for radon loss from soil is included in the results given for ${ }^{226} \mathrm{Ra} . M=1.26$.

- Net count rates for the calculations are determined by using the calibration equations and the assumed contaminant concentrations.

- The uncertainties associated with the calibration coefficients $\left[u\left(F_{\mathrm{i}}, F_{\mathrm{j}}\right)\right.$ in Equation A.5b, for example] are provided in Table D.2. The uncertainty associated with calibration is determined by using Equation A.5b (for example).

- Background counts (and subsequently gross counts) for the calculations are determined by using the relationships provided in Section E.2.

- Determining the uncertainty associated with the net count rate and the uncertainty associated with counting rely on the approximations discussed in Sections E.1 and E.3. An example calculation of the uncertainty in the net count rate is given in Section L.3.

- Radon corrections to the wet-weight concentration of ${ }^{226} \mathrm{Ra}$ are made by using Equation F.2. 
- The relative uncertainty associated with the moisture correction is 0.03 , as is discussed in Appendix G. 


\section{APPENDIX B:}

\section{UNCERTAINTIES IN CALIBRATION SOURCES AND PAD}

Uncertainty exists in the concentrations of radionuclides in the calibration sources used with the calibration pad. Uncertainty also exists as a result of the finite number of sources used in the pad and errors in their positioning. The uncertainties associated with the pad and sources are not evaluated explicitly in this report. However, a conservative estimate of the uncertainties associated with the calibration pad and sources can be obtained by evaluating available highpurity germanium (HPGe) detector measurements made on the pad.

For HPGe measurements on the pad, uncertainty results from counting errors and calibration errors. The uncertainty in calibration is due primarily to uncertainty in the sources used to calibrate the detector. The relative uncertainty associated with calibration is assumed to be about 5\%. The counting error for HPGe measurements is assumed to be as large as that observed at the pad for measurements of much lower concentrations. That relative counting error (one standard deviation) is $7.0 \%$ for ${ }^{238} \mathrm{U}, 3.1 \%$ for ${ }^{226} \mathrm{Ra}$, and $4.6 \%$ for ${ }^{232} \mathrm{Th}$. (These are the average uncertainties for 91 measurements made at the pad from October 2000 through August 2002. The average measured dry-weight concentrations were $15.3,1.7$, and $1.2 \mathrm{pCi} / \mathrm{g}$ for ${ }^{238} \mathrm{U}$,

${ }^{226} \mathrm{Ra}$, and ${ }^{232} \mathrm{Th}$, respectively. The 91 measurements were Field Quality Control Station measurements made as part of an effort to determine the effects of environmental influences on in situ measurements. All measurements were made with the same number of sources in the past. After more than 2 years of nearly daily measurements, site regulators gave permission to end the study.) The total (conservative) uncertainty (calibration plus counting) for an HPGe measurement is therefore about $8.6 \%$ (i.e., $\left[5^{2}+7^{2}\right]^{0.5}=8.6$ ) for ${ }^{238} \mathrm{U}, 5.9 \%$ for ${ }^{226} \mathrm{Ra}$, and $6.8 \%$ for ${ }^{232} \mathrm{Th}$.

HPGe measurements made on the pad with all sources used were compared with theoretical values for effective pad concentrations in DOE (2001), Table 4-2. (The theoretical values for effective pad concentration are used in the efficiency calibration of the NaI detectors.) For ${ }^{238} \mathrm{U}$, the theoretical value is $326 \mathrm{pCi} / \mathrm{g}$; the $\mathrm{HPGe}$ value is $331 \mathrm{pCi} / \mathrm{g}$. For ${ }^{226} \mathrm{Ra}$, the theoretical value is $20.37 \mathrm{pCi} / \mathrm{g}$; the HPGe value is $19.10 \mathrm{pCi} / \mathrm{g}$. For ${ }^{232} \mathrm{Th}$, the theoretical value is $9.05 \mathrm{pCi} / \mathrm{g}$; the $\mathrm{HPGe}$ value is $8.78 \mathrm{pCi} / \mathrm{g}$. The largest relative difference between the HPGe and theoretical values for the pad is for ${ }^{226} \mathrm{Ra}$, for which the difference is about $6.6 \%$ relative to the HPGe measurement $[(20.37-19.10) / 19.10=0.066]$. For ${ }^{238} \mathrm{U}$, the relative difference is about $1.5 \%$, and for ${ }^{232} \mathrm{Th}$, it is about $3.1 \%$. The theoretical values are within about $0.3,1.3$, and 0.6 standard deviations of the HPGe measurements for ${ }^{238} \mathrm{U},{ }^{226} \mathrm{Ra}$, and ${ }^{232} \mathrm{Th}$, respectively, when it is assumed that the uncertainty in the HPGe measurements at the concentrations of interest is only $5 \%$ (due entirely to HPGe calibration errors). For example, for ${ }^{238} \mathrm{U}$, when the standard deviation in the HPGe measurement is assumed to be $5 \%$, the standard deviation is $0.05 \times 331=16.6 \mathrm{pCi} / \mathrm{g}$. The theoretical value is $326 \mathrm{pC} / \mathrm{g}$, so the difference between the theoretical value and measured value is $5 \mathrm{pCi} / \mathrm{g}$, or $5 / 16.6=0.3$ standard deviation of the HPGe measurement. Because the differences observed between the measured and theoretical values are not inconsistent with the differences that are considered to be reasonably likely as a result of 
uncertainties in the HPGe measurements, there is no significant difference between the HPGe measurements and the theoretical values.

Given the consistency between theoretical values and HPGe measurements, the uncertainty in the pad concentration should be no more than that for an HPGe measurement, for which a conservative estimate is less than $10 \%$, as determined above. Therefore, $10 \%$ appears to be a conservative estimate for the relative uncertainty for the pad and sources. The relative uncertainty associated with the pad and sources for the analyses done in this report is $10 \%$.

\section{APPENDIX B REFERENCE}

DOE (U.S. Department of Energy), 2001, Calibration of NaI In Situ Gamma Spectroscopy Systems, Fernald Area Office, Final, March. 


\section{APPENDIX C:}

\section{UNCERTAINTY IN THE SOIL PROFILE OF RADIONUCLIDES}

The estimated soil concentrations of radionuclides determined by the NaI systems are based on the assumption that the vertical distribution of the radionuclides is constant with depth. Variations from such a distribution introduce uncertainty into the measurements. Uncertainty associated with the vertical distribution of radionuclides in the soil also affects measurements made with a high-purity geranium (HPGe) detector. The uncertainty in HPGe measurements resulting from a nonuniform distribution of radionuclides with depth is quantified here, and a similar uncertainty is assumed to apply to measurements made with the NaI systems.

In an effort to obtain a conservative estimate of the magnitude of the uncertainty, measurements made by using HPGe instruments were compared with those made using conventional sampling and analysis. DOE (1999) provides results for a number of locations at Fernald for which total uranium and ${ }^{232} \mathrm{Th}$ were measured by using HPGe instruments and various laboratory methods. Data are provided in Appendix D and summarized in Tables 5-1A and 6-1 of DOE (1999) for HPGe results obtained at a detector height of $31 \mathrm{~cm}$. The laboratory results are those that an HPGe instrument should obtain if the concentration of the radionuclides does not vary with depth (i.e., in this case, the HPGe measurements should provide the average concentration, as do the laboratory measurements). DOE (1999) also provides results comparing HPGe and laboratory measurements for ${ }^{226} \mathrm{Ra}$. However, those results are not used here because the additional uncertainty associated with radon loss from soil that affects the in situ measurement of ${ }^{226} \mathrm{Ra}$ results in a higher value for the uncertainty associated with the vertical distribution of radionuclides in soil obtained by using the approach applied in this appendix.

For each location for which a comparison was made, laboratory measurements were obtained by using $10-\mathrm{cm}$ soil samples taken in a pattern that covered the field of view of the HPGe instrument. Averages for each location were obtained by weighting the results of the individual laboratory measurements to match the varying responses of the HPGe detector over its field of view. Four laboratory methods were used to measure uranium, and two methods were used to measure ${ }^{232} \mathrm{Th}$. For comparison with the HPGe results, the results from the various laboratory methods were averaged, reducing the uncertainty associated with any individual laboratory method.

Sources of uncertainty that affect the laboratory or HPGe measurements include factors related to physical sampling, counting errors, the horizontal heterogeneity of the radionuclides in the soil, and the calibration of the HPGe detectors. The areas where the measurements were made were chosen because they were believed to be horizontally homogeneous; thus, effects due to horizontal heterogeneity would be minimized. In addition, the use of weighted laboratory results was intended to match the varying response of an HPGe detector across its field of view. Therefore, the results from the weighted laboratory analysis and those from the HPGe measurements should not differ substantially because of any horizontal heterogeneity that may be present in the soil. 
The ratios of HPGe results to the average weighted laboratory results were determined for 12 locations for uranium and 10 locations for ${ }^{232} \mathrm{Th}$. The average and standard deviations for the ratios are 1.04 and 0.13 for uranium and 1.04 and 0.12 for ${ }^{232} \mathrm{Th}$. When it is assumed that all the variability is due to variability in the vertical distribution of the radionuclides, a conservative estimate of the relative uncertainty in HPGe measurements for the Fernald Closure Project that is due to that effect is $13 \%$. This value is also used as an estimate of the uncertainty in

measurements made with $\mathrm{NaI}$ detectors that is due to vertical variations in the distribution of radionuclides in soil.

\section{APPENDIX C REFERENCE}

DOE (U.S. Department of Energy), 1999, Comparability of In-Situ Gamma Spectrometry and Laboratory Data, Fernald Area Office, Jan. 


\section{APPENDIX D:}

\section{UNCERTAINTIES ASSOCIATED WITH CALIBRATION}

The excavation monitoring system (EMS) has been calibrated a number of times by using the calibration pad. An evaluation of the results of this series of calibrations allows an estimate to be made of the uncertainty associated with the calibration process. Table D.1 summarizes the results of the series of calibrations. Results (calibration coefficients) are shown for a total of six calibrations made during March and April 2002 and April 2003. The covariances for these calibration coefficients are given in Table D.2. Note that the diagonal elements are variances. Covariances are given only for coefficients that are used together in a calibration equation [e.g., no value is given for $\mathrm{u}\left(F_{1}, F_{5}\right)$ because the calibration coefficients $F_{1}$ and $F_{5}$ are not used together in any calibration equation].

The covariances given in Table D.2 account empirically for the variability of the coefficients and their correlations. They result from uncertainties related to an individual calibration due to counting errors, uncertainties resulting from the fact that the physical setup used for an individual calibration cannot be reproduced exactly, variations in environmental conditions between calibrations, and changes in the instruments between calibrations.

The covariances in Table D.2 are used to estimate the quantities $u\left(F_{\mathrm{i}}, F_{\mathrm{j}}\right)$ in Equation 3.4. They are assumed to apply to all the NaI systems.

TABLE D.1 Results of EMS Calibrations (detector number 518)a

\begin{tabular}{lrrrrrr}
\hline & \multicolumn{7}{c}{ Date of Calibration } \\
\cline { 2 - 7 } & \multicolumn{7}{c}{ 21 March } & \multicolumn{7}{c}{ 16 April } & 22 April & 24 April & 29 April & 21 April \\
Coefficient & 2002 & 2002 & 2002 & 2002 & 2002 & \multicolumn{1}{c}{2003} \\
\hline & & & & & & \\
$F_{1}$ & 3.7371 & 3.8825 & 3.9196 & 3.4606 & 3.4471 & 3.2138 \\
$F_{2}$ & -0.1075 & -0.0766 & -0.1439 & -0.1161 & -0.0861 & -0.0947 \\
$F_{3}$ & -2.5958 & -2.9233 & -2.8283 & -2.2913 & -2.5310 & -2.4817 \\
$F_{4}$ & -0.0086 & -0.0088 & -0.0078 & -0.0079 & -0.0076 & -0.0068 \\
$F_{5}$ & 0.1198 & 0.1313 & 0.1316 & 0.1248 & 0.1291 & 0.1104 \\
$F_{6}$ & 0.0011 & 0.0017 & 0.0011 & 0.0019 & 0.0007 & 0.0003 \\
$F_{7}$ & -0.0002 & -0.0012 & -0.0004 & -0.0004 & -0.0004 & -0.0003 \\
$F_{8}$ & 0.0005 & 0.0002 & 0.0004 & 0.0002 & -0.0001 & 0.0008 \\
$F_{9}$ & 0.0739 & 0.0740 & 0.0756 & 0.0759 & 0.0760 & 0.0633 \\
\hline
\end{tabular}

a Units are in $\mathrm{pCi} / \mathrm{g}$ per net count per second. 
TABLE D.2 Covariances for Calibration Coefficients ${ }^{a}$

\begin{tabular}{|c|c|c|c|c|c|c|c|c|c|}
\hline & $F_{1}$ & $F_{2}$ & $F_{3}$ & $F_{4}$ & $F_{5}$ & $F_{6}$ & $F_{7}$ & $F_{8}$ & $F_{9}$ \\
\hline$F_{1}$ & 0.0784 & -0.0020 & -0.0525 & & & & & & \\
\hline$F_{2}$ & -0.0020 & 0.0006 & -0.0002 & & & & & & \\
\hline$F_{3}$ & -0.0525 & -0.0002 & 0.0541 & & & & & & \\
\hline$F_{4}$ & & & & $5.22 \mathrm{E}-07$ & $-3.25 \mathrm{E}-06$ & $-3.07 \mathrm{E}-07$ & & & \\
\hline$F_{5}$ & & & & $-3.25 \mathrm{E}-06$ & $6.78 \mathrm{E}-05$ & $2.75 \mathrm{E}-06$ & & & \\
\hline$F_{6}$ & & & & $-3.07 \mathrm{E}-07$ & $2.75 \mathrm{E}-06$ & $3.59 \mathrm{E}-07$ & & & \\
\hline$F_{7}$ & & & & & & & $1.30 \mathrm{E}-07$ & $3.73 \mathrm{E}-08$ & $-3.06 \mathrm{E}-07$ \\
\hline$F_{8}$ & & & & & & & $3.73 \mathrm{E}-08$ & $9.47 \mathrm{E}-08$ & $-1.20 \mathrm{E}-06$ \\
\hline$F_{9}$ & & & & & & & $-3.06 \mathrm{E}-07$ & $-1.20 \mathrm{E}-06$ & $2.40 \mathrm{E}-05$ \\
\hline
\end{tabular}

a Units are in $\mathrm{pCi}^{2} \mathrm{~s}^{2} / \mathrm{g}^{2}$ count $\mathrm{t}^{2}$. 


\section{APPENDIX E:}

\section{UNCERTAINTIES IN NET COUNT RATES}

\section{E.1 DETERMINATION OF UNCERTAINTY}

The net count rate $\left(r_{N}\right)$ for a particular radionuclide is given by the following equation:

$$
r_{N}=(G-C) / T
$$

where $G$ is the number of gross counts, $C$ is the number of background (continuum) counts, and $T$ is the counting period. The variance of $r_{N}$ is given by

$$
\begin{aligned}
u^{2}\left(r_{N}\right)= & u^{2}(G) / T^{2}+u^{2}(\mathrm{C}) / T^{2}+\left[(G-C) / T^{2}\right]^{2} u^{2}(T)-\left(2 / T^{2}\right) u(G, C) \\
& -\left[2(G-C) / T^{3}\right] u(T, G)+\left[2(G-C) / T^{3}\right] u(T, C) .
\end{aligned}
$$

Table E.1 provides results obtained for one of the radiation scanning systems (RSS-1) showing estimated values of the various terms in Equation E.2 for 4- and 8-second measurements for uranium, radium, and thorium for cases in which either no sources or all sources were used. In the table, T1 corresponds to the first term (i.e., $u^{2}(G) / T^{2}$ ) on the right-hand side of the equation, T2 to the second term, and so on. Also, in the table, $u^{2}\left(r_{N}\right)$ provides the estimated value for the variance in $r_{\mathrm{N}}$; the values of $u^{2}\left(r_{N}\right)$ were obtained by summing the variance components in each row. The table shows that the contribution of the terms involving the variance of $T$ and the covariance of $T$ and $G$ or $T$ and $C$ are negligible (T3, T5, and T6). Because of correlation between the gross and background counts, their covariance is significant for uranium and radium. However, the term involving the covariance (T4) approximately offsets the contribution due to the variance in the background counts (T2). Therefore, the variance in the net count rate can be approximated (in a generally conservative manner) by the first term on the right-hand side of Equation E.2 [compare T1 and $u^{2}\left(r_{N}\right)$ in Table E.1]. Results for RSS-2 and RSS-3 are similar to those shown for RSS-1.

Comparing the results in Table E.1 for 4- and 8-second measurements indicates that T1 $\left[u^{2}(G) / T^{2}\right]$ decreases by approximately a factor of two when the measurement period increases from 4 to 8 seconds. This is expected because going from 4- to 8-second measurements increases $G$ by a factor of two and $T^{2}$ by a factor of 4 . [If gross counts have a Poisson distribution, then $u^{2}(G) / T^{2} \cong \operatorname{mean}(G) / T^{2}$. Increasing the mean by a factor of two and $T^{2}$ by a factor of four reduces the ratio by a factor of two.] However, comparing the results for $\mathrm{T} 2\left[u^{2}(\mathrm{C}) / T^{2}\right]$ shows that there is considerably less change as the measurement time increases from 4 to 8 seconds. The sanding method used to determine background counts relies on averaging 174 -second spectra. The 8-second measurements are aggregations of two 4-second measurements. However, the two 4-second background counts that are aggregated are essentially the same, because 16 of the 17 measurements that are averaged are the same in both cases. Because the two 4-second measurements of background counts are approximately the same, aggregating them doubles the number of counts but also approximately doubles the range in the aggregated counts. The range 
TABLE E.1 Contributions to the Variance in the Net Count Rate

\begin{tabular}{|c|c|c|c|c|c|c|c|c|}
\hline Radionuclide & $\begin{array}{c}\text { Number of } \\
\text { Sources }\end{array}$ & $\mathrm{T} 1^{\mathrm{b}}$ & $\mathrm{T} 2$ & $\mathrm{~T} 3$ & $-\mathrm{T} 4$ & $-\mathrm{T} 5$ & T6 & $u^{2}\left(r_{N}\right)^{\mathrm{c}}$ \\
\hline \multicolumn{9}{|c|}{ 4-Second Measurement ${ }^{d}$} \\
\hline \multirow[t]{2}{*}{${ }^{238} \mathrm{U}$} & 0 & 8.97 & 1.06 & 0 & -2.25 & 0 & 0 & 7.78 \\
\hline & 45 & 52.00 & 6.08 & 0.004 & -13.22 & -0.03 & -0.005 & 44.84 \\
\hline \multirow[t]{2}{*}{${ }^{226} \mathrm{Ra}$} & 0 & 3.77 & 0.18 & 0 & -0.15 & 0 & 0 & 3.80 \\
\hline & 45 & 91.51 & 17.83 & 0.13 & -27.41 & 1.18 & 0.15 & 83.42 \\
\hline \multirow[t]{2}{*}{${ }^{232} \mathrm{Th}$} & 0 & 2.61 & 0.04 & 0 & -0.10 & 0 & 0 & 2.54 \\
\hline & 45 & 52.54 & 0.45 & 0 & -0.48 & 0 & 0 & 52.51 \\
\hline \multicolumn{9}{|c|}{ 8-Second Measurement ${ }^{\mathrm{e}}$} \\
\hline \multirow[t]{2}{*}{${ }^{238} \mathrm{U}$} & 0 & 4.71 & 0.88 & 0 & -1.73 & 0 & 0 & 3.86 \\
\hline & 45 & 29.44 & 4.51 & 0 & -10.05 & 0.03 & 0 & 23.92 \\
\hline \multirow[t]{2}{*}{${ }^{226} \mathrm{Ra}$} & 0 & 1.92 & 0.17 & 0 & -0.09 & 0 & 0 & 2.00 \\
\hline & 45 & 47.44 & 16.17 & 0 & -25.30 & 0.51 & 0.08 & 39.00 \\
\hline \multirow[t]{2}{*}{${ }^{232} \mathrm{Th}$} & 0 & 1.21 & 0.03 & 0 & -0.10 & 0 & 0 & 1.14 \\
\hline & 45 & 27.78 & 0.41 & 0 & -0.43 & 0 & 0 & 27.77 \\
\hline
\end{tabular}

a Measurements were made on the calibration pad by using RSS-1. The background measurements (no sources) are from Run 0834. The measurements with 45 uranium, radium, or thorium sources are from Runs 0837, 0843, and 0825, respectively. All runs were made in June 2003.

b T1 refers to the first term on the right-hand side of Equation E.2, T2 to the second term, and so on. Units are in counts ${ }^{2} / \mathrm{s}^{2}$.

c The values for $u^{2}\left(r_{N}\right)$ are obtained by summing the variance components in the same row.

d Variances are based on about 300 measurements of nominal 4-second length.

e Variances are based on about 140 to 150 measurements of nominal 8-second lengths obtained by aggregating the 4-second measurements.

approximately doubles because the high correlation between adjacent background counts results in little opportunity for elevated counts in one 4-second interval to offset decreased counts in an adjacent interval, as would occur if the counts were independent. Therefore, the range approximately doubles, resulting in an increase in the variance of about four times, which approximately offsets the factor of four increase in $T^{2}$.

Increasing the degree of aggregation (to 12, 16 seconds, etc.) will result in sizable decreases in $u^{2}(G) / T^{2}$. However, for the reason discussed above, $u^{2}(C) / T^{2}$ will not decrease correspondingly (at least when considerably fewer than 17 aggregations are used). Therefore, in such cases, $u^{2}(G) / T^{2}$ may no longer be a good approximation for $u^{2}\left(r_{N}\right)$. Given the importance of the covariance term (T4), however, additional evaluation should be carried out for any specific measurement period greater than 8 seconds that may be of interest. 
Considering the above, the variance in the net count rate for 4- and 8-second measurements can be approximated simply as

$$
u^{2}\left(r_{N}\right) \cong u^{2}(G) / T^{2} .
$$

(Again, if estimates are needed for longer measurement times, additional evaluation should be done.) When it is assumed that the gross counts have a Poisson distribution (for which the variance equals the mean),

$$
u^{2}\left(r_{N}\right) \cong \mu_{G} / T^{2}
$$

where $\mu_{G}$ is the mean value for gross counts for a particular measurement time.

As Table I.1 shows, the sample mean and variance for $G$ are approximately the same for 4-second measurements, so the assumption is acceptable. (Given that there appears to be a non-Poisson component of variance in $G$, use of the assumption means that the variance in the net count rate will be underestimated somewhat. However, even if the variance exceeds the mean by $25 \%$, as occurs for some cases in Table I.1, the uncertainty (i.e., the standard deviation) in the net count rate is underestimated by only about $10 \%$.)

To estimate the variance in $r_{N}$ for a particular situation, an estimate of $\mu_{G}$ is needed. For measurements made in the field, this quantity is provided directly by the measurement process (i.e., the number of gross counts). However, when defined cases are being examined, such as is done in Chapter 4 of this report, it is necessary to estimate $\mu_{G}$ on the basis of the soil concentrations of the radionuclides used to define the case. To illustrate how this can be done, an example is provided in Appendix L (see Section L.3) of how $u^{2}\left(r_{N}\right)$ can be determined for a case involving the excavation monitoring system. However, in order to carry out the calculations presented in the example, additional information on the relationship among $G, C$, and net counts is needed.

\section{E.2 RELATIONSHIP BETWEEN BACKGROUND AND NET COUNTS}

Figure E.1 shows relationships between background counts and net counts for the NaI systems developed by using data collected with RSS-1, RSS-2, and RSS-3. (The data plotted in Figure E.1 are given in Table E.2.) The two quantities have a linear relationship for cases in which the reason for the change in net counts is that the concentration of the radionuclide of interest changes. For example, in Figure E.1, the four groups of points on the line for ${ }^{232} \mathrm{Th}$ correspond to measurements made by using progressively larger numbers of ${ }^{232} \mathrm{Th}$ sources in the calibration pad. (The three points in each of the four groups of points for each regression line correspond to individual results for the three systems used to obtain the data.) If measurements are made repeatedly for a particular soil concentration of ${ }^{232} \mathrm{Th}$ (for example), then no correlation would be expected between net and background counts. In addition, if the net counts are the result of interferences in the region of interest due to other radionuclides, then the relationships shown in Figure E.1 would not apply. 


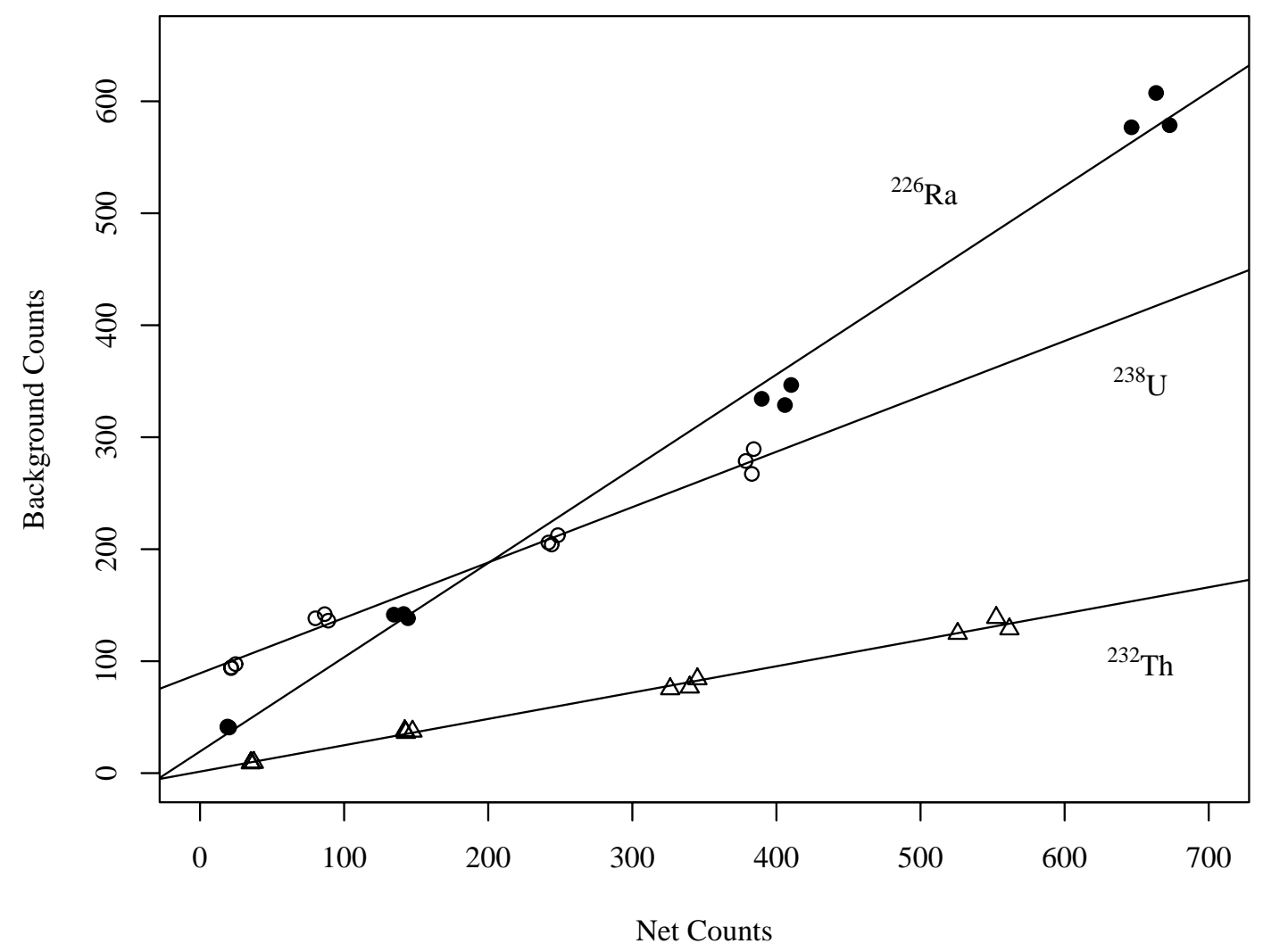

FIGURE E.1 Relationships between Background Counts and Net Counts for the NaI Systems (Results are shown for RSS-1, RSS-2, and RSS-3. The data plotted are given in Table E.2, and the counts are for a 4-second period.)

The regression lines presented in Figure E.1 are based on pooled measurements for RSS-1, RSS-2, and RSS-3. The results for the individual systems are similar. For low net count rates, the results are so similar that the three individual measurements cannot always be distinguished on the plot. On the basis of the data plotted in Figure E.1, the regression relationships between background $(B C)$ and net counts $(N C)$ for the $\mathrm{NaI}$ systems are the following (standard errors are given along with the estimated coefficients):

$$
\begin{gathered}
\text { 238 } \mathrm{U}: B C=(0.495 \pm 0.015) N C+(89.2 \pm 3.6), \text { adjusted } \mathrm{R}^{2}=0.990 \\
\text { 226Ra: } B C=(0.842 \pm 0.020) N C+(19.3 \pm 7.7), \text { adjusted } \mathrm{R}^{2}=0.994 \\
\text { 232Th: } B C=(0.235 \pm 0.005) N C+(1.4 \pm 1.7), \text { adjusted } \mathrm{R}^{2}=0.995
\end{gathered}
$$

\section{E.3 COMPONENTS OF UNCERTAINTY IN COUNTING}

From Equation A.5c, the variance in wet-weight concentrations associated with counting is given by

$$
u_{\text {count }}^{2}=F_{1}^{2} u^{2}\left(r_{N U}\right)+F_{2}^{2} u^{2}\left(r_{N R a}\right)+F_{3}^{2} u^{2}\left(r_{N T h}\right)
$$


TABLE E.2 Data for Background Counts and Net Counts for Three NaI Systems ${ }^{\mathbf{a}}$

\begin{tabular}{rrrrrrrr}
\hline System & $\begin{array}{c}\text { Number of } \\
\text { Sources }\end{array}$ & \multicolumn{1}{c}{$N_{U}$} & \multicolumn{1}{c}{$C_{U}$} & \multicolumn{1}{c}{$N_{R a}$} & \multicolumn{1}{c}{$C_{R a}$} & \multicolumn{1}{c}{$N_{T h}$} & \multicolumn{1}{c}{$C_{T h}$} \\
\hline RSS-1 & 0 & 21.55 & 94.49 & 20.22 & 40.73 & 35.42 & 9.34 \\
& 16 & 89.02 & 136.12 & 144.27 & 138.32 & 147.45 & 37.32 \\
& 25 & 244.06 & 204.12 & 405.94 & 328.70 & 339.82 & 76.69 \\
& 45 & 382.94 & 267.21 & 672.86 & 578.58 & 561.67 & 128.70 \\
& & & & & & & \\
RSS-2 & 0 & 21.54 & 93.78 & 19.10 & 41.59 & 35.28 & 9.00 \\
& 16 & 80.05 & 138.22 & 134.48 & 141.55 & 142.07 & 37.78 \\
& 25 & 248.35 & 212.53 & 410.21 & 346.66 & 345.16 & 84.09 \\
& 45 & 378.63 & 278.76 & 663.48 & 607.42 & 552.52 & 138.84 \\
RSS-3 & 0 & 24.69 & 97.35 & 19.03 & 41.17 & 37.33 & 9.45 \\
& 16 & 86.51 & 142.02 & 141.32 & 142.13 & 142.89 & 36.20 \\
& 25 & 241.80 & 205.94 & 389.79 & 334.28 & 326.27 & 75.18 \\
& 45 & 384.25 & 289.35 & 646.40 & 576.79 & 525.80 & 124.67 \\
\hline
\end{tabular}

a Results were obtained on the calibration pad. Approximately 300 consecutive 4-second measurements were made for each configuration (i.e., for each combination of system, radionuclide, and number of sources). Measurements were nominally four seconds each, although live time was slightly less. The average counts were adjusted to provide net and background counts for a 4-second period. $N_{U}$ is the average net counts for the uranium ROI, etc. $C_{U}$ is the average background counts for the uranium ROI, etc. Measurements for RSS-1 are from Runs 0823-0825, 0834-0837, and 0840-0843; for RSS-2, they are from Runs 0520-0523, 0526-0529, and 0532-0535; and for RSS-3, they are from Runs 0146-0155. All runs were made in June 2003.

b The number of sources used in the calibration pad was varied to produce the results provided in this table and plotted in Figure E.1. The number of sources used was 0 (none), 16, 25, and 45, with 45 being the maximum number of sources that the pad is designed to accommodate. Measurements for uranium were done with uranium sources, measurements for radium were done with radium sources, and measurements for thorium were done with thorium sources. The different numbers of sources correspond to different soil concentration levels of the radionuclides, varying from background to elevated levels.

for uranium measurements. It is given by

$$
u_{\text {count }}^{2}=F_{4}^{2} u^{2}\left(r_{N U}\right)+F_{5}^{2} u^{2}\left(r_{N R a}\right)+F_{6}^{2} u^{2}\left(r_{N T h}\right)
$$

for ${ }^{226} \mathrm{Ra}$ measurements. Finally, it is given by

$$
u_{\text {count }}^{2}=F_{7}^{2} u^{2}\left(r_{N U}\right)+F_{8}^{2} u^{2}\left(r_{N R a}\right)+F_{9}^{2} u^{2}\left(r_{N T h}\right)
$$


for ${ }^{232} \mathrm{Th}$ measurements. Table E.3 gives the estimated values of the terms in these equations, along with the total variance $\left(u_{\text {count }}{ }^{2}\right)$, for measurements made with RSS-1 on the calibration pad and by using various numbers of sources. The number of sources used varies from zero (background conditions) to 45 , which is the maximum number that the pad can accommodate. The table also provides values for estimates of the variance in the counting that are based on the use of the approximation in Equation E.4. The table illustrates two major points:

1. With the exception of background conditions for uranium (no sources), $u_{\text {count }}{ }^{2}$ is approximately equal to the term involving the primary calibration coefficients (i.e., $F_{1}, F_{5}$, and $F_{9}$ ). Except for background conditions for uranium, secondary terms are negligible. Even for the exception, the contribution of the other terms is less than about $20 \%$ of the total.

2. The approximation developed by using the result given in Equation E.4 provides an acceptable estimate of the total variance.

Therefore, the variance associated with counting can be approximated by using only the primary term in Equations E.6 through E.8. Also, the relation shown in Equation E.4 provides an acceptable approximation for use in obtaining the total variance associated with counting. Example calculations for uncertainties in net count rate are provided in Appendix L. 
TABLE E.3 Components of Variances Associated with Counting ${ }^{a}$

\begin{tabular}{|c|c|c|c|c|}
\hline \multirow[b]{2}{*}{ Quantity ${ }^{\mathrm{b}}$} & \multicolumn{4}{|c|}{ Number of Sources in Pad } \\
\hline & 0 & 16 & 25 & 45 \\
\hline \multicolumn{5}{|l|}{${ }^{238} \mathbf{U}$} \\
\hline$F_{1}^{2} u^{2}\left(r_{N U}\right)$ & $8.01 \mathrm{E}+01$ & $1.70 \mathrm{E}+02$ & $3.06 \mathrm{E}+02$ & $4.61 \mathrm{E}+02$ \\
\hline$F_{2}^{2} u^{2}\left(r_{N R a}\right)$ & $7.76 \mathrm{E}-02$ & $9.43 \mathrm{E}-02$ & $1.41 \mathrm{E}-01$ & $1.84 \mathrm{E}-01$ \\
\hline$F_{3}^{2} u^{2}\left(r_{N T h}\right)$ & $1.52 \mathrm{E}+01$ & $1.62 \mathrm{E}+01$ & $1.85 \mathrm{E}+01$ & $1.67 \mathrm{E}+01$ \\
\hline$u_{\text {count }}{ }^{2}$ & $9.53 \mathrm{E}+01$ & $1.87 \mathrm{E}+02$ & $3.25 \mathrm{E}+02$ & $4.78 \mathrm{E}+02$ \\
\hline$F_{1}^{2} \mu_{\mathrm{GU}} / T^{2}$ & $7.58 \mathrm{E}+01$ & $1.48 \mathrm{E}+02$ & $2.97 \mathrm{E}+02$ & $4.33 \mathrm{E}+02$ \\
\hline \multicolumn{5}{|l|}{${ }^{226} \mathbf{R a}$} \\
\hline$F_{4}^{2} u^{2}\left(r_{N U}\right)$ & $4.00 \mathrm{E}-04$ & $8.30 \mathrm{E}-04$ & $2.04 \mathrm{E}-03$ & $2.71 \mathrm{E}-03$ \\
\hline$F_{5}^{2} u^{2}\left(r_{N R a}\right)$ & $5.77 \mathrm{E}-02$ & $3.09 \mathrm{E}-01$ & $7.29 \mathrm{E}-01$ & $1.19 \mathrm{E}+00$ \\
\hline$F_{6}^{2} u^{2}\left(r_{N T h}\right)$ & $1.01 \mathrm{E}-07$ & $1.45 \mathrm{E}-07$ & $2.22 \mathrm{E}-07$ & $2.70 \mathrm{E}-07$ \\
\hline$u_{\text {count }}{ }^{2}$ & $5.82 \mathrm{E}-02$ & $3.09 \mathrm{E}-01$ & $7.29 \mathrm{E}-01$ & $1.19 \mathrm{E}+00$ \\
\hline$F_{5}^{2} \mu_{G R a} / T^{2}$ & $5.53 \mathrm{E}-02$ & $2.59 \mathrm{E}-01$ & $6.91 \mathrm{E}-01$ & $1.20 \mathrm{E}+00$ \\
\hline \multicolumn{5}{|l|}{${ }^{232} \mathrm{Th}$} \\
\hline$F_{7}^{2} u^{2}\left(r_{N U}\right)$ & $7.00 \mathrm{E}-07$ & $1.76 \mathrm{E}-06$ & $6.59 \mathrm{E}-06$ & $2.12 \mathrm{E}-05$ \\
\hline$F_{8}^{2} u^{2}\left(r_{N R a}\right)$ & $1.52 \mathrm{E}-07$ & $3.23 \mathrm{E}-07$ & $4.89 \mathrm{E}-07$ & $9.66 \mathrm{E}-07$ \\
\hline$F_{9}^{2} u^{2}\left(r_{N T h}\right)$ & $1.24 \mathrm{E}-02$ & $6.56 \mathrm{E}-02$ & $1.33 \mathrm{E}-01$ & $2.56 \mathrm{E}-01$ \\
\hline$u_{\text {count }}^{2}$ & $1.24 \mathrm{E}-02$ & $6.56 \mathrm{E}-02$ & $1.33 \mathrm{E}-01$ & $2.56 \mathrm{E}-01$ \\
\hline$F_{9}^{2} \mu_{G T h} / T^{2}$ & $1.38 \mathrm{E}-02$ & $5.75 \mathrm{E}-02$ & $1.31 \mathrm{E}-01$ & $2.21 \mathrm{E}-01$ \\
\hline
\end{tabular}

a Units are in $\mathrm{pCi}^{2} / \mathrm{g}^{2}$. The results presented are for RSS-1 for the same measurements used to develop Table E.2.

b The first four entries for ${ }^{238} \mathrm{U},{ }^{226} \mathrm{Ra}$, and ${ }^{232} \mathrm{Th}$ are quantities in Equations E.6, E.7, and E.8, respectively. The last quantity in each group is an estimate of the total variance that is based on Equation E.4. The first three entries in each group may not sum to $u_{\text {count }}{ }^{2}$ because of independent rounding. 


\section{APPENDIX F:}

\section{UNCERTAINTIES DUE TO RADON CORRECTIONS}

\section{F.1 BACKGROUND}

The measurement of soil concentrations of ${ }^{226} \mathrm{Ra}$ by using in situ gamma spectrometry is complicated by two factors: (1) the technique relies on emissions from progeny of ${ }^{226} \mathrm{Ra}$ and (2) an intermediate decay product, ${ }^{222} \mathrm{Rn}$, is a highly mobile gas. As a consequence, in situ measurements of ${ }^{226} \mathrm{Ra}$ have the potential to significantly underestimate actual soil concentrations for cases in which ${ }^{222} \mathrm{Rn}$ escapes from the soil. Also, in some cases, in situ measurements can potentially overestimate the actual soil concentration of ${ }^{226} \mathrm{Ra}$ because of the accumulation of the progeny of ${ }^{222} \mathrm{Rn}$ in the atmosphere.

In situ gamma spectrometric determinations of the concentration of ${ }^{226} \mathrm{Ra}$ in soil made with $\mathrm{NaI}$ detectors at Fernald rely on gamma-ray emissions from ${ }^{214} \mathrm{Bi}(1764.49 \mathrm{keV})$. In situ measurements of ${ }^{226} \mathrm{Ra}$ made with high-purity germanium (HPGe) detectors at Fernald use emissions from ${ }^{214} \mathrm{~Pb}(351.9 \mathrm{keV})$ and ${ }^{214} \mathrm{Bi}(609.3$ and $1120.4 \mathrm{keV}) .{ }^{226} \mathrm{Ra}$ decays to produce

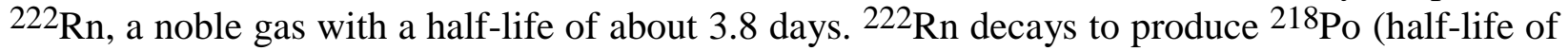
3.04 minutes), which decays to ${ }^{214} \mathrm{~Pb}$ (half-life of 26.8 minutes), which in turn decays to ${ }^{214} \mathrm{Bi}$ (half-life of 19.9 minutes). The in situ measurement of ${ }^{226} \mathrm{Ra}$ is influenced by the behavior of its progeny, which in general are not in secular equilibrium with ${ }^{226} \mathrm{Ra}$ in soil.

Decay of ${ }^{226} \mathrm{Ra}$ in soil particles produces ${ }^{222} \mathrm{Rn}$. Because of the recoil of the radon atom after the alpha decay of the radium atom, the radon atom may reach the pore fluids surrounding the soil particle. Measured values for the fraction of radon atoms that reach the pore space (the emanation coefficient, $\mathcal{E}$ ) for soils vary from less than 0.1 to about 0.7 (Nazaroff 1992), with typical values of about 0.15 to 0.25 for soils representative of the eastern United States (Greeman and Rose 1996). Measured values of emanation coefficients for uranium ores and tailings range from less than 0.1 to more than 0.9 (Nazaroff 1992).

The emanation coefficient depends on a variety of factors. These include the distribution

of ${ }^{226} \mathrm{Ra}$ within the soil particles, the internal structure of the particles, their size and shape, the presence of organic coatings enriched in ${ }^{226} \mathrm{Ra}$ on the soil particles, moisture content, and temperature (Nazaroff 1992; Morawska and Philips 1993; Greeman and Rose 1996; Schumann and Gundersen 1996).

Transport of radon from soil pores to the atmosphere appears to be due primarily to molecular diffusion, particularly on a long-term average basis for uncovered soil (Nazaroff 1992). Advection also can play a significant role in radon transport in soil (Chen et al. 1995). The soil moisture level is important in determining the movement of radon in soil because water can effectively block pore spaces. 
Soil concentrations of ${ }^{226} \mathrm{Ra}$ and ${ }^{222} \mathrm{Rn}$ for uncontaminated locations at Fernald are given in Table F.1, along with atmospheric concentrations of ${ }^{222} \mathrm{Rn}$. Estimated background concentrations of ${ }^{222} \mathrm{Rn}$ at depth in soil-pore air are several orders of magnitude larger than those expected on average in the atmosphere. Estimated background concentrations of ${ }^{222} \mathrm{Rn}$ in soilpore air are provided in the table for depths of 5,10 , and $15 \mathrm{~cm}$ for dry to moist soil. The background concentration of ${ }^{222} \mathrm{Rn}$ in soil-pore air increases with depth. Essentially all the radon (half life of about 3.8 days) in near-surface soil pores can reach the atmosphere by diffusion when soil is dry to moist. About $93 \%$ of the radon in the top $15 \mathrm{~cm}$ of soil will leave the soil for the case considered in the table. Nearer the surface, the actual depletion of the radon is higher. Therefore, in a practical sense, essentially all the radon that reaches soil pores in the portion of the soil that most influences in situ measurements made by using gamma spectrometry is lost to the atmosphere, unless the soil is wet. Consequently, for dry to moist soil and in the absence of effects due to progeny of ${ }^{222} \mathrm{Rn}$ in the air, measurements of $226 \mathrm{Ra}$ made with gamma-ray detectors located above the soil surface can be expected to be related to the fraction of the ${ }^{222} \mathrm{Rn}$ that does not leave the soil particles. The concentration of the ${ }^{222} \mathrm{Rn}$ that does not leave the soil particles is $(1-\varepsilon)$ times the soil concentration of ${ }^{226} \mathrm{Ra}$. If the soil concentrations of ${ }^{226} \mathrm{Ra}$ and $\varepsilon$ are constant, then the concentration of ${ }^{222} \mathrm{Rn}$ in soil particles does not vary with depth. The ${ }^{214} \mathrm{~Pb}$ and ${ }^{214} \mathrm{Bi}$ in the soil-pore air sorb to soil particles and will be in secular equilibrium with the ${ }^{222} \mathrm{Rn}$ in the soil.

In addition to the effects due to the loss of ${ }^{222} \mathrm{Rn}$ from the soil, in situ measurements of ${ }^{226} \mathrm{Ra}$ in soils are further complicated by the fact that radon gas leaving the soil can accumulate in the air above the soil. The presence of radon gas in the atmosphere results in gamma-ray emissions that affect the detectors being used to determine soil concentrations of ${ }^{226} \mathrm{Ra}$. Radon concentrations (activity per unit volume) in the atmosphere at Fernald are much smaller than radon concentrations in soil. (On the basis of the information provided in Table F.1, for the average background soil concentration of ${ }^{226} \mathrm{Ra}$, the typical concentration of ${ }^{222} \mathrm{Rn}$ in soil that is due to the ${ }^{222} \mathrm{Rn}$ contained in soil-pore air alone is expected to exceed $15 \mathrm{kBq} / \mathrm{m}^{3}$ $\left[0.5 \times 33 \mathrm{kBq} / \mathrm{m}^{3}\right]$ at several meters in depth. The average atmospheric concentration of ${ }^{222} \mathrm{Rn}$ at Fernald's fence line is about $30 \mathrm{~Bq} / \mathrm{m}^{3}$; the maximum is near $1 \mathrm{kBq} / \mathrm{m}^{3}$.) However, because of the much lower attenuation of gamma rays in air than in soil, the volume of air that has a significant effect on a detector is large compared to the volume of soil that has a significant influence. Gamma-ray emissions from radon progeny in the atmosphere can affect the detector more than gamma-ray emissions from the soil. Results obtained from using an HPGe detector at Fernald on September 15, 1999, are provided in Figure F.1. As shown in the figure, the "concentration" of $226 \mathrm{Ra}$ as determined with an in situ HPGe detector can vary by more than a factor of two over a period of several hours at a location with a low soil concentration of ${ }^{226} \mathrm{Ra}$. Such variability is due to temporal variations in the atmospheric concentrations of the progeny of ${ }^{222} \mathrm{Rn}$. On average, the diurnal variation in the atmospheric concentration of radon at Fernald for an altitude of $1 \mathrm{~m}$ can be a factor of two or more (Merrill and Akbar-Khanzadeh 1998). Depending on weather conditions and time of day, variations of two orders of magnitude in radon concentration can occur near a 1-m height for a continental climate in a location with strong nighttime temperature inversions (Porstendörfer 1994), which is consistent with the results summarized in Table F.1. The large changes in concentrations during a 24-hour period are due to changes in atmospheric mixing conditions. The influence on the diurnal changes in radon 
TABLE F.1 Concentrations of ${ }^{226}$ Ra and ${ }^{222}$ Rn at Fernald

\begin{tabular}{|c|c|c|}
\hline Quantity & Estimated Value & Comments \\
\hline \multirow[t]{2}{*}{$\begin{array}{l}\text { 95th percentile of background } \\
\text { soil concentration of }{ }^{226} \mathrm{Ra}\end{array}$} & $\begin{aligned} 0-1.5 \mathrm{ft}: & 1.42 \mathrm{pCi} / \mathrm{g} \\
& (52.5 \mathrm{~Bq} / \mathrm{kg})\end{aligned}$ & \multirow[t]{2}{*}{ Source: DOE (1995). } \\
\hline & $\begin{aligned}<1.5 \mathrm{ft}: & 1.47 \mathrm{pCi} / \mathrm{g} \\
& (54.4 \mathrm{~Bq} / \mathrm{kg})\end{aligned}$ & \\
\hline \multirow[t]{2}{*}{$\begin{array}{l}\text { Range in background soil } \\
\text { concentrations of }{ }^{226} \mathrm{Ra}\end{array}$} & $\begin{aligned} 0-1.5 \mathrm{ft}: & 0.85-1.48 \mathrm{pCi} / \mathrm{g} \\
& (32-55 \mathrm{~Bq} / \mathrm{kg})\end{aligned}$ & \multirow{2}{*}{$\begin{array}{l}\text { Source: DOE (1995). Mid-range value is } \\
\text { about } 1.1 \mathrm{pCi} / \mathrm{g} \text { (about } 40 \mathrm{~Bq} / \mathrm{kg} \text { ). This is } \\
\text { equivalent to about } 65 \mathrm{kBq} / \mathrm{m}^{3} \text { for a soil } \\
\text { with a density of } 1600 \mathrm{~kg} / \mathrm{m}^{3} \text {. }\end{array}$} \\
\hline & $\begin{array}{cc}<1.5 \mathrm{ft}: \begin{array}{c}0.59-1.61 \mathrm{pCi} / \mathrm{g} \\
(22-60 \mathrm{~Bq} / \mathrm{kg})\end{array}\end{array}$ & \\
\hline $\begin{array}{l}\text { Average atmospheric } \\
\text { concentration of }{ }^{226} \mathrm{Rn} \text { at site } \\
\text { perimeter (1-m altitude) }\end{array}$ & $\begin{array}{l}0.82 \mathrm{pCi} / \mathrm{L}\left(30.3 \mathrm{~Bq} / \mathrm{m}^{3}\right) \\
(\text { Standard deviation is } 0.60 \mathrm{pCi} / \mathrm{L} \\
\left.\left[22.3 \mathrm{~Bq} / \mathrm{m}^{3}\right]\right)\end{array}$ & $\begin{array}{l}\text { Source: Merrill and Akbar-Khanzadeh } \\
\text { (1998). Based on } 8,732 \text { hourly samples } \\
\text { taken from Feb. } 1993 \text { through Jan. } 1994 .\end{array}$ \\
\hline $\begin{array}{l}\text { Range in atmospheric } \\
\text { concentrations of }{ }^{222} \mathrm{Rn} \text { at site } \\
\text { perimeter ( } 1-\mathrm{m} \text { altitude) }\end{array}$ & $\begin{array}{l}0.05-21.0 \mathrm{pCi} / \mathrm{L} \\
\left(1.8-777.0 \mathrm{~Bq} / \mathrm{m}^{3}\right)\end{array}$ & $\begin{array}{l}\text { Source: Merrill and Akbar-Khanzadeh } \\
\text { (1998). For Feb. } 1993 \text { through Jan. } 1994 .\end{array}$ \\
\hline $\begin{array}{l}\text { Estimated typical background } \\
\text { concentration of }{ }^{222} \mathrm{Rn} \text { in soil- } \\
\text { pore air at depth }\left(I_{\infty}\right) \\
(\text { e.g., below } 10 \mathrm{~m})\end{array}$ & $\begin{array}{l}900 \mathrm{pCi} / \mathrm{L}\left(33 \mathrm{kBq} / \mathrm{m}^{3}\right) \\
\text { for } \varepsilon=0.2\end{array}$ & $\begin{array}{l}\text { Estimated by using diffusion model in } \\
\text { Nazaroff (1992) for silty to clayey soil } \\
\text { with total porosity of } 0.5 \text { and a soil } \\
\text { concentration of }{ }^{226} \mathrm{Ra} \text { in soil of } 1.1 \mathrm{pCi} / \mathrm{g} \text {. }\end{array}$ \\
\hline $\begin{array}{l}\text { Estimated typical background } \\
\text { concentration of }{ }^{222} \mathrm{Rn} \text { in soil- } \\
\text { pore air at a depth of } \\
\text { - } 5 \mathrm{~cm} \\
\text { - } 10 \mathrm{~cm} \\
\text { - } 15 \mathrm{~cm}\end{array}$ & $\begin{array}{l}0.044 I_{\infty} \\
0.087 I_{\infty} \\
0.13 I_{\infty}\end{array}$ & $\begin{array}{l}\text { Estimated by using the diffusion model in } \\
\text { Nazaroff (1992) and a diffusion length of } \\
1.1 \mathrm{~m} \text { (typical value for dry to moist soil). } \\
\text { Assumes that the radon concentration at } \\
\text { the soil surface is negligible when } \\
\text { compared to } I_{\infty} \text {. }\end{array}$ \\
\hline
\end{tabular}

concentration in the atmosphere due to changes in the rate at which radon leaves the soil is usually small. For different weather conditions, the day-to-day changes in radon concentrations in the afternoon (minimum concentrations) are much less than those at night.

In air near the ground (e.g., 1-m [ 3.3 ft] altitude), ${ }^{222} \mathrm{Rn}$ generally is not in secular equilibrium with ${ }^{214} \mathrm{~Pb}$ and ${ }^{214} \mathrm{Bi}$ (Porstendörfer 1994). The decay products of radon are isotopes of heavy metals and can easily and quickly (1 to 100 seconds) attach to aerosol particles present in the atmosphere, which are removed from the atmosphere by various physical processes (e.g., dry deposition, rainout). Equilibrium between ${ }^{222} \mathrm{Rn}$ and its progeny occurs at altitudes of $10 \mathrm{~m}[\sim 3.3 \mathrm{ft}]$ or more. The degree of disequilibrium and the height to which it extends depends on the degree of atmospheric turbulence present. For cases of low turbulence, the disequilibrium below 1-m altitude is large but decreases rapidly with height above the ground. For higher levels of turbulence, the degree of disequilibrium is smaller, but it extends to higher levels. Therefore, 


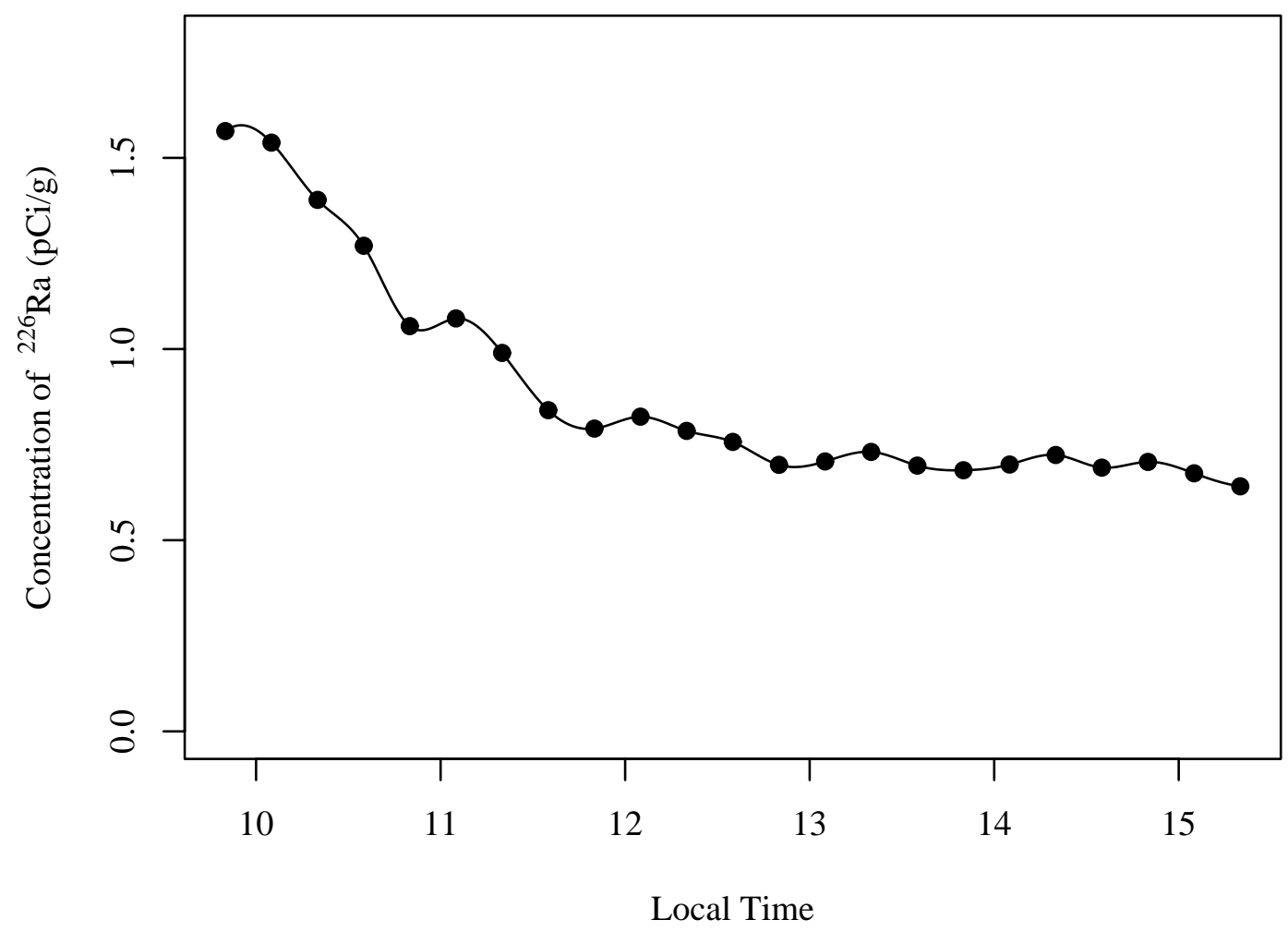

FIGURE F.1 Results Obtained at a Fixed Location on September 15, 1999 (Wet-weight concentrations are shown.)

for a situation in which a large diurnal variation in radon concentration occurs due to the presence of a strong nighttime inversion, a larger disequilibrium will occur near the ground at night than in the afternoon.

The behavior of radon makes measurement of the soil concentrations of ${ }^{226} \mathrm{Ra}$ a complex problem for in situ gamma spectrometry. The problem can be simplified by making measurements during periods when the atmospheric influence is at a minimum (i.e., in the afternoon). However, the fundamental problem remains unchanged: without additional information one does not know how a particular in situ measurement relates to an actual $226 \mathrm{Ra}$ concentration in the soil.

\section{F.2 RADON CORRECTION}

Measurements of ${ }^{226} \mathrm{Ra}$ made at Fernald by using the NaI systems are corrected to account for radon loss from the soil. The correction process used is discussed in Section 5.5.3 of DOE (2004). The process is empirical, and the actual uncertainty associated with the corrections has not been determined. Nevertheless, as is shown in Appendix A, even if the correction process has no uncertainties, it has the potential for significantly magnifying measurement uncertainties. Corrections for diurnal atmospheric changes are not generally done for $\mathrm{NaI}$ measurements made at Fernald. 
To adjust a wet-weight concentration for the effects of radon loss from the soil, the following empirical correction is used:

$$
C_{W c}=b_{1} C_{W}+b_{2} C_{W}{ }^{2}
$$

where $C_{W c}$ is the corrected wet-weight concentration and $b_{1}$ and $b_{2}$ are coefficients determined on the basis of a comparison of laboratory and field measurements. From DOE (2004), $b_{1}=0.551$ and $b_{2}=0.460$. Dry-weight concentration can be determined by using a moisture correction factor $(M)$ :

$$
C_{D}=M C_{W c}=M\left(b_{1} C_{W}+b_{2} C_{W}^{2}\right) .
$$

\section{F.3 SIGNIFICANCE OF UNCERTAINTIES}

Uncertainties in $b_{1}$ and $b_{2}$ have not been established, although they are expected to be sizable. However, the sensitivity of uncertainties in the estimated concentration of $226 \mathrm{Ra}$ to uncertainties in those coefficients can be determined by using a simple simulation. Results are provided in Table F.2 for the excavation monitoring system. If uncertainties (standard deviations) in both $b_{1}$ and $b_{2}$ are as large as $60 \%$, uncertainties for corrected wet-weight concentrations would increase by about $65 \%$ for a ${ }^{226} \mathrm{Ra}$ concentration of three times the final remediation level (FRL) and by about $45 \%$ for ${ }^{226} \mathrm{Ra}$ concentrations equal to the FRL, when compared with the case for which there are no uncertainties in $b_{1}$ and $b_{2}$. Uncertainties in $C_{W c}$ increase with increased concentrations because of the term involving $C_{W}^{2}$ in Equation F.2. Uncertainties in concentrations are sensitive to uncertainties in $b_{2}$ when concentrations are at or above three times the FRL. Uncertainties in concentration are less sensitive to uncertainties in $b_{1}$.

Uncertainties in ${ }^{226} \mathrm{Ra}$ concentrations resulting from atmospheric variations can be substantial. If measurements are made in the afternoon, uncertainties are reduced because atmospheric effects are minimized. If measurements are made in midmorning, wet-weight concentrations could be overestimated by a factor of two or more, as illustrated by the results in Figure F.1. Uncertainties associated with atmospheric effects are not considered quantitatively in this report. It is assumed that measurements are made in the afternoon and that little correction is necessary. However, for measurements made at times when atmospheric effects are significant, potentially significant uncertainties can be introduced in the results. Situations in which

measurements will tend to provide an overestimate of ${ }^{226} \mathrm{Ra}$ concentrations will yield conservative results. 


\section{TABLE F.2 Sensitivity of Uncertainties in ${ }^{226}$ Ra Concentrations Measured by Using the EMS to Uncertainties in $b_{1}$ and $b_{2}$}

\begin{tabular}{|c|c|c|c|c|c|c|}
\hline $\begin{array}{c}C_{W} \\
(\mathrm{pCi} / \mathrm{g})^{\mathrm{a}} \\
\end{array}$ & $\begin{array}{c}C_{D} \\
(\mathrm{pCi} / \mathrm{g})^{\mathrm{b}}\end{array}$ & $\begin{array}{l}\text { Relative } \\
\text { Uncertainty } \\
\text { in } C_{W}{ }^{c}\end{array}$ & $\begin{array}{l}\text { Assumed } \\
\text { Relative } \\
\text { Uncertainty } \\
\text { in } b_{1}{ }^{\mathrm{d}} \\
\end{array}$ & $\begin{array}{c}\text { Assumed } \\
\text { Relative } \\
\text { Uncertainty } \\
\text { in } b_{2}{ }^{\mathrm{e}}\end{array}$ & $\begin{array}{l}\text { Relative } \\
\text { Uncertainty } \\
\text { in } C_{W c}{ }^{\mathrm{f}} \\
\end{array}$ & $\begin{array}{l}\text { Relative } \\
\text { Increase in } \\
\text { Uncertainty } \\
\text { in } C_{W c}{ }^{\mathrm{g}}\end{array}$ \\
\hline 1.22 & 1.70 & 0.30 & 0.00 & 0.00 & 0.44 & 0.00 \\
\hline 1.22 & 1.70 & 0.30 & 0.30 & 0.00 & 0.46 & 0.05 \\
\hline 1.22 & 1.70 & 0.30 & 0.00 & 0.30 & 0.47 & 0.07 \\
\hline 1.22 & 1.70 & 0.30 & 0.30 & 0.30 & 0.49 & 0.11 \\
\hline 1.22 & 1.70 & 0.30 & 0.60 & 0.00 & 0.53 & 0.20 \\
\hline 1.22 & 1.70 & 0.30 & 0.00 & 0.60 & 0.57 & 0.30 \\
\hline 1.22 & 1.70 & 0.30 & 0.60 & 0.60 & 0.64 & 0.45 \\
\hline 2.43 & 5.10 & 0.23 & 0.00 & 0.00 & 0.37 & 0.00 \\
\hline 2.43 & 5.10 & 0.23 & 0.30 & 0.00 & 0.39 & 0.05 \\
\hline 2.43 & 5.10 & 0.23 & 0.00 & 0.30 & 0.44 & 0.19 \\
\hline 2.43 & 5.10 & 0.23 & 0.30 & 0.30 & 0.45 & 0.22 \\
\hline 2.43 & 5.10 & 0.23 & 0.60 & 0.00 & 0.42 & 0.14 \\
\hline 2.43 & 5.10 & 0.23 & 0.00 & 0.60 & 0.59 & 0.59 \\
\hline 2.43 & 5.10 & 0.23 & 0.60 & 0.60 & 0.61 & 0.65 \\
\hline
\end{tabular}

a Average uncorrected wet-weight concentration.

b Corresponding average dry-weight concentration, determined by using Equation F.3. $M=1.26$.

c Determined from Table A.1. Relative uncertainty in $C_{W}$ equals the square root of the sum of the relative variances in the ${ }^{226} \mathrm{Ra}$ concentration associated with uncertainty in the vertical distribution of the radionuclide, the pad, calibration, and counting.

d Average value of $b_{1}$ is 0.551 .

e Average value of $b_{2}$ is 0.460 .

f The relative standard deviation (RSD) in $C_{W c}$ was obtained from a simulation done by using Equation F.2, on the basis of the assumption that $C_{W}, b_{1}$, and $b_{2}$ are normally distributed with parameters given in this table. The number of trials was 100,000 .

$\mathrm{g}$ Increase relative to the case for which the RSDs of both $b_{1}$ and $b_{2}$ equal zero.

\section{F.4 APPPENDIX F REFERENCES}

Chen, C., D.M. Thomas, and R.E. Green, 1995, "Modeling of Radon Transport in Unsaturated Soil," J. Geophysical Research 100(B8):15,517-15,525, Aug. 10.

DOE (U.S. Department of Energy), 1995, Remedial Investigation Report for Operable Unit 5, Final, Fernald Area Office, March.

DOE, 2004, User Guidelines, Measurement Strategies, and Operational Factors for Deployment of In Situ Gamma Spectrometry at the Fernald Site, Fernald Area Office, Jan. 
Greeman, D.J., and A.W. Rose, 1996, "Factors Controlling the Emanation of Radon and Thoron in Soils of the Eastern U.S.A.," Chemical Geology 129:1-14.

Merrill, E.A., and F. Akbar-Khanzadeh, 1998, "Diurnal and Seasonal Variations of Radon Levels, Effects of Climatic Conditions, and Radon Exposure Assessment in a Former Uranium Metal Production Facility," Health Physics 74(5):568-573, May.

Morawska, L., and C.R. Phillips, 1993, "Dependence of the Radon Emanation Coefficient on Radium Distribution and Internal Structure of the Material," Geochimica et Cosmochimica Acta 57:1783-1797.

Nazaroff, W.M., 1992, "Radon Transport from Soil to Air," Reviews of Geophysics 30(2):137-160, May.

Porstendörfer, J., 1994, "Properties and Behaviour of Radon and Thoron and Their Decay Products in the Air," J. Aerosol Science 25(2):219-263.

Schumann, R.R., and L.C.S. Gundersen, 1996, "Geologic and Climatic Controls on the Radon Emanation Coefficient," Environment International 22, Suppl. 1:S439-S446. 


\section{APPENDIX G:}

\section{UNCERTAINTY IN MOISTURE CORRECTIONS}

\section{G.1 BACKGROUND}

The moisture correction factor $(M)$ used to convert wet-weight concentrations into dry-weight concentrations is defined as

$$
M=C_{D} / C_{W}
$$

where

$$
\begin{aligned}
& C_{D}= \begin{array}{l}
\text { quantity of radionuclide per unit volume of soil } / \text { mass of soil per unit } \\
\text { volume of soil, and }
\end{array} \\
& C_{W}=\begin{array}{l}
\text { quantity of radionuclide per unit volume of soil/(mass of soil }+ \text { water per } \\
\text { unit volume of soil). }
\end{array}
\end{aligned}
$$

Therefore,

$$
\begin{aligned}
M & =(\text { mass of soil }+ \text { mass of water }) / \text { mass of soil } \\
& =1+\text { mass of water/mass of soil. }
\end{aligned}
$$

Defining $m_{D}$ as mass of water/mass of soil, which is the moisture level on a dry-weight basis, yields

$$
M=1+m_{D}
$$

The variance in $M$ equals the variance in $m_{D}\left[u^{2}(M)=u^{2}\left(m_{D}\right)\right]$, so the relative variance of $M$ is

$$
u^{2}(M) / M^{2}=u^{2}\left(m_{D}\right) / M^{2}
$$

At Fernald, $m_{D}$ is measured with a handheld Zeltex KJE-100 near-infrared reflectance moisture meter. The instrument determines moisture content on the basis of the degree of absorption of near-infrared light at four wavelengths at which water has absorption bands (1.2, 1.45, 1.94, and $2.94 \mu \mathrm{m})$. The instrument irradiates the soil with infrared light at these wavelengths and with light at other near-infrared wavelengths (i.e., reference wavelengths), not in the absorption bands for water, and it measures the amount of reflected light at the various wavelengths. The results for the reference wavelengths are used to compensate for factors other than water that could affect the amount of reflected light (e.g., surface conditions, particle sizes, and sample color). The absorbance due to soil moisture is calculated by comparing the quantity of light reflected at absorption and reference wavelengths. The absorbance is related to the actual soil moisture by calibrating the instrument by using soil samples with known moisture contents. 
The instrument has been found to provide satisfactory measurements of soil moisture under the field conditions encountered at Fernald.

Soil moisture measurements at Fernald were previously made with a Troxler model 3440 moisture/density gauge, which provides independent measurements of soil density and moisture content (mass of water per unit volume of soil). When making measurements of moisture content, the instrument uses a neutron source and then detects neutrons that have been slowed by the hydrogen present in the soil - normally hydrogen in water. When making measurements of soil density to be used with measurements of moisture content, the instrument uses gamma radiation originating from a gamma source in the instrument. The instrument allowed $M$ to be determined satisfactorily, but it is no longer used because of the potential for interference with the in situ gamma spectrometers used to determine radionuclide concentrations in soil. In addition to the Troxler instrument, an instrument that uses the principle of time domain reflectometry to determine soil moisture was tested for application at the site. However, it was found that instrument does not work in a satisfactory manner with soils having the high clay content commonly found at Fernald.

\section{G.2 REASONABLE UPPER BOUND ON UNCERTAINTY IN MOISTURE CORRECTIONS}

The range in values of $m_{D}$ that are expected during field measurements is about 0.05 to 0.40 . The soil will never be completely dry, and, at Fernald, measurements are not made if $m_{D}$ is expected to be above 0.4. The average value of $m_{D}$ at Fernald is about 0.26 , a value that was based on many (generally daily) measurements made over the course of a year at a fixed field location. When no moisture measurements are available, the default value used for $m_{D}$ is 0.2 . The variance of a rectangular (uniform) continuous distribution having $a$ as its lower limit and $b$ as its upper limit is $(b-a)^{2} / 12$. Therefore when it is assumed that the moisture level is uniformly distributed over the range 0.050 to 0.40 , the variance in the moisture level is

$$
u^{2}\left(m_{D}\right)=(0.40-0.05)^{2 / 12}=0.010
$$

Therefore, when Equation G.4 is used, the relative variance of $M$ is

$$
u^{2}(M) / M^{2}=0.010 /(1+0.225)^{2}=0.0067,
$$

where the mean value of $m_{D}(0.225)$ for the assumed uniform distribution is used. The relative uncertainty (relative standard deviation) for $M$ is $\sqrt{0.0067}=0.08$, or $8 \%$, if a constant value for $m_{D}$ of 0.225 is used (i.e., if no moisture measurements are made, and if the mean value for the assumed uniform distribution of $m_{D}$ is used) and if values for $m_{D}$ are uniformly distributed from 0.05 to 0.4 . (Note that 0.225 is slightly different from the actual observed average of 0.26 . Use of 0.26 instead of 0.225 would also yield a relative uncertainty of 0.08 .) If the distribution for $m_{D}$ is more peaked near the mean, then the relative uncertainty will be less. Therefore, $8 \%$ is a reasonably conservative upper limit on the relative standard deviation for $M$. Field measurements of moisture will reduce this value. 


\section{G.3 SOURCES OF UNCERTAINTY IN MOISTURE MEASUREMENTS}

A variety of factors can result in uncertainty in the moisture corrections made by using the moisture measurements obtained with the Zeltex instrument. These factors include the following:

- Vertical variation in soil moisture levels,

- The use of nonrepresentative locations for moisture measurements,

- Differences between the type of soil that is present and the type of soil for which the calibration was developed,

- The temperature of the soil,

- Uncertainties associated with the calibration used to relate absorbance to $M_{D}$, and

- Variability in absorbance measurements (e.g., some variation can result from differences in distances between the instrument and the soil for different measurements).

Vertical variation in soil moisture is addressed by a requirement at Fernald to make two field measurements, one at the surface and one at a depth of about $5 \mathrm{~cm}$, and to average the results. That average should approximate the average soil moisture over the depth of interest for soil measurements.

No data have been collected on the horizontal variability in soil moisture. Significant differences could occur in an area if changes in topography were present. The use of nonrepresentative measurements as the basis for moisture corrections will adversely affect the determination of dry-weight concentrations.

Separate calibrations have been developed for six different soil types. If additional soil types are actually present or if the classification into six types does not capture all variability in site soils, additional uncertainty is introduced, as would be the case if an incorrect calibration was used.

It is assumed that (1) the field approach used adequately addresses the issue of vertical variations in soil moisture, (2) horizontal (as well as temporal) variations in soil moisture are adequately addressed, (3) the proper calibration is selected for the type of soil present, and (4) all

soil types have been considered. Soil temperature is not expected to significantly affect the results, and any related uncertainty associated with the measurement of soil moisture is neglected.

The analysis presented below specifically addresses uncertainties associated with calibration and the measurement-to-measurement variation in absorbance measurements. 
However, environmental influences have the potential to result in larger uncertainties than the uncertainties that result from these two factors, particularly if moisture measurements are not made correctly.

\section{G.4 UNCERTAINTY IN ZELTEX MEASUREMENTS}

Figure G.1 shows a calibration curve for the Zeltex instrument for one soil type. The regression relationship developed for the calibration can be expressed as

$$
m_{D}=a_{0}+a_{1} X
$$

where $a_{0}$ and $a_{1}$ are regression coefficients and $X$ is absorbance (no units) measured by the instrument. The variance in $m_{D}$ is then 1

$$
u^{2}\left(m_{D}\right)=u^{2}\left(a_{0}\right)+X^{2} u^{2}\left(a_{1}\right)+a_{1}^{2} u^{2}(X)+2 X u\left(a_{0}, a_{1}\right) .
$$

Using Equations G.4, G.3, and G.5 yields

$$
\begin{aligned}
u^{2}(M) / M^{2} & =u^{2}\left(m_{D}\right) / M^{2}=u^{2}\left(m_{D}\right) /\left(1+m_{D}\right)^{2} \\
& =u^{2}\left(m_{D}\right) /\left(1+a_{0}+a_{1} X\right)^{2}
\end{aligned}
$$

where $u^{2}\left(m_{D}\right)$ is given by Equation G.6.

The quantities used in Equations G.6 and G.7, other than $X$, are provided in Table G.1 for the calibration curve shown in Figure G.1. The value for $u(X)$ is estimated on the basis of repeated measurements of absorbance made with the instrument. The measurements used are shown in Table G.2. (The values of $m_{\mathrm{D}}$ and mean absorbances in that table were used to obtain the calibration curve in Figure G.1.) The value of $u^{2}(M) / M^{2}$ depends on $X$; a plot of the relative uncertainty in $M, u(M) / M$, as a function of $X$ is shown in Figure G.2. For the range of interest for $X$, the relative uncertainty in $M$ is less than or equal to about 0.01 , or $1 \%$. This uncertainty is due to uncertainty in the calibration and variability in absorbance measurements. The various environmental factors noted above will increase the overall uncertainty of the measurement.

The calibration curve shown in Figure G.1 represents a best-case calibration. The results provided in the previous paragraph give a lower bound on the uncertainty associated with moisture corrections. The most common soils found during remediation at Fernald are clays that are encountered during excavation. The Zeltex calibration curves developed for those soils are not linear, and the uncertainties associated with their use are considerably higher than those for

1 In developing the regression shown in Equation G.5, it is assumed that there is no uncertainty associated with $X$. However, uncertainty in $X$ is considered in Equation G.6. Any covariance between the regression coefficients and $X$ is ignored. 


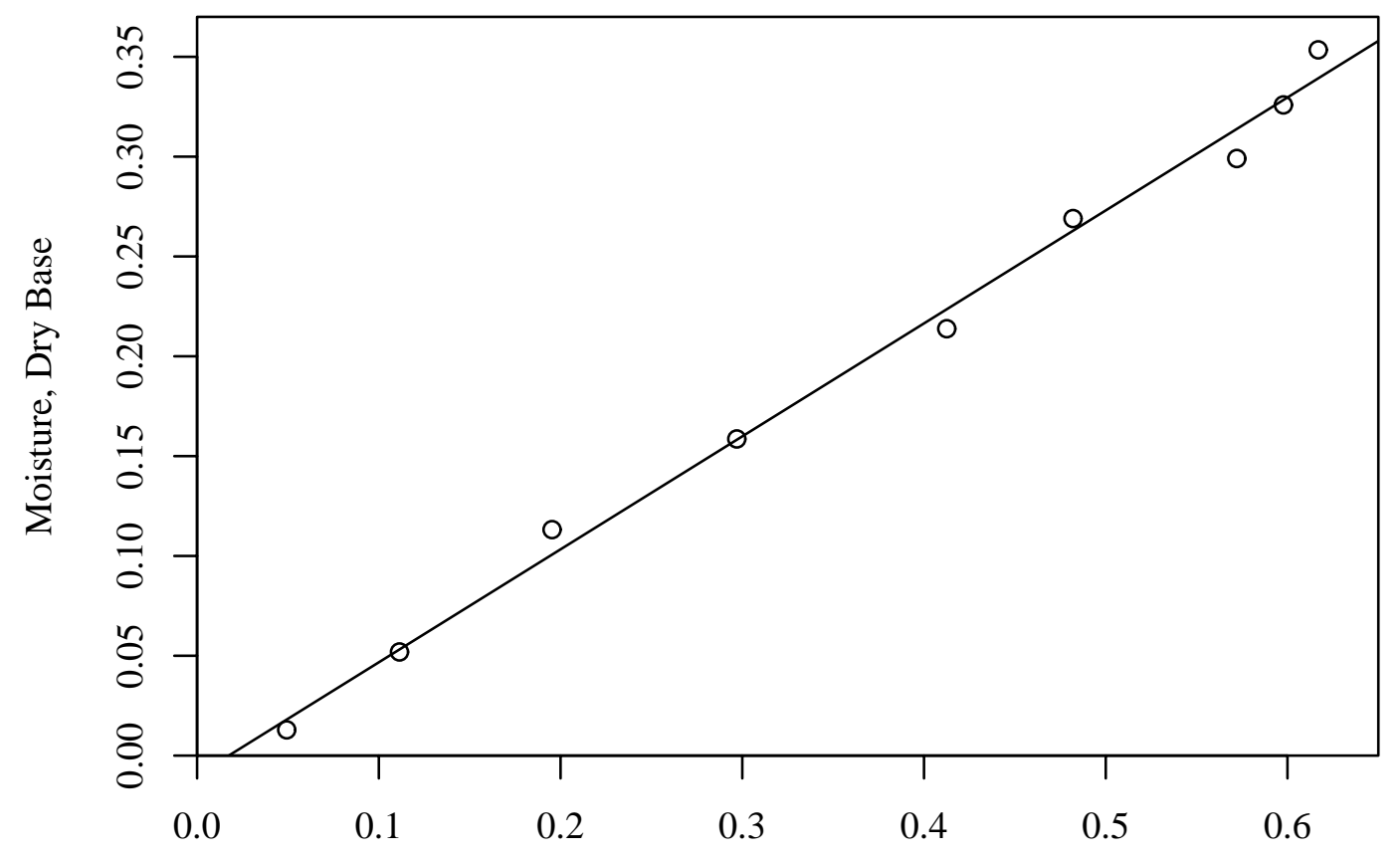

Absorbance

\section{FIGURE G.1 Calibration Curve for Zeltex Instrument (No. 971667) for A2/P2 Hardwood Topsoil}

the calibration curve shown in Figure G.1. Because the nature of the calibration is sensitive to soil type, an approach to estimating uncertainty that is independent of calibration curve and soil type is used to obtain a reasonably conservative estimate of uncertainty in $M$.

Given the availability of field measurements of moisture, it is expected that, at a minimum, one will be able to distinguish among wet, dry, and average conditions (i.e., be able to reduce the range of the possible values of $m_{D}$ associated with a particular measurement to about $0.10)$. In such a case, the variance in $m_{D}$ would be about $(0.10)^{2} / 12=0.00083$ or less, and the relative variance in $M$ would generally be less than about $0.00083 /(1+0.10)^{2}=0.00069$, where a value of 0.10 is used as the expected value of $m_{D}$. For average or wet conditions, the expected value of $m_{D}$ would be higher (e.g., about 0.2 or 0.3 , respectively), and the relative variance would be smaller. Therefore, the relative uncertainty in $M$ is generally expected to be less than about $0.026(=\sqrt{0.00069})$, or about $2.6 \%$.

To summarize, if no measurements of soil moisture are available and if a constant value is used for $m_{D}$ in all cases, the relative uncertainty in $M$ is about $8 \%$ or less. Under best-case conditions (topsoil and optimal measurements), the relative uncertainty in $M$ is about $1 \%$. In general, a conservative estimate for the uncertainty in $M$ is about $2.6 \%$. For purposes of analysis in this report, a relative uncertainty of $3 \%$ is used. Such a value is expected to provide a reasonably conservative estimate of the uncertainty in $M$. 
TABLE G.1 Quantities for Equations G.6 and G.7 ${ }^{\mathbf{a}}$

\begin{tabular}{lc}
\hline & \\
Quantity & Value \\
\hline & \\
$a_{0}$ & -0.00987 \\
$u\left(a_{0}\right)$ & 0.00714 \\
$a_{1}$ & 0.566 \\
$u\left(a_{1}\right)$ & 0.0169 \\
$u\left(a_{0}, a_{1}\right)$ & -0.000106 \\
$u(X)$ & $0.0150^{\mathrm{b}}$ \\
\hline
\end{tabular}

a These quantities apply to the calibration curve shown in Figure G.1.

b 0.0150 is chosen as a representative value for the standard deviation of the absorbance in Table G.2. The average standard deviation is 0.0129 . If all the absorbance measurements in the table are normalized by subtracting the mean values shown, the standard deviation for the 36 normalized absorbance measurements taken as a group is 0.0120 .

TABLE G.2 Absorbance Measurementsa

\begin{tabular}{ccccccc}
\hline & & & & & & Mean \\
$m_{D}$ & $X_{1}$ & $X_{2}$ & $X_{3}$ & $X_{4}$ & $\begin{array}{c}\text { Std. Dev. } \\
\text { Absorbance }\end{array}$ & of Absorbance \\
\hline & & & & & & \\
0.3535 & 0.6077 & 0.6192 & 0.6264 & 0.6142 & 0.6169 & 0.0079 \\
0.3259 & 0.6139 & 0.5924 & 0.6016 & 0.5832 & 0.5978 & 0.0131 \\
0.2991 & 0.5691 & 0.5730 & 0.5560 & 0.5902 & 0.5721 & 0.0141 \\
0.2690 & 0.4897 & 0.4718 & 0.5068 & 0.4597 & 0.4820 & 0.0206 \\
0.2138 & 0.4337 & 0.4140 & 0.4000 & 0.4023 & 0.4125 & 0.0154 \\
0.1586 & 0.2778 & 0.2950 & 0.3185 & 0.2965 & 0.2970 & 0.0167 \\
0.1132 & 0.1836 & 0.1828 & 0.2087 & 0.2061 & 0.1953 & 0.0140 \\
0.0519 & 0.1159 & 0.1195 & 0.0982 & 0.1121 & 0.1114 & 0.0093 \\
0.0129 & 0.0499 & 0.0478 & 0.0451 & 0.0543 & 0.0493 & 0.0039 \\
\hline
\end{tabular}

a $\quad m_{D}$ is the moisture level calculated from laboratory measurements. The $X_{i}$ 's are a series of absorbance measurements made for the moisture level shown. 


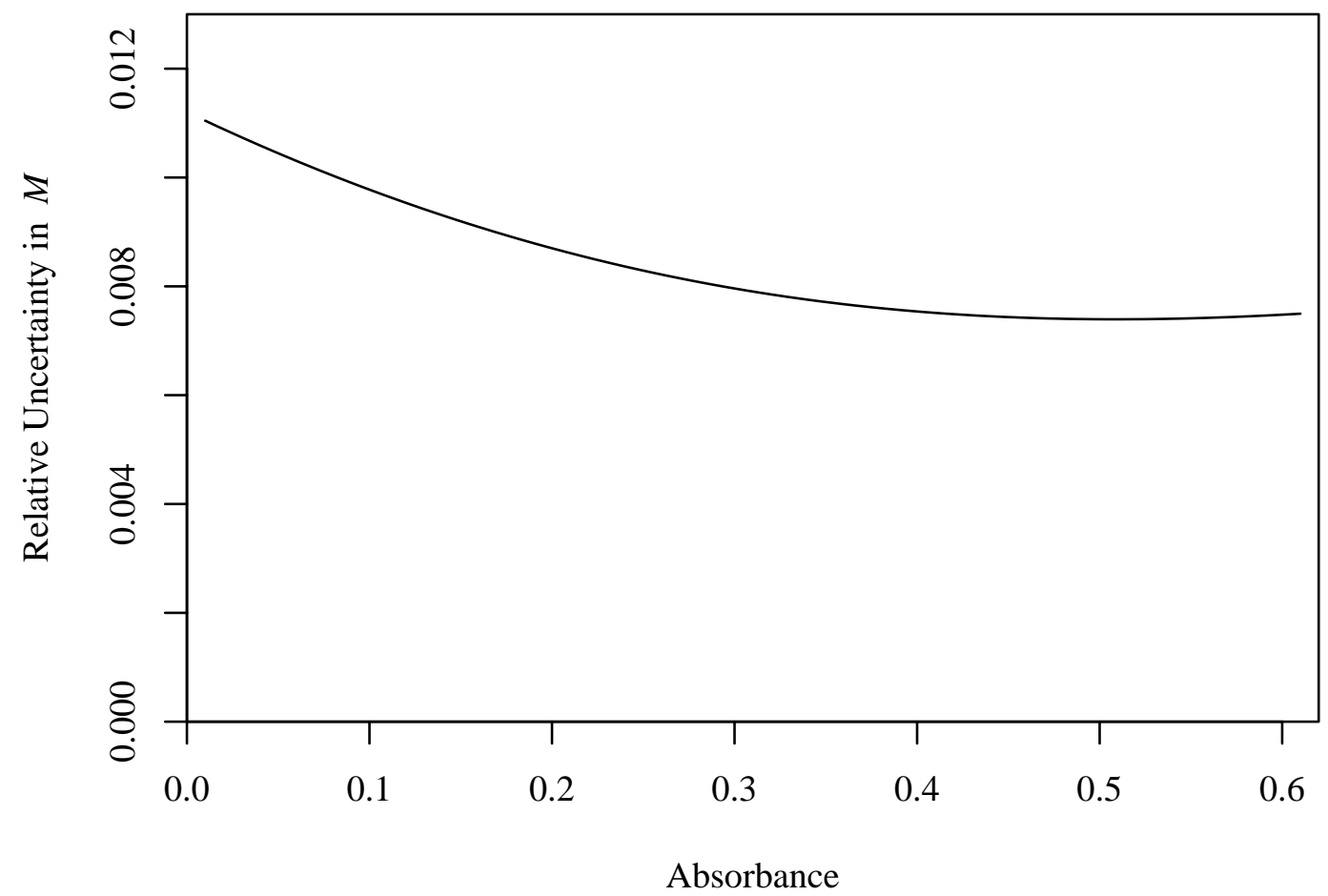

FIGURE G.2 Relative Uncertainty in $M$ as a Function of Absorbance (Results apply to the calibration shown in Figure G.1.) 


\section{APPENDIX H:}

\section{DETERMINATION OF BACKGROUND COUNTS BY USING SANDING}

For the NaI systems, background counts for a region of interest (ROI) are determined by using a process called sanding, which is described and analyzed briefly in this appendix. The spectral sanding process involves obtaining "sanded" values for counts for each channel in the spectrum. For each channel, a sanded value is determined by averaging counts per channel by using a window that is approximately the same width as the base of the photopeak of interest in that portion of the spectrum but is centered on the channel. The sanded value is compared to counts for the channel. If the number of counts exceeds the sanded value, then the number of counts is set equal to the sanded value. The process is repeated until a smooth spectrum with no peaks is obtained, which is an estimate of the continuum.

Applying the sanding process 20 times over the same region has been found empirically to yield sanded values for counts that adequately approximate the continuum under a photopeak. The effect of the sanding process on a spectrum is the same as the effect of sandpaper on a rough piece of wood: removal of high points and creation of a smooth surface. The process is repeated, just as the sanding of a rough surface is repeated. The process stops when the spectrum has become acceptably smooth.

Spectra obtained with 4- or 8-second counting times generally do not have adequate structure to allow estimation of the continuum by using sanding. Therefore, multiple 4-second spectra are summed, and the sum is sanded. Although the number is user selectable, normally 17 spectra are summed. The result is normalized to the acquisition period of interest on the basis of live time. As a consequence, the uncertainty associated with estimating the background counts is less than the uncertainty that would be associated with estimating background counts by using only the acquisition time for a single spectrum. (However, for the 300-second counts obtained for calibration, only a single spectrum is used.) The uncertainty is reduced even more when compared with the uncertainty in background counts obtained for nonsanded spectra by using background windows that are located on either side of the ROI but that, due to the need to avoid interferences, have fewer channels than the region of interest. In such an approach, the number of counts in those background windows must be increased to account for the difference in the number of channels in the region of interest and the background. That process also increases the uncertainty in the estimate of background counts.

Figure H.1 illustrates graphically the ability of the sanding process to reduce the uncertainty associated with measuring background counts. The figure shows gross and background counts obtained for the uranium ROI by using one of the radiation scanning systems (RSS-1) on the pad for background conditions. The mean values for the gross and background counts for the series of measurements shown are 114.3 and 93.1, respectively. Note that the background counts $\left(C_{U}\right)$ have been shifted downward by 75 counts to avoid an overlap in the figure with the gross counts. Gross and background counts for the ROI for a single spectrum are expected to follow a Poisson distribution, for which the mean and variance are equal. The 


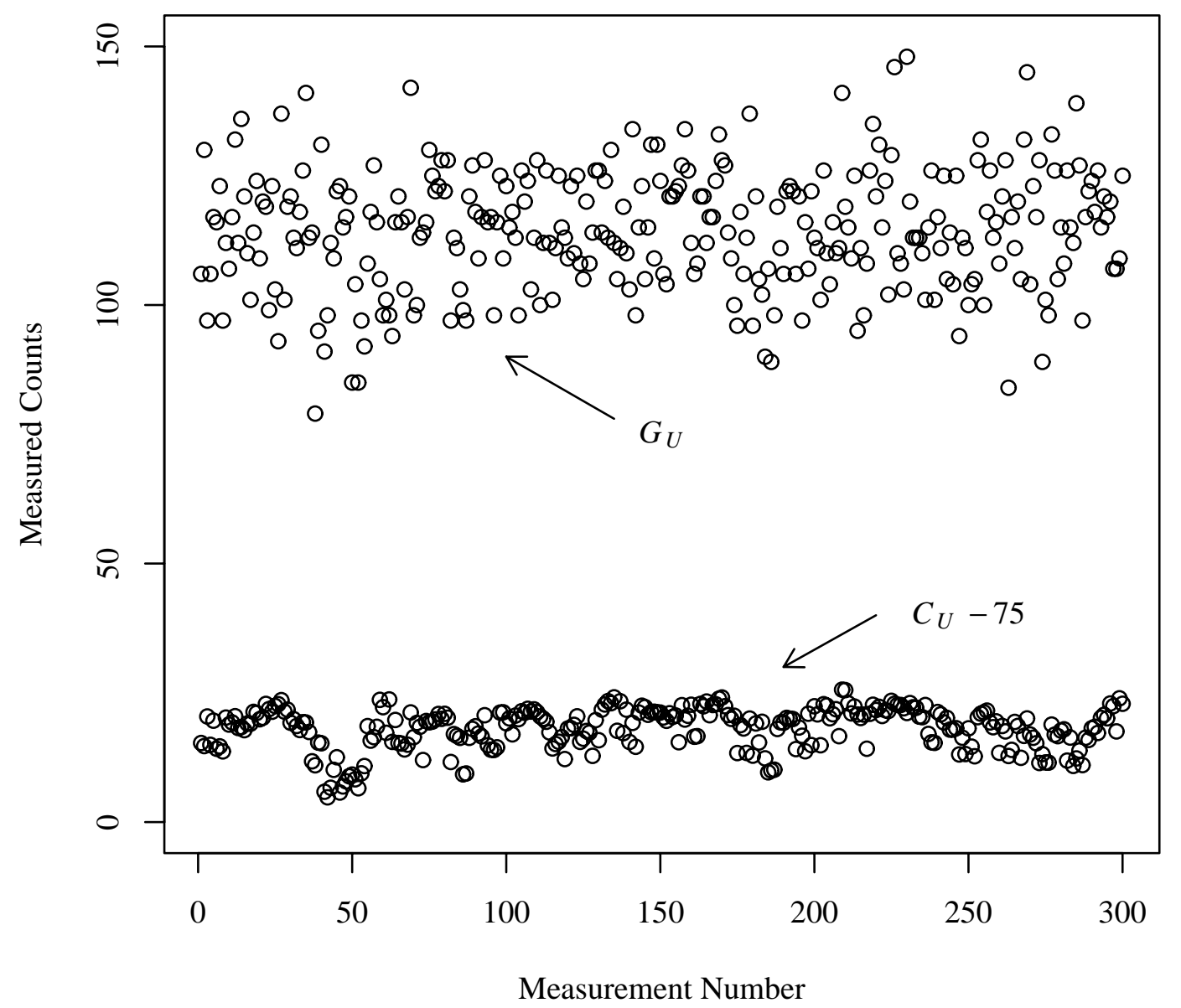

FIGURE H.1 Comparison of Variability in Gross and Background Counts (The results shown are sequential 4-second measurements obtained for the ${ }^{238} \mathrm{U}$ ROI by using RSS-1 on the calibration pad [no sources used] on June 24, 2003 [Run 0834]. $G_{U}$ identifies the gross counts, and $C_{U}$ identifies the background counts. The background counts have been shifted by 75 counts to avoid overlap with gross counts.)

variances for the gross and background counts are 139.2 and 16.5 counts squared, respectively. The variance for the gross counts is somewhat larger than the mean, possibly indicating the presence of a non-Poisson component of variance. The variance of background counts is much smaller than the mean, illustrating the effects of the sanding process, which involves the averaging of approximately 17 spectra. The ratios of the mean to the variance for the gross and background counts are 0.8 and 5.4, respectively. When looked at another way, the ratios of the standard deviations to the means (the relative uncertainties) for the gross and background counts are 0.10 and 0.04 , respectively. The sanding process reduces the uncertainty associated with background counts by about a factor of two relative to what would be expected if the background counts had been determined by using results from a single spectrum (assuming that could be done).

Because the sanding process involves use of a moving average of 17 spectra to obtain background counts, correlations are introduced between background counts in nearby 
measurements. The correlation is apparent in the plot of background counts shown in Figure H.1; the results for an individual measurement are not independent from nearby measurements. The correlations introduced by sanding are shown quantitatively in Figure H.2. The two plots in the figure show autocorrelation functions for the gross and background counts plotted in Figure H.1. An autocorrelation function describes the correlation of a series of measurements with itself for various lags (i.e., one-measurement lag, two-measurement lag, etc.). The results in Figure H.2 show that generally for the gross counts, no significant autocorrelations exist except for when the lag is equal to zero. However, for background counts, significant autocorrelation appears to be present at least up to about lag 12 or so; also, the autocorrelations generally decrease in a consistent manner up to about lag 15. Such a result is consistent with what would be expected from the process used during sanding and provides a quantitative explanation for the nonrandom behavior seen in the background counts.

The background counts produced by sanding can be modeled by a moving-average process (plus a constant). A moving-average process generates random variables by summing a number (in this case 17) of lagged members from a sequence of weighted random variables that are independently and identically distributed and that have a mean equal to zero and some fixed variance (e.g., the deviations from the mean of the background counts in the spectra that are summed prior to sanding). When the weights are the same and equal $1 / \mathrm{n}$, the variance of the result is equal to the variance of the variables being summed divided by n (Pollock 1999). Therefore, if a moving-average process (with an added constant) adequately describes the results obtained from the sanding being applied to background counts and if the background counts have a Poisson distribution, the variance of the sanded background counts should be about $\mu_{G} / 17$, where $\mu_{G}$ is the mean of the background counts. In other words, the ratio of the mean to the

Gross Counts

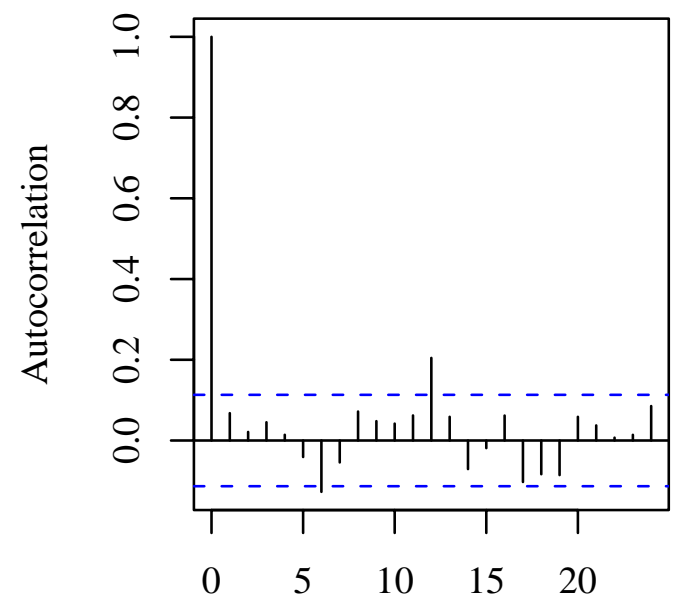

Lag
Background Counts

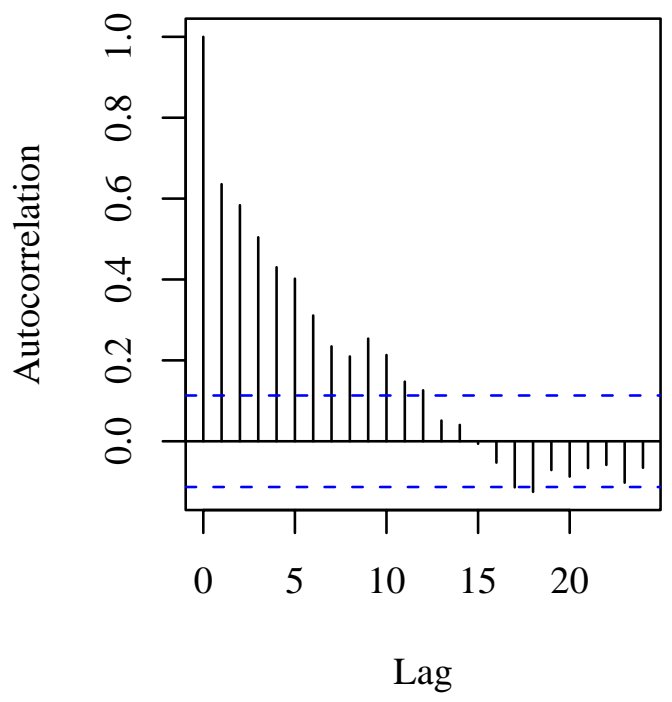

FIGURE H.2 Autocorrelations for Gross and Background Counts (Results are for the ${ }^{238} \mathrm{U}$ count data given in Figure H.1. Approximate 95\% confidence limits are shown.) 
variance for such a case would be expected to be about 17. Table H.1 summarizes results for several $\mathrm{NaI}$ systems for the three radionuclides of interest for background conditions and for cases in which the pad was fully loaded with sources. The table indicates that the performance varies by radionuclide, with the best results (i.e., highest ratios) being for ${ }^{232} \mathrm{Th}$. The average for ${ }^{232} \mathrm{Th}$ for background conditions is 13.0 , and it is nearly 15 for the case when all thorium sources are loaded. The table also indicates that for ${ }^{238} \mathrm{U}$ and ${ }^{226} \mathrm{Ra}$, the results are best when concentrations are low, but the ratio for those radionuclides can be below three for elevated concentrations. The source concentration appears to have little effect on the results for ${ }^{232} \mathrm{Th}$.

For a series described by a moving-average process of order 17 , the variance of samples of size 300 can vary substantially from sample to sample. Therefore, variability such as that seen in Table H.1 is expected. However, the ratios are generally low if the simple model and assumptions described above apply. After adding the 17 spectra, the sanding process appears to contribute considerable noise to the sanded results when compared with what would be expected on the basis of a simple moving-average process. Such a conclusion suggests that there could be an opportunity for further reducing the uncertainty associated with background counts. However, in spite of any possible theoretical shortcomings of the sanding process, the actual measurement uncertainties and the minimum detectable concentrations for the NaI systems would be little affected for 4- or 8-second measurements even if the uncertainty in background counts could be improved substantially. That uncertainty is already so low that it is not a significant factor in determining the performance of the systems for those measurement times.

\section{APPENDIX H REFERENCE}

Pollock, D.S.G., 1999, A Handbook of Time-Series Analysis, Signal Processing and Dynamics, Academic Press, San Diego, Calif. 
TABLE H.1 Performance of Sanding in Reducing Uncertainty

\begin{tabular}{|c|c|c|c|}
\hline \multirow[b]{2}{*}{ Case $^{\mathrm{a}}$} & \multicolumn{3}{|c|}{$\begin{array}{l}\text { Ratio of the Mean of the } \\
\text { Background Counts to } \\
\text { the Variance of the } \\
\text { Background Counts for } \\
\text { Various Runs with } \\
\text { the NaI Systems }\end{array}$} \\
\hline & ${ }^{238} \mathrm{U}$ & ${ }^{226} \mathrm{Ra}$ & ${ }^{232} \mathrm{Th}$ \\
\hline \multicolumn{4}{|l|}{ Background } \\
\hline RSS-1 (0840) & 3.9 & 7.6 & 13.6 \\
\hline RSS-1 (0834) & 5.7 & 14.3 & 16.0 \\
\hline RSS-2 (0520) & 5.9 & 8.2 & 10.5 \\
\hline RSS-2 (0532) & 5.4 & 13.4 & 10.0 \\
\hline RSS-2 (0526) & 6.1 & 6.3 & 9.7 \\
\hline RSS-3 (0146) & 5.9 & 15.5 & 17.9 \\
\hline Average & 5.5 & 10.9 & 13.0 \\
\hline \multicolumn{4}{|l|}{${ }^{238}$ U Sources } \\
\hline RSS-1 (0837) & 2.9 & & \\
\hline RSS-2 (0529) & 3.1 & & \\
\hline RSS-3 (0155) & 2.0 & & \\
\hline Average & 2.7 & & \\
\hline \multicolumn{4}{|l|}{${ }^{226}$ Ra Sources } \\
\hline RSS-1 (0843) & & 2.2 & \\
\hline RSS-2 (0535) & & 1.7 & \\
\hline RSS-3 (0149) & & 1.6 & \\
\hline Average & & 1.8 & \\
\hline \multicolumn{4}{|l|}{${ }^{232}$ Th Sources } \\
\hline RSS-1 (0825) & & & 19.0 \\
\hline RSS-2 (0523) & & & 11.9 \\
\hline RSS-3 (0152) & & & 13.1 \\
\hline Average & & & 14.7 \\
\hline
\end{tabular}

a Results are for the systems indicated and for the runs shown in parentheses. Approximately 300 measurements of 4 seconds each were used for each run. All runs were made in June 2003. 


\section{APPENDIX I: \\ DETERMINATION OF DETECTION LIMITS}

In determining a detection limit, one considers the net signal, which is the gross signal minus the blank:

$$
S=(S+B)-B
$$

where $S+B$ is the gross signal and $B$ is the blank. ${ }^{1}$ For the NaI systems, the blank corresponds to measurements made on the pad with no sources in place (standards containing only pad soil are used), which can be considered to represent "background" conditions. The gross signal corresponds to measurements made with some sources present.

The variance of the net signal is given by

$$
\sigma_{S}^{2}=\sigma_{S+B}^{2}+\sigma_{B}^{2}
$$

Because measurements of gross signal and blank are made independently, the covariance between $S+B$ and $B$ is zero.

Let $\sigma_{0}^{2}$ be the variance of the net signal when only a blank is used (i.e., $S=0$ ). Then, $\sigma_{0}^{2}=\sigma_{B}^{2}+\sigma_{B}^{2}=2 \sigma_{B}^{2}$. (If many measurements of the blank have been made, it is called a "well-known blank," and the variance of the estimated average of the blank becomes small. In such cases, $\sigma_{0}^{2}$ equals approximately $\sigma_{B}^{2}$, as opposed to $2 \sigma_{B}^{2}$ when the blank is not well known.)

For the NaI systems, one determines net counts. These counts are total counts in the region of interest (ROI) minus background counts for the ROI. Figure 2.1 shows a spectrum obtained with a NaI system, indicating the ROIs for ${ }^{238} \mathrm{U},{ }^{226} \mathrm{Ra}$, and ${ }^{232} \mathrm{Th}$. The net counts for the system should not be confused with the net signal. Also, background counts should not be confused with net counts above background (i.e., net counts above the blank). Net counts, $N$, for the $\mathrm{NaI}$ systems are given by:

$$
N=G-C
$$

1 The basic definitions used are taken from Currie (1968). A blank is defined by Currie as the "signal resulting from a sample which is identical, in principle, to the sample of interest, except that the substance sought is absent (or small compared to $\sigma_{B}$ )." The blank does include the effects of interfering species. 
where $G$ is the total (gross) counts in the ROI and $C$ is the background (continuum) counts for the ROI. The variance of the net counts for the NaI systems is given by

$$
\sigma_{N}^{2}=\sigma_{G}^{2}+\sigma_{C}^{2}-2 u(G, C)
$$

where $u(G, C)$ is the covariance between $G$ and $C$.

Table I.1 provides estimated values for $G, C$, and $N$ for one of the radiation scanning systems (RSS-1) for cases in which various numbers of sources were used in the calibration pad. The table also provides estimated values of variances for those quantities, as well as $u(G, C)$. The table illustrates that the variance of $C$ is always much less than the variance of $G$. Because of a positive correlation between $C$ and $G$, the variance of $N$ is always less than the sum of the variances of $C$ and $G$. Generally, the variance of $N$ is less than the variance of $G$ alone. When the variance of $N$ is greater than the variance of $G$, the variances are approximately equal. Results for RSS-2 and RSS-3 are similar. For ${ }^{232} \mathrm{Th}$, the variance of $G$ is a good approximation for the variance of $N$. For ${ }^{238} \mathrm{U}$ and ${ }^{226} \mathrm{Ra}$, the variance of $G$ is an acceptable approximation for the variance of $N$. Therefore, the value of $\sigma_{N}^{2}$ can be reasonably approximated by $\sigma_{G}^{2}$.

The critical level, $L_{C}$, is defined as

$$
L_{C}=k_{\alpha} \sigma_{0}
$$

where $k_{\alpha}$ is the $(1-\alpha)^{\text {th }}$ quantile of the standard normal distribution. $L_{C}$ is the net response level (i.e., net counts above background) at which the detector output can be considered "above background." The a priori detection limit is defined as

$$
L_{D}=L_{C}+k_{\beta} \sigma_{D}
$$

where $k_{\beta}$ is the $(1-\beta)^{\text {th }}$ quantile of the standard normal distribution and $\sigma_{D}$ is the standard deviation of the net signal when its actual value is $L_{D}$. $L_{D}$ is the net response level that can be expected to be seen with a detector for a specified portion of the time. Figure I.1 illustrates the relationship between $L_{D}$ and $L_{C}$ and the meaning of $\alpha$ and $\beta$.

Let $k_{\alpha}=k_{\beta}=k=1.645$ for this discussion. In other words, the probabilities of both Type I and Type II errors are assumed to be 0.05. Type I errors are false positives (i.e., a net response is considered to be above background when the true radionuclide concentration is below background levels). Type II errors are false negatives (i.e., a net response is considered to be at background when the true radionuclide level is above background).

Then, for the case in which the blank is not well known (i.e., $\sigma_{0}^{2}=2 \sigma_{B}^{2}$ ),

$$
L_{C}=k \sigma_{0}=\sqrt{2} k \sigma_{B}
$$

and

$$
L_{D}=L_{C}+k \sigma_{D}
$$


TABLE I.1 Counting Results for RSS-1a

\begin{tabular}{|c|c|c|c|c|c|c|c|c|c|}
\hline \multirow{2}{*}{$\begin{array}{l}\text { Number } \\
\text { of } \\
\text { Sources }\end{array}$} & \multirow{2}{*}{$\begin{array}{l}\text { Live } \\
\text { Time } \\
\text { (s) }\end{array}$} & \multirow[b]{2}{*}{$n$} & \multicolumn{7}{|c|}{ Estimated Values } \\
\hline & & & $G$ & C & $N$ & $\sigma_{G}^{2}$ & $\sigma_{C}^{2}$ & $-2 u(G, C)$ & $\sigma_{N}^{2}$ \\
\hline \multicolumn{10}{|l|}{ Uranium } \\
\hline 0 & 3.94 & 300 & 114.30 & 93.07 & 21.22 & 139.21 & 16.45 & -34.88 & 120.78 \\
\hline 16 & 3.92 & 285 & 220.63 & 133.40 & 87.24 & 273.90 & 17.03 & -36.35 & 254.58 \\
\hline 25 & 3.88 & 286 & 434.75 & 198.00 & 236.75 & 496.57 & 43.66 & -92.75 & 447.48 \\
\hline 45 & 3.86 & 286 & 627.36 & 257.84 & 369.52 & 774.79 & 90.57 & -196.94 & 668.43 \\
\hline \multicolumn{10}{|l|}{ Radium } \\
\hline 0 & 3.94 & 288 & 60.03 & 40.12 & 19.92 & 63.75 & 5.27 & -6.41 & 62.61 \\
\hline 16 & 3.90 & 287 & 275.52 & 134.86 & 140.66 & 321.22 & 23.68 & -16.26 & 328.64 \\
\hline 25 & 3.80 & 286 & 697.91 & 312.27 & 385.64 & 824.44 & 130.22 & -219.05 & 735.61 \\
\hline 45 & 3.72 & 287 & 1162.61 & 537.51 & 625.10 & 1263.64 & 246.26 & -378.48 & 1131.43 \\
\hline \multicolumn{10}{|l|}{ Thorium } \\
\hline 0 & 3.94 & 300 & 44.08 & 9.20 & 34.89 & 40.53 & 0.58 & -1.62 & 39.49 \\
\hline 16 & 3.91 & 286 & 180.88 & 36.53 & 144.34 & 203.04 & 3.08 & -1.06 & 205.06 \\
\hline 25 & 3.86 & 285 & 401.93 & 74.00 & 327.93 & 418.24 & 4.88 & -17.03 & 406.09 \\
\hline 45 & 3.80 & 285 & 655.85 & 122.26 & 533.59 & 758.70 & 6.44 & -6.90 & 758.24 \\
\hline
\end{tabular}

a Data were collected on the calibration pad by using the sources indicated. $n$ is the number of measurements used, with the average live time per measurement shown. (The first 17 measurements from a run were not used in the analysis.) Other quantities are defined in the text. Data obtained by using the uranium sources were collected on June 24, 2003 (Runs 0834, 0835, 0836, and 0837). Data obtained by using the radium sources were collected on June 25, 2003 (Runs 0840, 0841, 0842, and 0843). Data obtained by using the thorium sources were collected on June 16, 2003 (Runs 0823, 0824, and 0825); background data for thorium (no sources) were collected on June 24, 2003 (Run 0834). Counts shown are average values. The units for $G, C$, and $N$ are counts. The units for variances and covariance are count ${ }^{2}$.

For the NaI systems, $\sigma_{B}$ is the standard deviation of the net counts (net of background counts) on the pad with no sources present (blank). This quantity is represented by $\sigma_{N 0}$. (Similarly, $\sigma_{N D}$ is the standard deviation of the net counts at the detection limit.) Therefore,

$$
L_{C}=\sqrt{2} k \sigma_{N 0} \cong \sqrt{2} k \sigma_{G 0} .
$$

The gross counts are assumed to have a Poisson distribution, for which the variance equals the mean. As can be seen from Table I.1, sample variances and means for gross counts are approximately equal. Therefore,

$$
L_{C} \cong k\left(2 \mu_{G 0}\right)^{1 / 2},
$$

where $\mu_{G 0}$ is the mean value for gross counts when no sources are present in the pad. 


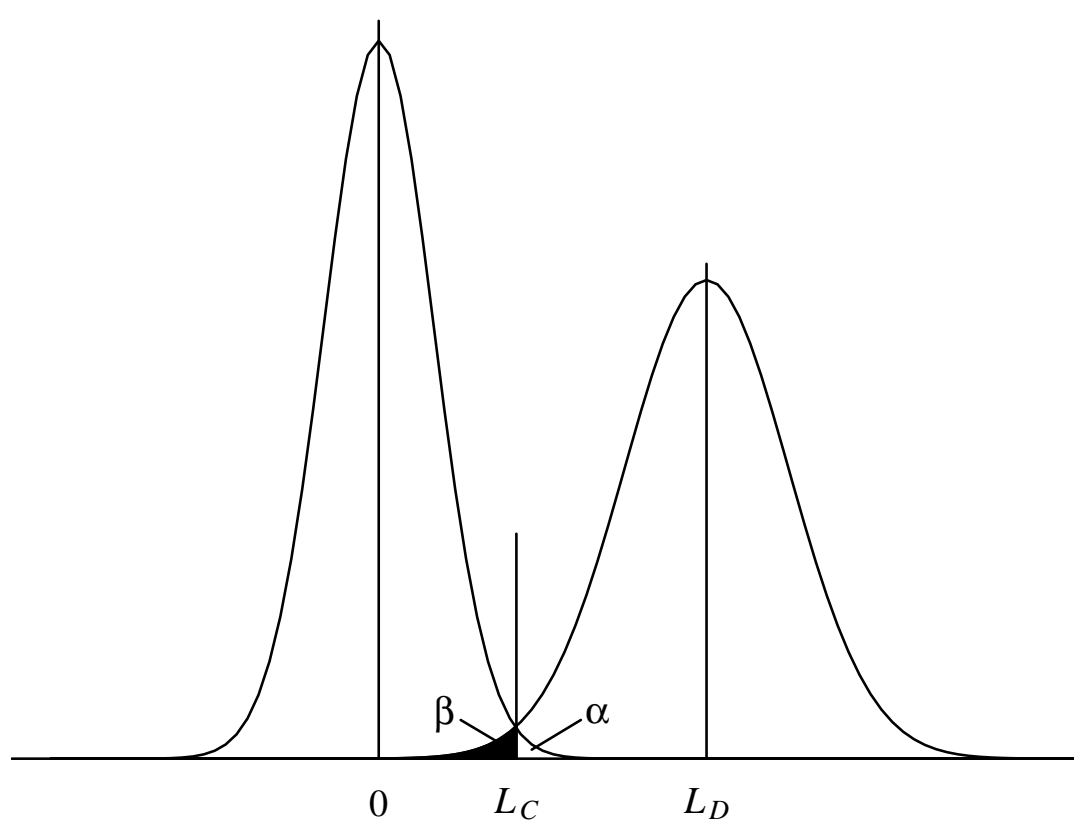

FIGURE I.1 Illustration of Quantities

If many measurements of net counts are made with no sources present ("well-known blank"),

$$
L_{C}=k \sigma_{N 0} \cong k \mu_{G 0}^{1 / 2} .
$$

Note that the variance of the net signal at the detection limit $\left(\sigma_{D}^{2}\right)$ is given by

$$
\sigma_{D}^{2}=\sigma_{S+B}^{2}+\sigma_{B}^{2}=\sigma_{N D}^{2}+\sigma_{N 0}^{2} .
$$

Therefore, for the NaI systems,

$$
L_{D}=L_{C}+k\left(\sigma_{N D}^{2}+\sigma_{N 0}^{2}\right)^{1 / 2} \cong L_{C}+k\left(\sigma_{G D}^{2}+\sigma_{N 0}^{2}\right)^{1 / 2},
$$

where $\sigma_{G D}^{2}$ is the variance of the gross counts in the ROI at the detection limit. When it is assumed that the gross counts have a Poisson distribution,

$$
L_{D} \cong L_{C}+k\left(\mu_{G D}+\sigma_{N 0}^{2}\right)^{1 / 2} .
$$

The net signal at the detection limit equals the gross signal at the detection limit minus the blank. For the NaI systems, the net signal at the detection limit then equals the net counts at the detection limit with sources in the pad minus the net counts with no sources. Therefore,

$$
L_{D}=\mu_{N D}-\mu_{B}=\mu_{G D}-\mu_{C D}-\mu_{B}
$$


and

$$
\mu_{G D}=L_{D}+\mu_{C D}+\mu_{B}
$$

However, Appendix E indicates that background counts can be expressed as a function of net counts (for different numbers of sources),

$$
\mu_{C D}=d \mu_{N D}+e
$$

and from above

$$
\mu_{N D}=L_{D}+\mu_{B}
$$

Therefore,

$$
\mu_{C D}=d\left(L_{D}+\mu_{B}\right)+e .
$$

Thus,

$$
\mu_{G D}=L_{D}+d\left(L_{D}+\mu_{B}\right)+e+\mu_{B}
$$

Substituting the expression for $\mu_{G D}$ into Equation I.3 and performing some algebraic manipulations gives

$$
L_{D}^{2}-L_{D}\left[2 L_{C}+k^{2}(d+1)\right]+L_{C}^{2}-k^{2} \sigma_{N 0}^{2}-k^{2} e-k^{2} \mu_{B}(d+1)=0 .
$$

Let

$$
b=-\left(2 L_{C}+k^{2}(d+1)\right)
$$

and

$$
c=L_{C}^{2}-k^{2} \sigma_{N 0}^{2}-k^{2} e-k^{2} \mu_{B}(d+1) .
$$

Equation I.4 then can be written as

$$
L_{D}^{2}+b L_{D}+c=0
$$

Therefore (using the solution to a quadratic equation),

$$
L_{D}=0.5\left[-b \pm\left(b^{2}-4 c\right)^{1 / 2}\right]
$$

which is an expression for the detection limit for the NaI systems. Note that $L_{D}$ is a net signal $\left(\mu_{N D}=L_{D}+\mu_{B}\right)$. 
When the blank is not well known, the expression for $c$ can be simplified. For the NaI systems,

$$
\mu_{B}=\mu_{G 0}-\mu_{C 0}
$$

and

$$
\mu_{C 0}=d \mu_{N 0}+e
$$

Also, from Equation I.1, $k^{2} \sigma_{N 0}^{2}=0.5 L_{C}^{2}$. Making these substitutions in Equation I.6, substituting for $L_{C}$ (by using Equation I.2), and simplifying gives $c=0$.

From Equation I.7, with $c=0, L_{D}=-b$ (ignoring the root $L_{D}=0$ ). Also, when background counts are not a function of the net counts, $d=0$, and $b=-\left(k^{2}+2 L_{C}\right)$. Therefore,

$$
L_{D}=k^{2}+2 L_{C}
$$

which is Currie's Equation 13, the expression commonly used to determine $L_{D}$. Therefore, the solution to Equation I.4 is given by Currie's equation when $\mu_{C}$ is a constant and the blank is not well known.

When the blank is well known, $L_{C}^{2}=k^{2} \sigma_{N 0}^{2}$. When this quantity, the expression for $\mu_{B}$ given in Equation I.8, and the expression for $\mu_{C 0}$ given in Equation I.9 are substituted in Equation I.6,

$$
c=-k^{2} \mu_{G 0}
$$

Values for $L_{C}$ and $L_{D}$ are given in Table I.2 for RSS-1 for the case in which the blank is not well known. The table provides the values of the inputs needed to determine those quantities and indicates how the calculations were done. The table also provides $L_{D}$ obtained by using Equation I.10, Currie's equation. Its value is somewhat less than that obtained when the dependence of background counts on source strength is considered. However, the difference is of no practical importance.

Minimum detectable concentrations (MDCs) can be determined by using the value of $L_{D}$ obtained from Equation I.7 in the appropriate calibration equation, when it is assumed that the net counts for the other radionuclides are equal to those values obtained on the pad when no sources are present. Note that because $L_{D}$ is determined relative to a blank, the use of a blank that has a significant concentration of the radionuclide of interest will result in the underestimation of the actual minimum detectable concentration for the radionuclide. 
TABLE I.2 Calculation of $L_{C}$ and $L_{D}$ for RSS-1 a

\begin{tabular}{lrccccc}
\hline $\begin{array}{c}\text { Radio- } \\
\text { nuclide }\end{array}$ & $\mu_{G 0}$ & $d$ & $b$ & $L_{C}$ & $\begin{array}{c}L_{D} \\
(\mathrm{I} .7)\end{array}$ & $\begin{array}{c}L_{D}{ }^{\mathrm{b}} \\
(\mathrm{I} .10)\end{array}$ \\
\hline & & & & & & \\
${ }^{238} \mathrm{U}$ & 116.04 & 0.495 & -54.2 & 25.1 & 54.2 & 52.9 \\
${ }^{226} \mathrm{Ra}$ & 60.94 & 0.842 & -41.3 & 18.2 & 41.3 & 39.1 \\
${ }^{232} \mathrm{Th}$ & 44.67 & 0.235 & -34.4 & 15.6 & 34.4 & 33.9 \\
\hline
\end{tabular}

a $\quad \mu_{G 0}$ was estimated by using results from Table I.1, adjusted to a 4-second measurement period. $d$ was obtained from Section E.2. $b$ was calculated by using Equation I.5. $c=0 . L_{C}$ was calculated by using Equation I.2. $L_{D}$ (I.7) and $L_{D}$ (I.10) were obtained by using Equations I.7 and I.10, respectively. All quantities have units of counts, except $d$, which has no units.

b Currie (1968) used a value of $k=2.71$ in the equation for $L_{D}$. It is now generally accepted that a constant factor of three should be used (e.g., see MARSSIM 2000, p. 6-34). However, using a constant factor of three in Equation I.10 instead of 2.71 would increase the results shown by only 0.3 , which is not a significant difference.

\section{APPENDIX I REFERENCES}

Currie, L.A., 1968, "Limits for Qualitative Detection and Quantitative Determination," Analytical Chemistry 40(3):586-593, March.

MARSSIM, 2000, Multi-Agency Radiation Survey and Site Investigation Manual, NUREG-1575, Rev. 1, EPA 402-R-97-016, Rev. 1, DOE/EH-0624, Rev. 1, Dec. 


\section{APPENDIX J:}

\section{DETERMINATION OF STANDARD DEVIATIONS IN MEASURED URANIUM CONCENTRATIONS AT WAC LEVEL}

As discussed in Chapter 6, a waste acceptance criterion (WAC) trigger level can be

defined by the following equation, with the trigger level set so that $95 \%$ of all measurements of soil having an actual uranium concentration of 1030 parts per million (ppm) (the uranium WAC) will be above the trigger level:

$$
\text { WAC Trigger }(\mathrm{ppm})=1030-1.645 \sigma_{W A C} \text {, }
$$

where $\sigma_{W A C}=$ the standard deviation in the measured dry-weight uranium concentration at 1030 ppm.

To determine such a trigger, $\sigma_{W A C}$ must be determined. By using the calibration equation for uranium (Equation 5.1) and converting to a uranium concentration in ppm (i.e., multiplying the ${ }^{238} \mathrm{U}$ concentration in $\mathrm{pCi} / \mathrm{g}$ by 2.99 ), the wet-weight uranium concentration is given by:

$$
C_{W U}=2.99\left(F_{1} r_{N U}+F_{2} r_{N R a}+F_{3} r_{N T h}\right),
$$

where $F_{1}, F_{2}$, and $F_{3}$ are calibration coefficents and $r_{N U}, r_{N R a}, r_{N T h}$ are raw (i.e., not corrected for interference from the other radionuclides) net count rates (counts/s) for ${ }^{238} \mathrm{U},{ }^{226} \mathrm{Ra}$, and ${ }^{232} \mathrm{Th}$.

When any covariances between the net count rates and also any systematic uncertainty in the calibration coefficients are neglected, the variance in the uranium concentration is

$$
\sigma_{C W U^{2}}=8.94\left(F_{1}^{2} \sigma_{r N U^{2}}+F_{2}^{2} \sigma_{r N R a^{2}}+F_{3}^{2} \sigma_{r N T h}^{2}\right)
$$

where $\sigma_{r N U^{2}}$ is the variance in $r_{N U}, \sigma_{r N R a}^{2}$ is the variance in $r_{N R a}$, and $\sigma_{r N T h}{ }^{2}$ is the variance in $r_{\mathrm{NTh}}$.

For the $\mathrm{NaI}$ systems, net counts $(N)$ for a radionuclide are determined by obtaining the total (gross) counts in the region of interest (ROI) for the radionuclide and then subtracting the background counts:

$$
N=G-C
$$

where $G$ is the total (gross) counts (in the ROI) and $C$ is the background (continuum) counts for the ROI. The net count rate is $r_{N}=N / T_{0}$, where $T_{0}$ is the time interval for which the counts were determined (live time). As discussed in Appendix E, the variance in the net count rate can be approximated by $\mu_{G} / T_{0}^{2}$ (where $\mu_{G}$ is the mean value of $G$ ) when $T_{0}$ is equal to 4 or 8 seconds. 
If the mean counts were determined for some period $T_{1}$ other than $T_{0}$, then the variance in the net count rate $\left(\sigma_{r}^{2}\right)$ for the time period $T_{0}$ would be given by

$$
\sigma_{r}^{2} \cong \mu_{G} /\left(T_{0} T_{1}\right)
$$

By using Equations. J.2 and J.3,

$$
\sigma_{C W U}{ }^{2} \cong\left(8.94 / T_{0} T_{1}\right)\left(F_{1}^{2} \mu_{G U}+F_{2}^{2} \mu_{G R a}+F_{3}^{2} \mu_{G T h}\right)
$$

where the quantities $\mu_{G U}$, etc. are estimated by using the average counts for time period $T_{1}$. $\sigma_{C W U^{2}}$ applies to the time period $T_{0}$.

From Equation J.4, the standard deviation in the uranium concentration (in ppm) is

$$
\sigma_{C W U}=\frac{2.99}{\sqrt{T_{0} T_{1}}}\left(F_{1}^{2} \mu_{G U}+F_{2}^{2} \mu_{G R a}+F_{3}^{2} \mu_{G T h}\right)^{0.5}
$$

When the standard deviation is determined at the uranium WAC level and the result is corrected for the moisture level, $\sigma_{W A C}=M \sigma_{C W U}$. The resulting value of $\sigma_{W A C}$ can be substituted into Equation J.1 to give the WAC trigger. If net counts were determined for a 300-second period and a trigger is needed for a 4-second period, $T_{0}=4$ and $T_{1}=300$. (Sanding is not used for 300-second measurements. However, the gross counts obtained for such measurements can be used in Equation J.5 because the sanding process does not affect mean gross counts. It reduces the uncertainty in background and net counts.)

By using the data provided in Appendix K, trigger levels can be determined for the NaI systems. Results are given in Table J.1, which also shows the calculated variances and the standard deviation in the measured uranium concentration at the WAC level. An example calculation for the RTRAK is provided in Section L.1 of Appendix L. 
TABLE J.1 Weighted Variances for Isotopic Net Count Rates and Determination of WAC Triggers for a 4-Second Count ${ }^{\mathrm{a}}$

\begin{tabular}{lrrrrrr}
\hline & \multicolumn{7}{c}{ System } \\
\cline { 2 - 7 } \multicolumn{1}{c}{ Quantity } & \multicolumn{1}{c}{ EMS } & Gator & \multicolumn{1}{c}{ RSS-1 } & RSS-2 & RSS-3 & RTRAK \\
\hline & & & & & & \\
$8.94 F_{1}^{2} \sigma_{r N U}{ }^{2}$ & 4483.1 & 5480.5 & 4242.8 & 5134.2 & 5163.8 & 5166.3 \\
$8.94 F_{2}^{2} \sigma_{r N R a}{ }^{2}$ & 0.7 & 2.2 & 1.4 & 2.0 & 1.5 & 1.4 \\
$8.94 F_{3}^{2} \sigma_{r N T h}{ }^{2}$ & 205.1 & 213.0 & 173.1 & 232.3 & 204.9 & 212.6 \\
$\sigma_{C W U}{ }^{2}$ & 4689.0 & 5695.9 & 4417.4 & 5368.6 & 5370.2 & 5380.3 \\
$\sigma_{W A C}$ & 76.0 & 83.8 & 73.8 & 81.3 & 81.3 & 81.4 \\
WAC trigger level & 905 & 892 & 909 & 896 & 896 & 896 \\
\hline
\end{tabular}

a Basis: $\sigma_{r N U}{ }^{2}, \sigma_{r N R a}{ }^{2}$, and $\sigma_{r N T h}^{2}$ were estimated by using Equation J.3. $\sigma_{C W U}{ }^{2}$ was calculated by using Equation J.4. $\sigma_{W A C}$ was determined by using $\sigma_{W A C}=M \sigma_{C W U}$, where $M=1.11$ is used to adjust for moisture because measurements were made on the pad. The WAC trigger was determined by using Equation J.1. The counting data and the calibration coefficients used are given in Tables K.2 and K.1, respectively, in Appendix K. $\mu_{G}$ in Equation J.3 was estimated by using the measured counts for the 300 -second acquisition period. $\sigma_{W A C}$ and the WAC trigger level are in units of ppm and are on a dry-weight basis. The other quantities are in units of $\mathrm{ppm}^{2}$. 


\section{APPENDIX K:}

\section{DATA}

TABLE K.1 Calibration Coefficients for the NaI Systems ${ }^{a}$

\begin{tabular}{crrrrrr}
\hline & \multicolumn{7}{c}{ System } \\
\cline { 2 - 7 } Coefficient & EMS & \multicolumn{1}{c}{ Gator } & RSS-1 & RSS-2 & RSS-3 & RTRAK \\
\hline & & & & & & \\
$F_{1}$ & 3.2138 & 3.8231 & 3.2078 & 3.6525 & 3.7642 & 3.8678 \\
$F_{2}$ & -0.0947 & -0.1864 & -0.1429 & -0.1759 & -0.1515 & -0.1533 \\
$F_{3}$ & -2.4817 & -2.7963 & -2.4439 & -2.8574 & -2.6647 & -2.9189 \\
$F_{4}$ & -0.0068 & -0.0079 & -0.0069 & -0.0069 & -0.0069 & -0.0079 \\
$F_{5}$ & 0.1104 & 0.1375 & 0.1196 & 0.1231 & 0.1191 & 0.1389 \\
$F_{6}$ & 0.0003 & -0.0021 & 0.0002 & -0.0018 & 0.0003 & 0.0014 \\
$F_{7}$ & -0.0003 & -0.0003 & -0.0003 & -0.0007 & -0.0002 & -0.0003 \\
$F_{8}$ & 0.0008 & 0.0024 & 0.0002 & 0.0007 & 0.0015 & 0.0014 \\
$F_{9}$ & 0.0633 & 0.0771 & 0.0698 & 0.0720 & 0.0750 & 0.0761 \\
\hline & & & & & &
\end{tabular}

a Determined by using the count data in Table K.2. Units are in $\mathrm{pCi} / \mathrm{g}$ per net count per second. 
TABLE K.2 Count Data ${ }^{a}$

\begin{tabular}{|c|c|c|c|c|c|c|c|}
\hline \multirow[b]{2}{*}{$\mathrm{ID}^{\mathrm{b}}$} & \multirow[b]{2}{*}{ Source ${ }^{c}$} & \multicolumn{6}{|c|}{ Counts $^{\mathrm{d}}$} \\
\hline & & $G_{U}$ & $C_{U}$ & $G_{R a}$ & $C_{R a}$ & $G_{T h}$ & $C_{T h}$ \\
\hline \multicolumn{8}{|c|}{ EMS (Detector No. 518, 21 April 2003) } \\
\hline 107 & None & 9,843 & $8,835.7$ & 4,872 & $3,769.3$ & 3,911 & $1,056.7$ \\
\hline 108 & ${ }^{238} \mathrm{U}$ & 58,262 & $26,641.3$ & 10,253 & $7,265.7$ & 4,471 & $1,513.3$ \\
\hline 109 & ${ }^{232} \mathrm{Th}$ & 74,050 & $39,801.2$ & 28,667 & $25,640.3$ & 57,699 & $11,870.9$ \\
\hline 110 & ${ }^{226} \mathrm{Ra}$ & 72,804 & $70,720.5$ & 104,843 & $48,325.7$ & 10,483 & $8,349.4$ \\
\hline \multicolumn{8}{|c|}{ Gator (Detector No. 0M197, 21 April 2003) } \\
\hline 171 & None & 8,813 & $7,555.2$ & 4,224 & $3,456.6$ & 3,360 & $1,084.9$ \\
\hline 172 & ${ }^{238} \mathrm{U}$ & 50,331 & $23,334.1$ & 8,614 & $6,371.7$ & 3,657 & $1,318.2$ \\
\hline 173 & ${ }^{232} \mathrm{Th}$ & 59,154 & $32,033.7$ & 24,324 & $21,526.3$ & 48,626 & $11,127.2$ \\
\hline 174 & ${ }^{226} \mathrm{Ra}$ & 56,492 & $54,062.9$ & 83,117 & $37,845.5$ & 8,247 & $7,337.5$ \\
\hline \multicolumn{8}{|c|}{ RSS-1 (Detector No. 072198C, 21 April 2003) } \\
\hline 804 & None & 8,426 & $7,294.9$ & 4,198 & $3,189.4$ & 3,366 & 949.6 \\
\hline 805 & ${ }^{238} \mathrm{U}$ & 55,346 & $23,496.2$ & 8,957 & $6,176.3$ & 3,891 & $1,337.2$ \\
\hline 806 & ${ }^{232} \mathrm{Th}$ & 63,097 & $32,153.9$ & 24,506 & $21,835.7$ & 51,792 & $10,342.3$ \\
\hline 807 & ${ }^{226} \mathrm{Ra}$ & 59,516 & $56,209.0$ & 90,145 & $37,922.1$ & 8,197 & $5,919.3$ \\
\hline \multicolumn{8}{|c|}{ RSS-2 (Detector No. 072198A, 01 October 2003) } \\
\hline 568 & None & 8,716 & $7,391.3$ & 4,473 & $3,493.8$ & 3,331 & $1,040.3$ \\
\hline 569 & ${ }^{238} \mathrm{U}$ & 51,658 & $23,237.2$ & 8,826 & $6,321.8$ & 3,819 & $1,265.8$ \\
\hline 570 & ${ }^{232} \mathrm{Th}$ & 64,740 & $33,601.1$ & 25,207 & $21,989.3$ & 51,530 & $11,266.6$ \\
\hline 571 & ${ }^{226} \mathrm{Ra}$ & 59,624 & $56,255.7$ & 91,033 & $40,288.3$ & 8,402 & $6,562.5$ \\
\hline \multicolumn{8}{|c|}{ RSS-3 (Detector No. 082602AZ, 17 December 2003) } \\
\hline 362 & None & 8,905 & $7,595.6$ & 4,537 & $3,411.4$ & 3,425 & 967.3 \\
\hline 363 & ${ }^{238} \mathrm{U}$ & 48,917 & $21,489.3$ & 8,618 & $5,987.3$ & 3,873 & $1,363.8$ \\
\hline 364 & ${ }^{232} \mathrm{Th}$ & 55,928 & $28,907.7$ & 23,571 & $21,048.4$ & 48,930 & $10,231.7$ \\
\hline 365 & ${ }^{226} \mathrm{Ra}$ & 61,449 & $58,787.4$ & 93,582 & $41,072.5$ & 8,815 & $7,369.3$ \\
\hline \multicolumn{8}{|c|}{ RTRAK (Detector No. 516, 02 April 2003) } \\
\hline 935 & None & 7,836 & $6,773.6$ & 3,913 & $3,060.2$ & 3,181 & 1,035.6 \\
\hline 936 & ${ }^{238} \mathrm{U}$ & 46,355 & $19,852.7$ & 8,039 & $5,744.2$ & 3,349 & $1,126.5$ \\
\hline 937 & ${ }^{232} \mathrm{Th}$ & 58,850 & $30,764.6$ & 22,872 & $20,845.2$ & 47,739 & $9,847.8$ \\
\hline 938 & ${ }^{226} \mathrm{Ra}$ & 57,531 & $55,344.1$ & 82,650 & $37,741.4$ & 7,529 & 6,206.6 \\
\hline
\end{tabular}

a All counts were made for a 300-second acquisition period.

b Identification number for the run.

c "None" means that only blanks were used. For U, Ra, and Th, 45 uranium, radium, and thorium sources, respectively, were used.

d $G_{U}, G_{R a}$, and $G_{T h}$ provide total counts for the ROI. $C_{U}, \mathrm{C}_{R a}$, and $\mathrm{C}_{T h}$ provide background counts for the ROI; these counts were obtained by using the spectral sanding process discussed in Appendix $\mathrm{H}$. 


\section{APPENDIX L:}

\section{EXAMPLE CALCULATIONS}

\section{L.1 WASTE ACCEPTANCE CRITERION (WAC) TRIGGER LEVEL}

The trigger level is given by Equation J.1:

$$
\text { WAC Trigger }=1030-1.645 \sigma_{W A C} \text {. }
$$

The standard deviation in the wet-weight uranium concentration in parts per million (ppm) is given by Equation J.5:

$$
\sigma_{C W U}=\frac{2.99}{\sqrt{T_{0} T_{1}}}\left[F_{1}^{2} \mu_{G U}+F_{2}^{2} \mu_{G R a}+F_{3}^{2} \mu_{G T h}\right]^{0.5}
$$

The standard deviation can be evaluated at the WAC level (1030 ppm), adjusted for moisture, and substituted into Equation J.1 to give the WAC trigger.

When the 300-second counts for the radiation tracking system (RTRAK) (April 2, 2003, calibration; see Table K.2) with the uranium sources on the pad are used, the estimated counts are as follows: $\mu_{G U}=46,355, \mu_{G R a}=8039$, and $\mu_{G T h}=3349$. Because 300-second counts are used, $T_{1}=300$ seconds. Because a 4 -second trigger is desired, $T_{0}=4$ seconds. From Table K.1, $F_{1}=3.868, F_{2}=-0.153$, and $F_{3}=-2.919$. Substituting these values into Equation J.5 gives $\sigma_{C W U}=73.3 \mathrm{ppm}$. Therefore, when the average moisture level for the calibration pad is used, $\sigma_{W A C}=M \sigma_{C W U}=(1.11)(73.3)=81.4 \mathrm{ppm}$, and the WAC trigger $=1030-1.645 \sigma_{W A C}=1030-$ $(1.645)(81.4)=896 \mathrm{ppm}($ for a 4 -second count). This is a dry-weight concentration.

\section{L.2 MINIMUM DETECTABLE CONCENTRATION (MDC)}

To provide an example of how the results in Chapter 5 were obtained, details of the calculations of $L_{C}, L_{D}$, and MDC for uranium for the March 21, 2003, calibration of the excavation monitoring system (EMS) are provided.

\section{L.2.1 Calculation of $L_{C}$}

$L_{C}$ is calculated by using Equation I.2:

$$
L_{C} \cong k\left(2 \mu_{G 0}\right)^{0.5}
$$

where $k=1.645 . \mu_{G 0}$ can be estimated by using the count data from the April 21, 2003, calibration of the EMS (Table K.2): 
$\mu_{G 0}=(4 / 300)(9843)$. (Using $G_{U}$, no sources on pad, adjusted to 4 seconds.)

Substituting the values for the various quantities into Equation I. 2 gives $L_{C}=26.7$ counts.

\section{L.2.2 Calculation of $L_{D}$}

Using Equation I.7, with $c=0$ and the value of $L_{D}>0$, yields

$$
L_{D}=-b
$$

From Equation (I.5),

$$
b=\left[2 L_{C}+k^{2}(d+1)\right]
$$

where $d$ is the coefficient in the equation $\mu_{C D}=d \mu_{N D}+e$, which is based on the linear relationship between background and net counts (Figure E.1). If, for some reason, one chooses not to use the average results obtained by using data collected with the radiation scanning systems (RSSs) and presented in Equation E.5, $d$ can be determined by using the available count data because the background and net counts are known for two points — namely, when the uranium sources are in place on the pad and when no sources are on the pad. The following table summarizes the data (from Table K.2) for the 300-second count for the April 21, 2003, calibration of the EMS and provides calculated values for a 4-second count.

\begin{tabular}{lcrc}
\hline & \multicolumn{3}{c}{ Background } \\
\multicolumn{1}{c}{ Condition } & $G_{U}$ & $C_{U}$ & $\begin{array}{c}\text { Net Counts } \\
G_{U}-C_{U}\end{array}$ \\
\hline 238 U sources (300 s) & 58,262 & $26,641.3$ & - \\
No sources (300 s) & 9,843 & $8,835.7$ & - \\
$238 \mathrm{U}$ sources (4 s) & 776.8 & 355.2 & 421.6 \\
No sources (4 s) & 131.2 & 117.8 & 13.4 \\
\hline
\end{tabular}

The value of $d$ in Equation I.5 is given by

$$
d=\text { (change in background counts)/(change in net counts). }
$$

So, $d=(355.2-117.8) /(421.6-13.4)=0.582$. (For comparison, the value from Equation E.5 is 0.495.) All of the quantities needed to determine $b$ are now known, and can be substituted into the expression for $b$ given above to yield a value for $b$ of -57.7 . Now that $b$ is known, $L_{\mathrm{D}}$ can be determined by using Equation I.7: $L_{\mathrm{D}}=-b=57.7$ counts. (If the average value of $d$ from Equation E.5, namely 0.495, is used instead, the result is $L_{\mathrm{D}}=-b=57.4$ counts.) 


\section{L.2.3 Calculation of MDC}

The MDC is determined by using the calibration equation for ${ }^{238} \mathrm{U}$ (see Chapter 5), modified to provide a uranium concentration in ppm $\left({ }^{238} \mathrm{U}\right.$ concentration $\left.\times 2.99\right)$ :

$$
C_{W U}=2.99\left(F_{1} r_{N U}+F_{2} r_{N R a}+F_{3} r_{N T h}\right) .
$$

From the April 21, 2003, calibration of the EMS, $F_{1}=3.214, F_{2}=-0.0947$, and $F_{3}=-2.482$ (see Table K.1).

As noted in Section 5, the MDC is determined with $r_{N U}$ being equal to the net count rate corresponding to $L_{\mathrm{D}}$ for uranium, and it is determined with $r_{N R a}$ and $r_{N T h}$ being equal to the values obtained on the pad when no sources are present. Therefore, the MDC for total uranium in ppm is

$$
U_{M D C}=2.99[(3.214)(57.7 / 4)+(-0.0947)(14.7 / 4)+(-2.482)(38.1 / 4)]=67 .
$$

The counts are divided by 4 seconds to convert to a count rate. The net counts for ${ }^{226} \mathrm{Ra}(14.7)$ and ${ }^{232} \mathrm{Th}$ (38.1) are obtained in the same manner as shown in the table above for uranium (13.4) when no sources are on the pad.

The MDC of $67 \mathrm{ppm}$ is a wet-weight concentration. When the average moisture level of the calibration pad $(11 \%$, which corresponds to a moisture correction factor of 1.11) is used, because measurements were made on the pad, the MDC on a dry-weight basis is $74 \mathrm{ppm}$.

If the MDC is determined by using the $L_{\mathrm{D}}$ obtained on the basis of the average value of $d$ (i.e., $L_{D}=57.4$ counts), then the MDC on a wet-weight basis is $66.3 \mathrm{ppm}$, and the MDC on a dry-weight basis is $74 \mathrm{ppm}$. Therefore, results are not sensitive to how $d$ is determined.

\section{L.3 UNCERTAINTIES IN NET COUNT RATE}

Consider soil with dry-weight concentrations $\left(C_{D}\right.$ 's) of ${ }^{238} \mathrm{U},{ }^{226} \mathrm{Ra}$, and ${ }^{232} \mathrm{Th}$ of 82.0 , 0.5 , and $0.5 \mathrm{pCi} / \mathrm{g}$, respectively. What uncertainties in the net count rates are expected for 4-second measurements made with a NaI system in such a case? Begin with the calibration equations for the system:

$$
\begin{aligned}
& C_{W U}=F_{1} r_{N U}+F_{2} r_{N R a}+F_{3} r_{N T h}, \\
& C_{W R a}=F_{4} r_{N U}+F_{5} r_{N R a}+F_{6} r_{N T h,}, \text { and } \\
& C_{W T h}=F_{7} r_{N U}+F_{8} r_{N R a}+F_{9} r_{N T h},
\end{aligned}
$$

where the $C_{W}$ 's are concentrations on a wet-weight basis, the $F_{i}$ 's are calibration coefficients, and the $r_{N j}$ 's are net count rates. 
For the EMS, $F_{1}, F_{2}, \ldots, F_{9}$ are $3.2138,-0.0947,-2.4817,-0.0068,0.1104,0.0003$, $-0.0003,0.0008$, and $0.0633 \mathrm{pCi} / \mathrm{g}$ per net count per second, respectively (from the calibration done on April 21, 2003; see Table K.1). The concentrations have been specified $\left(C_{\mathrm{W}}=C_{\mathrm{D}} / M\right.$; use $M=1.11$, the average value for the calibration pad). Therefore, there are three equations with three unknowns (the net count rates) that can be solved to give the net count rates that correspond to the specified soil concentrations. (These net count rates can be used directly in Equation 3.4 to determine the uncertainty associated with calibration, $u_{\text {calib }}$. However, to determine the uncertainty associated with counting, $u_{\text {count }}$, the uncertainties in the net count rates, $u^{2}\left(r_{N}\right)$, are needed, not the net count rates themselves. These uncertainties can be determined by using Equation E.4. However, to determine the uncertainty in a net count rate with Equation E.4, the gross counts are required.)

Now consider again the example being examined $\left({ }^{238} \mathrm{U},{ }^{226} \mathrm{Ra}\right.$, and ${ }^{232} \mathrm{Th}$ dry-weight concentrations of $82.0,0.5$, and $0.5 \mathrm{pCi} / \mathrm{g}$, respectively, and $M=1.11$ ). For these conditions and the calibration coefficients of the EMS, the solution to Equation 5.1 is net count rates of 28.7, 5.8, and 7.2 counts per second for ${ }^{238} \mathrm{U},{ }^{226} \mathrm{Ra}$, and ${ }^{232} \mathrm{Th}$. By using the regression relation, Equation E.5, for $238 \mathrm{U}$, the 4 -second background count can be determined:

$$
B C=(0.495 \times 28.7 \times 4+89.2)=146.0 \text { counts } .
$$

Therefore, the gross count is $146.0+4 \times 28.7=260.8$ counts. When the gross and background counts have been determined, the variance in the net count rate for uranium can be determined by using Equation E.4:

$$
u^{2}\left(r_{N U}\right) \cong \mu_{G U} / T^{2}=260.8 / 4^{2}=16.3 \text { counts }^{2} / \mathrm{s}^{2} .
$$

Uncertainties in other count rates can be determined in a similar manner. 


\section{APPENDIX M:}

\section{GLOSSARY*}

a priori. As applied to measurements, a priori quantities are values that are used before any measurements are actually made in order to estimate the capability of a particular approach.

Blank. The signal that results from a sample that is identical in principle to the sample of interest, except that the substance to be measured is absent (or small in quantity when compared to the uncertainty in the blank). (Currie 1968)

Count. A discrete response of an instrument (a signal) resulting from the interaction of a photon with a detector.

Count rate. Number of counts per unit time.

Covariance. For two sets of values, the average of the sum of the products of the deviations of the corresponding values in the two sets from their respective means. The covariance is a measure of how strongly the values in the two sets are correlated. (The correlation between the two sets is defined as the covariance between the two sets of values divided by the product of the standard deviations of the two sets.)

Critical level $\left(\boldsymbol{L}_{\boldsymbol{C}}\right)$. The net response level (net counts above background) at which the detector output can be considered "above background." It is the lower bound on the $95 \%$ detection interval defined for the detection limit, and it is the level at which there is a 5\% chance of erroneously calling a background value greater than background. (MARSSIM 2000, Section 6.7.1)

Detection limit $\left(\boldsymbol{L}_{\boldsymbol{D}}\right)$. The net response level (net counts above background) that can be expected to be seen with a detector $95 \%$ of the time. It is an a priori estimate of the detection capability of a measurement system, and it is the level at which there is a 5\% chance of erroneously considering a detector's response to be background when radioactivity is actually present at levels above background. (MARSSIM 2000, Section 6.7.1)

Gross signal. An instrument output including the blank.

Live time. The actual time a spectroscopy system is available for counting. Live time equals total acquisition time less the dead time that occurs during pulse processing by system electronics. Dead time depends on source activity and increases with increasing activity.

Minimum detectable concentration (MDC). The detection limit multiplied by an appropriate conversion factor to give units of activity. It is the a priori net activity level above the critical

\footnotetext{
* Words in italics in the definitions are also defined in this glossary.
} 
level that an instrument can be expected to detect $95 \%$ of the time. The MDC should be used when giving the detection capability of an instrument. (MARSSIM 2000, Section 6.7.1)

Net signal. An instrument output relative to the blank (i.e., gross signal minus the blank).

Poisson distribution. A probability distribution commonly used to model radioactive decay. The distribution has the property that its mean and variance are equal.

Random error. Result of a measurement minus the mean that would result from an infinite number of measurements of the same quantity carried out under the same conditions. Because only a finite number of measurements can be made, only an estimate of random error can be determined. (ANSI 1997)

Region of interest (ROI). A range of channels (gamma energies) established to include a spectral peak related to the isotope of interest.

Signal. An instrument output; a meter reading. As used in this report, a signal is always an instrument output in counts.

Standard deviation. The positive square root of the variance.

Standard uncertainty. Uncertainty of the result of a measurement expressed as a standard deviation. (ANSI 1997)

Systematic Error. Mean that results from an infinite number of measurements of the same quantity carried out under the same conditions minus the true value of the quantity (ANSI 1997). It equals the total measurement error minus the random error. As for random error, only an estimate can be determined.

Trigger level. A specified radionuclide concentration that, if exceeded by a measurement, provides the basis for some subsequent action to be taken. (DOE 2004)

Uncertainty. A parameter that characterizes the dispersion of values that could reasonably be attributed to the quantity being measured. (ANSI 1997) In this report, the parameter used is the standard deviation.

Variance. For a set of values, the average of the squares of the deviations of the values from the mean of the values. It is a measure of dispersion.

Well-known blank. A blank for which many measurements have been made and for which, as a consequence, the uncertainty in its average value is small. 


\section{APPENDIX M REFERENCES}

ANSI (American National Standards Institute), 1997, U.S. Guide to the Expression of Uncertainty in Measurement, American National Standard ANSI/NCSL Z540-2-1997, published by the National Conference of Standards Laboratories, Boulder, Colo.

Currie, L.A., 1968, "Limits for Qualitative Detection and Quantitative Determination," Analytical Chemistry 40(3):586-593, March.

DOE (U.S. Department of Energy), 2004, User Guidelines, Measurement Strategies, and Operational Factors for Deployment of In Situ Gamma Spectrometry at the Fernald Site, Fernald Area Office. Jan.

MARSSIM, 2000, Multi-Agency Radiation Survey and Site Investigation Manual, NUREG-1575, Rev. 1, EPA 402-R-97-016, Rev. 1, DOE/EH-0624, Rev. 1, Dec. 
